\section{ENERGY LABORATORY}

MASSACHUSETTS INSTITUTE OF TECHNOLOGY
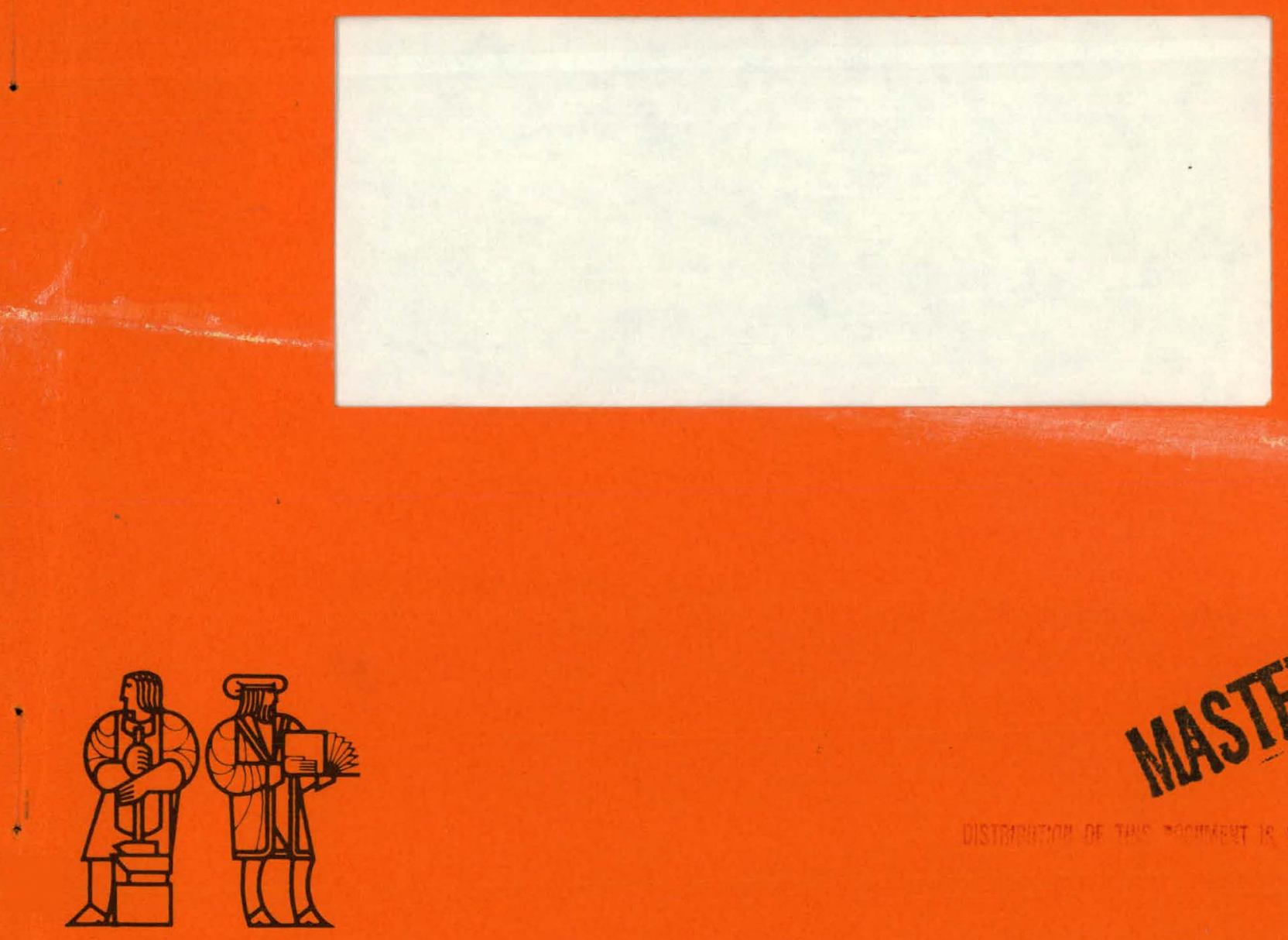


\section{DISCLAIMER}

This report was prepared as an account of work sponsored by an agency of the United States Government. Neither the United States Government nor any agency Thereof, nor any of their employees, makes any warranty, express or implied, or assumes any legal liability or responsibility for the accuracy, completeness, or usefulness of any information, apparatus, product, or process disclosed, or represents that its use would not infringe privately owned rights. Reference herein to any specific commercial product, process, or service by trade name, trademark, manufacturer, or otherwise does not necessarily constitute or imply its endorsement, recommendation, or favoring by the United States Government or any agency thereof. The views and opinions of authors expressed herein do not necessarily state or reflect those of the United States Government or any agency thereof. 


\section{DISCLAIMER}

Portions of this document may be illegible in electronic image products. Images are produced from the best available original document. 
MIT-EL- $-81-038$

DE82 013662

\section{SYSTEMS STUDIES ON THE \\ EXTRACTION OF URANIUM FROM SEAWATER}

by

M.J. Driscoll and F.R. Best

Energy Laboratory Report NO. MIT-EL81-038

Nuclear Engineering Dept. Report No. MITNE-248

November 1981

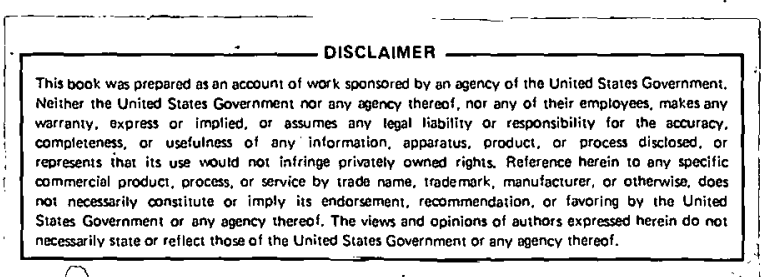

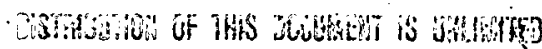

How 
MIT-EL81-038

MITNE-248

\title{
SYSTEMS STUDIES ON THE \\ EXTRACTION OF URANIUM FROM SEAWATER
}

by

M.J. Driscoll and F.R. Best

\begin{abstract}
Energy Laboratory and
Department of Nuclear Engineering

Massachusetts Institute of Technology

Cambridge, Massachusetts 02139
\end{abstract}

A Final Topical Report

on Research Sponsored by.

U.S. Department of. Energy Grand Junction Office

Bendix Field Engineering Corporation

November 1981 


\section{Abstract}

This report summarizes the work done at MIT during FY 1981 on the overall system design of a uranium-from-seawater facility. It consists of a sequence of seven major chapters, each of which was originally prepared as a stand-alone internal progress report. These chapters trace the historical progression of the MIT effort, from an early concern with scoping calculations to define the practical boundaries of a design envelope, as constrained by elementary economic and energy balance considerations, through a parallel evaluation of actively-pumped and passive current-driven concepts, and. thence to quantification of the features of a second generation system based on a shipboard-mounted, actively-pumped concept designed around the use of thin beds of powdered ion exchange resin supported by cloth fiber cylinders (similar to the baghouse flyash filters used on power station offgas).

An assessment of the apparently inherent limitations of even thin settled-bed sorber media then led to selection of an expanded bed (in the form of an ion exchange "wool"), which would permit an order of magnitude increase in flow loading, as a desirahle advance. Thus the final two chapters evaluate ways in which this approach could be implemented, and the resulting performance levels which could be attained. Overall, $\mathrm{U}_{3} \mathrm{O}_{8}$ production costs under $200 \$ / 1 \mathrm{~b}$ appear to be within reach if a high capacity (several thousand ppm $U$ ) ion exchange wool can be developed. 


\section{Acknowledgements}

The work reported here represents the work of many people, most of whom are cited as co-authors on the chapters which embody the main parts of their contributions. For completeness, however, the contributions of the following students should be recognized: Ms. C.K. Nitta, graduate research assistant; and the following undergraduate students: L.G. Riniker, J.L. Whaley, C.T. Graves, R.L. Coxe, D.C. Surber, D.A. Medek, E.A. Thompson and K.M. Story We also acknowledge the many useful discussions with participants in the Topical Meeting on the Recovery of Uranium from Seawater; held at MIT in December 1980, and subsequent discussions with several researchers who visited MIT to discuss their efforts in this area. Particular thanks are due to Dr. Theresa Chen Kuang of the Institute of Nuclear Energy Research, Republic of China, and Dr. Hisao Yamashita of Hitachi. Correspondence with Goran Lagstrom also provided the authors with a copy of the final report on a Swedish wave-powered system design, and Professor Masayoshi Kanno made available several papers on the main-line Japanese effort.

The critiquing of substantial portions of our work by Manson Benedict, MIT Institute Professor Emeritus, is especially appreciated.

Finally, information provided by researchers at the Rohm and Haas Corporation has been most helpful, and we wish to acknowledge discussions with S.G. Maroldo, G.H. Beasiley, H. Fred Wilson and M.G. Baldwin. 
Table of Contents

Page

Abstract $\quad 1$.

Acknowledgements $\quad 2$

Table of Contents

Chapter 1 Introduction 5

Chapter 2 "Practical Constraints on Systems for the Extraction of Uranium from Seawater" by M.J. Driscoll, J.L. Whaley, C.K. Nitta, and F.R. Best

Chapter 3 "The Effect of System Improvements on Uranium Recovery from Seawater"

by F.R. Best and M.J. Driscoll

Chapter 4 "Conceptual Design of a System to Extract Uranium from Seawater"

by M.J. Driscoll and L.G. Riniker

Chapter 5. "Conceptual Design of a Passive Uranium from seawater. System"

by M.J. Driscoll and J.L. Whaley.

Chapter 6 "An Improved Conceptual Design of a System to Extract Uranium from seawater"

by M.J. Driscoll, F.R. Best and C.K. Nitta 
Page

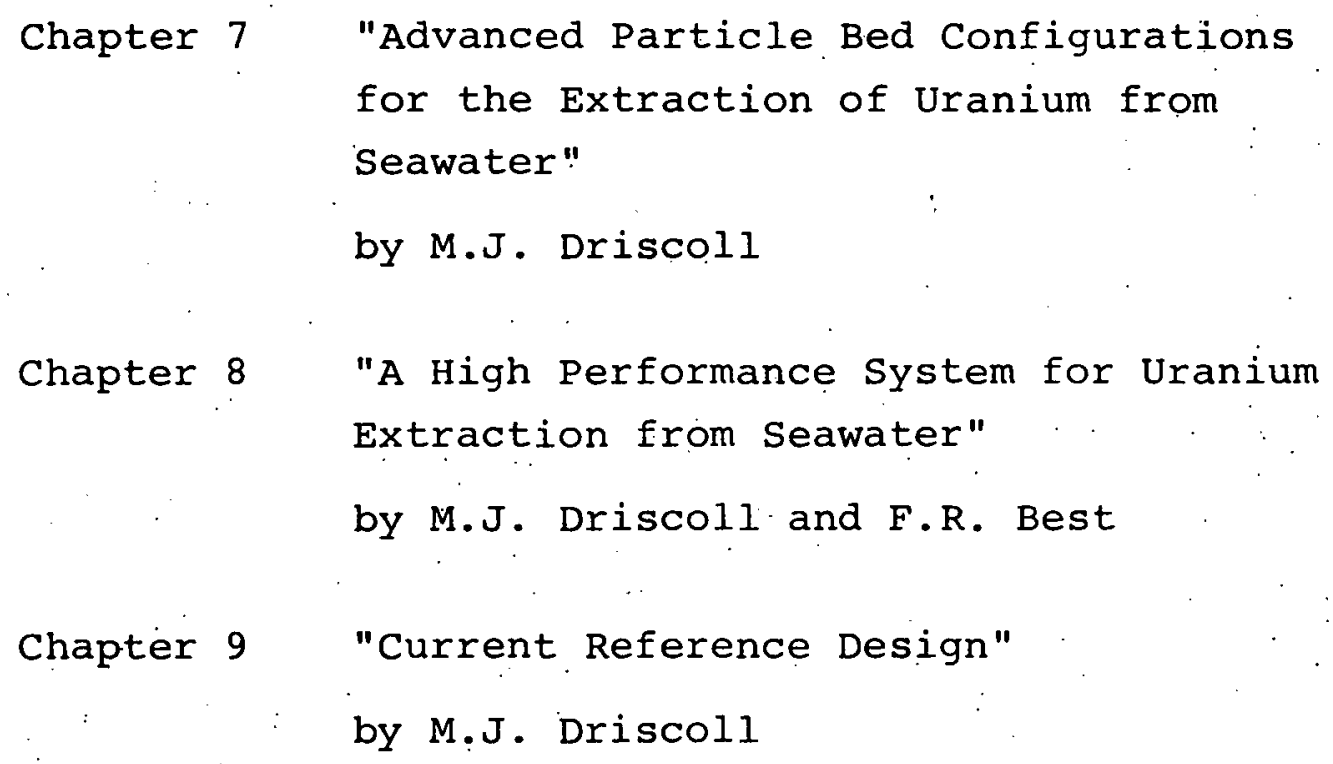

Chapter 9 "Current Reference Design"

by M.J. Driscoll 


\section{Chapter 1}

Introduction

\subsection{Foreword}

In September 1981 a research project was established by the United States Department of Energy with the MIT Energy Laboratory/Nuclear Engineering Department to evaluate the prospects for recovery of uranium from seawater, with a major emphasis on laboratory and field tests of new ion exchange media to be developed by the Rohm and Haas Corporation under subcontract to MIT. One subtask of the research project involved examination of the overall system aspects of the process, to help target the required performance characteristics for improved sorber media, and to assess yellowcake production costs which might be attainable from their use in partially suboptimized systems. The purpose of this topical report is to summarize these systems studies.

\subsection{Background}

The starting point for the present work was the study documented by Best (1), who investigated this topic as a doctoral research project under a seed money grant provided by the MIT Energy Laboratory. Additional background information is summarized in Ref. (2), which reports the proceedings of a topical conference on this subject, held at MIT under DOE auspices in December 1980. Of particular note 
is the earlier review and design study conducted for DOE by Exxon (3), a summary of which appears in Ref. (2).

\subsection{Organization of This Report}

This report is, in essence, a collection of internal write-ups documenting all recent MIT work on systems analysis in the area of uranium recovery from seawater completed since Ref. (1). Each document is reported as a separate chapter. It is important to note that the material is presented in approximate chronological order, and the preceding work has not been revised with the benefit of hindsight. Thus it is a historical document in many respects, and one must refer to the later chapters for our most recent thinking.

The first two chapters in the body of the report (Chapters 2 and 3) have been reproduced from Ref. (1) for the sake of completeness and because they succinctly present basic information essential to the understanding of the material which follows.

These write-ups are followed by two chapters which evaluate candidate actively pumped and passive current-driven systems. On the basis of this work it was decided to focus on the pump-driven system for all subsequent efforts. Chapter 6 reports on the design of a second generation packed sorber bed system of this type.

After completion of the work summarized in Chapter 6, it appeared that some very fundamental limits had been 
reached which would all but preclude further substantial improvements in settled bed systems of the type examined to date. However, considerations documented in Chapter 7 indicated that by going to an expanded bed configuration for the sorber, the throughput of a given facility could be increased by as much as an order of magnitude, with the attendant potential for significant cost reductions. Hence the final major section of this report, Chapter 8 , considers an advanced system of this new design and projects the cost of $\mathrm{U}_{3} \mathrm{O}_{8}$ which might be realized if $\mathrm{R} \& \mathrm{D}$ efforts on sorber media appropriate for this purpose were successful. The final chapter briefly sketches the characteristics of the current reference design being used as the basis for system performance evaluation at MIT.

Finally, it should be noted that a parallel report is under preparation, and soon to be published; on the major contract subtasks, which deal with the ion exchange media development and characterization carried out by the Rohm and Haas Corporation, the resin tests in seawater at the woods Hole Oceanographic Institute, and the subsequent performance measurements conducted at MIT (4).

\subsection{References}

(1) F.R. Best and M.J. Driscoll, "Prospects for the Recovery of Uranium from Seawater," MIT-EL80-001, January 1980 .

(2) F.R. Best and M.J. Driscoll (Eds.), "Proceedings of a Topical Meeting on the Recovery of Uranium from seawater," MIT-EL80-031, December 1980. 
(3) Extraction of Uranium from Seawater: Evaluation of Uranium Resources and Plant Siting, XN-RT-I4, Vol. I; Selected Bibliography for the Extraction of Uranium from Seawater: Evaluation of Uranium Resources and Plant Siting, XN-RT-14, Vol. II, Extraction of Uranium from Seawater: Chemical Process and Plant Design Feasibility Study, XN-RT-15, Vol. I; Selected Bibliography for the Extraction of Uranium from Seawater: Chemical Process and Plant Design Feasibility. Study, XN-RT-15, Vol. II; all February 1979.

(4) C.K. Nitta, F.R. Best and M.J. Driscoll, "Evaluation of. the Recovery of Uranium from Seawater by Ion Exchange Resins (tent.)," to be published, December 1981'(est.). 


\section{Chapter 2}

Practical constraints on Systems for the Extraction of Uranium from Seawater

by

M.J. Driscoll, J.L. Whaley, C.K. Nitta and F.R. Best MIT

\section{Introduction}

The application of elementary mass, energy and cost balances can define the useful range of key design features for uranium recovery stystems. Although workers in this field have undsubtedly computed such limiting cases during their research, very little information of this genre has been published.

Both actively-pumped systems, in which seawater is passed through a bed of absorber or ion exchange resin particles, and passive current-interceptor systems (1), are considered. Because of our current research interests, parameter values which might be appropriate for advanced ion exchange materials are lised in the illustrative examples. However, the results can also be applied, with minor changes, to the more conventional titanium hydroxide base absorbers.

\section{Limitations imposed by Bed Costs}

A first, and obvious, restriction is that the annualized cost of the adsorber bed be less. (by some appropriate factor) than the value of the recovered uranium. This transiates into the requirement: 
$I \geqslant R_{1}=\frac{\phi B X t_{0}}{5.26 \times 10^{5} \times W f G U}$

where (representative values in parentheses):

$$
\begin{aligned}
\mathrm{X}= & \text { concentration of uranium in seawater, } \\
& 1 \mathrm{~b} \mathrm{U} / \mathrm{lb} \text { water }\left(3.3 \times 10^{-9}\right) \\
\mathrm{W}= & \text { density of seawater, } 1 \mathrm{~b} / \mathrm{gal}(8.55) \\
\mathrm{f}= & \text { fraction of uranium recovered }(\leq 1.0) \\
\mathrm{G}= & \text { filter bed flow loading, } \mathrm{gpm} / \mathrm{ft}^{2}(i 1.0) \\
\mathrm{U}= & \text { market value of uranium, } \$ / 1 \mathrm{~b}(i 30) \\
\phi= & \text { annual carrying charge rate, } \mathrm{yr}^{-1}(\geq 0.10) \\
B= & \text { (installed) cost of bed material, } \$ / 1 \mathrm{~b}(1.0) \\
\gamma= & \text { density of bed material, } 1 \mathrm{~b} / \mathrm{ft}{ }^{3} \\
t_{0}= & \text { (extrapolated) void-free thickness of bed, ft } \\
= & \text { actual thickness, } t \div(1-\varepsilon), \text { where } \varepsilon=\text { volume fraction } \\
& \text { voids }
\end{aligned}
$$

Using the quoted numerical values and $R_{1}=1 / 2$, one finds that $t_{0} \leq 0.02 \mathrm{ft}=0.25 \mathrm{in}$. Hence the compacted bed thickness must be less than $1 / 4$ inch (the expanded thickness might be as much as an order of magnitude larger). Note that the cost per unit area of the filter bed, $s=\beta \dot{\gamma} t_{0}$, would be $\sim 2 s / \mathrm{ft}^{2}$, which must include the cost of superstructure and bed support, as well as the cost of the medium itself. Also note that the annual carrying charge rate for an industrially funded venture would be 2 to 2.5 times as large as the value used here, which is more appropriate for government sponsorship. The value of $\phi$ also depends on the useful system and filter medium life: if 
less than ten or so years, higher $\phi$ values would again be appropriate. The value of $\beta$ used was based on the current cost of ion exchange resin $(\sim 1 \$ / 1 b)-$ but note the optimism implicit here, in that this does not account for the bed support structure. On the other hand, the recent NASAP and INFCE studies indicate that LWR units could remaln competitive for uranium prices ranging up to five times the value used here.

Thus, while the above considerations can only be used to establish order of magnitude limits, it is clear that one is constrained to use thin beds and motivated to keep costs low by using active coatings on inexpensi.re substrates, etc.

The total bed surface area is also a parameter of interest. If our goal is to collect $F$ lbs $U / Y r .(\simeq 400,000$ for a lGwe LWR)

$$
A=\frac{F}{5.26 \times 10^{5} \times W \subseteq G}
$$

Again, for the values quoted --

$$
A \geq 3 \times 10^{7} \mathrm{ft}^{2}
$$

Thus extremely large frontal areas are called for. We can now compute the bed volume, hence absorber mass:

$$
M=\gamma d t_{0}=60 \times 10^{6} \text { lbs, }
$$

which, incidentally, is roughly comparable to the total annual US consumption of ion exchange resins (but only about 18 of the yearly us styrene production)

3. Constraints Imposed by an Energy Balance

The extraction of uranium from seawater will be attractive 
only if the energy expended to recover it is less (by some appropriate factor). than the energy which can be generated per unit mass of uranium in a representative nuclear reactor.

This restriction takes the form

$$
1 \geq R_{2}=\frac{5000(\mathrm{~F} / \mathrm{P}) \Delta \mathrm{P}}{r_{1} n_{2}\left(10^{9} \mathrm{X}\right) \text { \& } \mathrm{B} \rho}
$$

where terms not previously defined are:

$$
\begin{aligned}
(F / P)= & \text { lbs natural } U \text { per } l \mathrm{~b} \text { slightly enriched } U \text { charged } \\
& \text { to the reactor }(6) \\
\Delta \mathrm{p}= & \text { pressure drop across entire filter apparatus, psi } \\
\mathrm{B} \quad= & \text { reactor fuel burnup, MWD/MT }(30,000) \\
n_{1}= & \text { thermodynamic efficiency of heat engine driving the } \\
& \text { pump }(0.35) \\
n_{2}= & \text { overall mechanical efficiency of the pump }(0.8) \\
\rho \quad= & \text { density of seawater, } 1 \mathrm{~b} / \mathrm{ft}^{3}(64)
\end{aligned}
$$

For $R_{2}=1 / 10$ and the values shown above, $\Delta \mathrm{p} \leq 6 \mathrm{psi}$.

This restriction is again quite sobering, and motivates the thought that a seaborne unit might be preferred, if not essential, to keep parasitic losses sufficiently low.

In passing we may also note the impressive volume of water handled: $G A \simeq 30 \times 10^{6} \mathrm{gpm}$, which is approximately 60 times the flow rate of condenser cooling water in a $I$ Gwe LWR, and $3 / 4$ the flow rate of the Nile River! The sheer size of the overall venture may favor the use of several smaller units per reactor served. 
As a consistency check, the recovery system (shaft) pumping power is:

$$
\mathrm{S}=3.25 \times 10^{-6} \frac{\mathrm{w}}{\mathrm{p}} \Delta \mathrm{p}, \mathrm{Mw}
$$

or for $\Delta \mathrm{p}=6 \mathrm{psi} ; \mathrm{s}=78 \mathrm{Mw}$

\section{Elementary Mass Transfer Limitations}

Uranium must not only be transported to the bed, but once there it must be transferred to and into the particles.

For an inexhaustible filter bed the fractional removal is given by:

$$
f=1-e^{-N T U}
$$

where NTU = number of transfer units

For a bed of spherical particles of diameter d

$$
\mathrm{NTU}=\frac{6 \mathrm{~K}_{\mathrm{p}} \mathrm{t}_{\mathrm{O}}}{60 \mathrm{WG} \mathrm{d}}
$$

where $\mathrm{K}=$ mass transfer coefficient, $1 \mathrm{~b} / \mathrm{hr} \mathrm{ft}^{2}\left(\mathrm{lb} / \mathrm{ft}^{3}\right)$ For laminar flow around an isolated sphere:

$$
K=\frac{2 D}{d}
$$

where $D=$ diffusivity of uranyl carbonate complex in seawater $\left(7.75 \times 10^{-6} \mathrm{ft}^{2} / \mathrm{hr}\right)(2)$

Combining Eqs (4), (5) and (6):

$E=1-e^{-\frac{1.2 D \rho t_{0}}{60 \mathrm{~W} \mathrm{G} \mathrm{d}^{2}}}$

From Eq (7) it can be shown that the uranium collection rate, the product of $f$ and $G$, increases monotonically with $G$-but while $f G$ is directly proportional to $G$ at low $G$, it approaches 
an asymptotic limit at high. G. Hence attempting to go beyond $f=2 / 3$ will be wasteful in terms of bed thickness (hence bed cost) and pressure drop (hence pumping power). The large incentive to use small particle diameter is also evident: for $t_{0}=$ $0.02 \mathrm{ft}$ and $\mathrm{NTU}=1(\mathrm{f}=63.2 \%)$, Eq (7) indicates that : $a \leq 5 \times 10^{-4} \mathrm{ft}=0.15 \mathrm{~mm}$.

There are both optimistic and pessimistic assumptions built into Eq (7). The increase in mass transfer coefficient with flow rate has not been allowed for. On the other hand only fluid side resistance has been accounted for: resistance contributed by interior pores and the solid phase has been ignored. Over the range of interest the net effect should be to overestimate the fractional recovery.

5. Pressure Drop Relation

A complementary, if somewhat redundant, constraint can be obtained by considering the pressure drop correlation for laminar flow through a packed particle bed:

$$
\Delta p=\frac{150 \text { WG }(1-\varepsilon) t_{0}}{144(60) g d^{2} \rho \varepsilon^{3}}, p s i
$$

where

$$
\begin{aligned}
& \mu=\text { viscosity of seawater }\left(5 \times 10^{-4} \frac{1 \mathrm{~b}}{\mathrm{ft} \mathrm{sec}}\right) \\
& g=32.2 \mathrm{lb} \text { mass } \mathrm{ft} / \mathrm{lb} \text { force } \mathrm{sec}^{2} \\
& \varepsilon=\text { volume fraction voids }(\simeq 0.4)
\end{aligned}
$$

For $\Delta p \leq 6$ psi, $t_{0}=0.02 \mathrm{ft}$, and the previously quoted values of other parameters, $\mathrm{Eq}(8)$ gives $\mathrm{a} \geq 3.35 \times 10^{-5} \mathrm{ft}=$ 
$0.01 \mathrm{~mm}$, which is compatihle with the mass transfer target value of $d \leq 0.15 \mathrm{~mm}$.

Equation (8) shows that the otherwise beneficial small diameter has a detrimental effect on pressure dróp. This can be offset by using an expanded bed (larger $\varepsilon$ ), more transparent configurations (stacked/corrugated mesh, steel wool, etc); or even perhaps a fluidized bed, although the latter option would appear to involve some serious problems, such as particle attrition and the difficulty of avoiding channeling in thin beds. It may be necessary to go to beds having high porosity, in any event, to mitigate plugging by particulate matter.

\section{Other Configurations}

The cost and complexity of actively pumped systems strongly suggests that consideration be given to passive, current-driven systems. Free-stream mass fluxes can be quite high, i.e.

$$
\mathrm{G}=658 \mathrm{~m}, \mathrm{gpm} / \mathrm{ft} \mathrm{t}^{2}
$$

where $m=$ curront volocity, mph

Hence for a $3 \mathrm{mph}$ current $G$ would be quite large, 22000 $\mathrm{gpm} / \mathrm{ft}^{2}$; which in turn would provide mass transfer coefficients an order of magnitude larger than in the creep-flow conditions through packed beds previously discussed. The catch is that the filter would have to be very transparent. (eg a coated wire mesh or net, as in Ref (2)) so as not to impede flow. The combined effect of an open weave and a thin bed reduces the effective volume by more: than an order of magnitude -- negating the 
increase in K. Use of a less porous bed is counterproductive since stagnation pressures are quite low:

$$
\Delta \mathrm{p}_{\mathrm{s}}=\frac{0.015}{2 \mathrm{~g}} \mathrm{~m}^{2}, \mathrm{psi}
$$

Thus for our $3 \mathrm{mph}$ current a maximum head of $0.13 \mathrm{psi}$ could be provided.

In spite of these limitations the sheer simplicity of this approach justifies further attention.

7. Fluidized Beds

Use of a fluidized bed in liev of a packed bed is another option which has many points in its favor, not the least of which is resistance to fouling.

Stoke's law gives an optimistic upper limit on the flow loading sustainable without carryover for a fluidized bed:

$$
G \leq \frac{60 a^{2} g \rho^{2}(S G-1.0)}{18 \mu W}, g p m / f t^{2}
$$

where SG is the specific gravity of the absorber particles relative to seawater.

The pressure drop through a fluidized bed is given by:

$$
\Delta p=\frac{\rho t_{0}(S G-1.0)}{144}, p s i
$$

For an ion exchange resin having $S G=1.1, d=0.1 \mathrm{~mm}$, and $t_{0}=0.02 \mathrm{ft}$, the above equations give $\Delta \mathrm{p}=0.0009 \mathrm{psi}$, and $G \leq 1.1 \mathrm{gpm} / \mathrm{ft}^{2}$. Hence, while the flow loading has not been in- 
creased, the pressure drop is trivial, and well within the range of ocean current stagnation pressures.

It is tempting to contemplate increasing the bed thickness, but the limit of Eq (1) still applies, which makes this unattractive unless G can be increased proportionally. Use of a coated particle having a dense core (to increase SG) would be of benefit here, but less than a factor of ten improvement could be contemplated.

The concern over filter material losses (by carryover, attrition and dissolution), which is particularly strong for fluidized beds, is readily appreciated if one ratios the cost of losses to the value of the product:

$$
1 \geq R_{3}=\frac{B \quad Z}{U \cdot X \cdot I}
$$

where $\mathrm{z}$ = weight fraction of absorber material in effluent seawatcr:

For the representative parameter values already quoted and $\mathrm{R}_{3}=1 / 5$, one inds that $\mathrm{z} \leq 20 \mathrm{ppb}$.

8. Comments and Conclusions

As of now there is no generally agreed upon overall conceptual system design for a practical uranium-from-the-sea facility. Elementary considerations, some of which were recapitulated here, suggest that the design envelope of acceptable parameters severely restricts the available options. More work is clearly in order, but it would appear that a viable system must employ absorber par- 
ticles of small dimensions, in thin beds of high void fraction, most likely sited at sea.

It would also appear that considerable useful input in the formulation of a design approach could be gained by closer attention to research in progress on other energy options. For example, the high-capacity, low-head axial flow pumps under consideration for OTEC units are also ideal for sea-borne uranium facilities; and, in the area of passive systems, one should note that the kelp farm biomass concept shares many similar problems; including current-driven nutrient transport.

Figures 1 and 2 illustrate preliminary conceptual desiqns of active and passive units for the recovery of uranium from seawater which may have the potential of meeting the requirements established here. They will be used as the starting point for further work on system design in the DOE-sponsored project on uranium extraction from seawater at MIT.

\section{References}

(1) F. R. Best and M. J. Driscoll,

"Prospects for the Recovery of Uranium from Seawater" MITNE-231, Jan. 1980.

(2) C. Bettinali and F. Pantanetti,

"Uranium from Seawater: Possibilities of Recovery Exploiting Slow Coastal Currents"

Uranium Ore Processing, IAEA, Nov. 1975.

Appendix

A number of assumptions were made in the developments presented in the body of the text which require support. Several are connected with flow regime, which we assumed to be laminar. This is readily verified. The particle Reynolds number is: 


$$
\mathrm{N}_{\mathrm{Re}}=\frac{\mathrm{d} W \mathrm{WG}}{60 \mu}
$$

where $\mu$ is the viscosity of seawater. For $G$ in $g p m / f t^{2}$ and $d$ in $\mathrm{mm}:$

$$
\mathrm{N}_{\mathrm{Re}}=0.935 \mathrm{dG}
$$

Thus for $d=1 \mathrm{~mm}, G=1 \mathrm{gpm} / \mathrm{ft}^{2}, \mathrm{~N}_{\mathrm{Re}} \simeq 0.9$, which is far below the laminar/turbulent transition point of $\sim 10$. Hence we are assuredly laminar; moreover $\mathrm{N}_{\mathrm{Re}}$ is sufficiently low to justify use of the low-flow limit in computing the mass transfer coefficient (mass transfer Nusselt number $=2.0$ ).

In the mass transfer calculations we also ignored bed exhaustion. This may be considered an optimistic asymptotic case for low-capacity absorbers. However, we really had in mind advanced ion exchange media which might have a capacity, $C$, of as high as $0.1 \mathrm{lb} U$ per $l \mathrm{~b}$ resin. The cycle time (time between regeneration of the saturated bed) is:

$$
T=\frac{C \dot{\gamma} t_{0}}{5: 26 \times 10^{5} x w \pm G}
$$

For the previously quoted representative values of these parameters one finds that

$T \geq 13$ years.

Clearly, one would not find it practical to operate an advanced absorber to near-saturation. On the other hand, one might well be satisfied with materials having capacities a factor of 10 to 100 lower. 
Although uranium recovery from seawater is formidable engineering endeavor, it is comforting to know that the thermodynamic mimimum work of separation is quite modest:

$$
w_{s} \simeq \frac{1}{M_{u}}\left[\Delta H_{s}-R T \ln \left(\frac{x}{109} \frac{M_{s}}{M_{u}}\right)\right] \frac{K w h r}{1 b U}
$$

where $\Delta \mathrm{H}_{\mathrm{s}}=$ heat of solution,. $\mathrm{Kwhr} / \mathrm{lb}$ mole

$(\sim \pm 3$, varies with chemical species)

$\mathrm{RT}=0.3 \mathrm{Kwhr} / \mathrm{lb}$ mole

$M_{s^{\prime}} M_{u}=$ lbs per mole seawater and uranium, respectively $(218,238)$

Hence for the parameters cited; $W_{s} \simeq 0.04 \mathrm{Kwhr} / 1 \mathrm{~b} ;$ and even if energy costs a dollar per Kwhr, the minimum cost of separation would only be a few cents a pound: 
TOP VIEW

OF BARGE

SHOVING 2 ROWS

OF FUITER RACKS

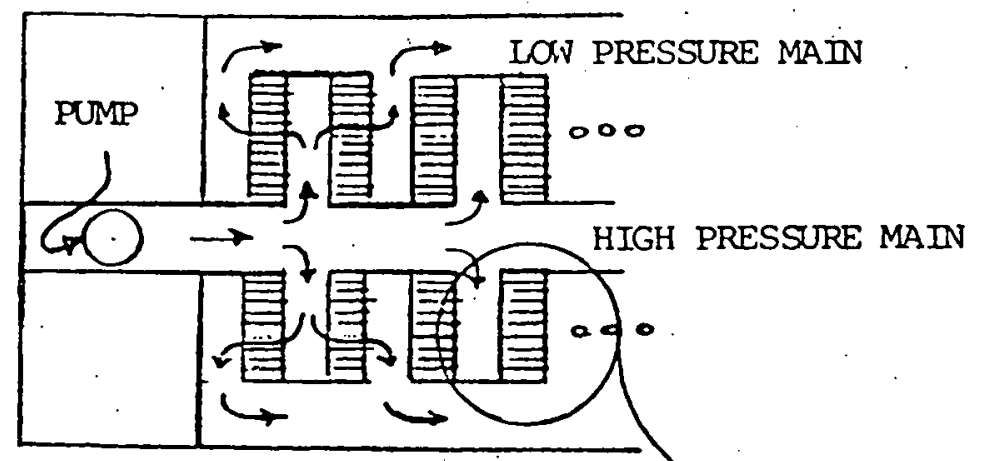

EXPANDED VIEW OF RACKS SHOWING FRAMES

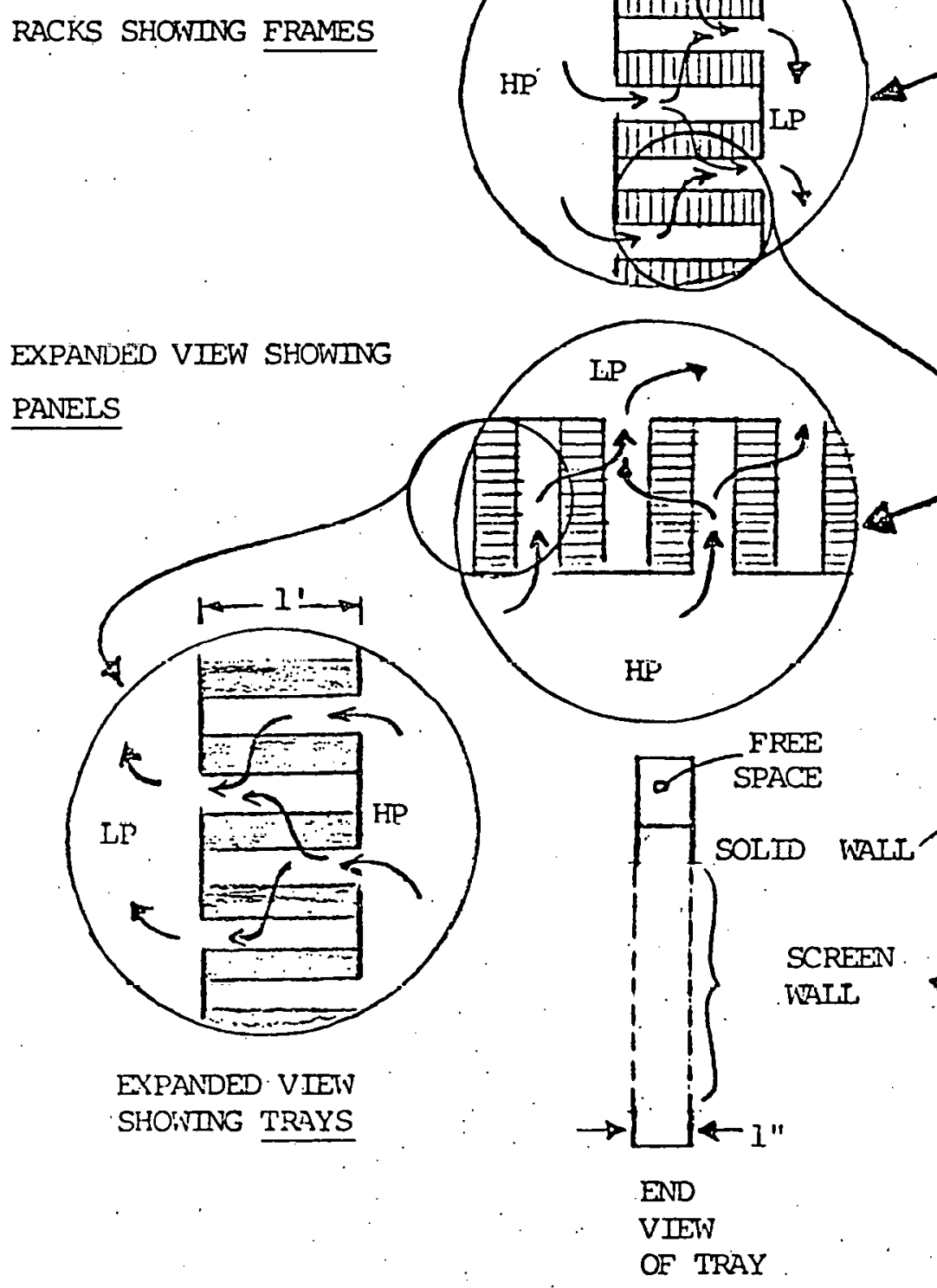

EACH BARGE HAS:

2 ROWS/BARGE

(80' $\times 400^{\prime}$ ea)

15 RACKS/ROW (20' $\times 80^{\prime}$ ea)

15 FRAMES/RACK

(4' $\times 20^{\prime}$ ea)

I,0 PANF.LS/TRAY

(I' $\times 4^{\prime}$ ea)

24 TRAYS/PANEL (1" $\times 1$ ' ea) $10 \mathrm{FT}^{2} / \mathrm{TRAY}$ HENCE $1.08 \times 10^{6} \mathrm{FT}^{2}$ /BARGE AND 30 BARGES PER 1 GWE REACTOR 


\section{NOT TO SCALE}

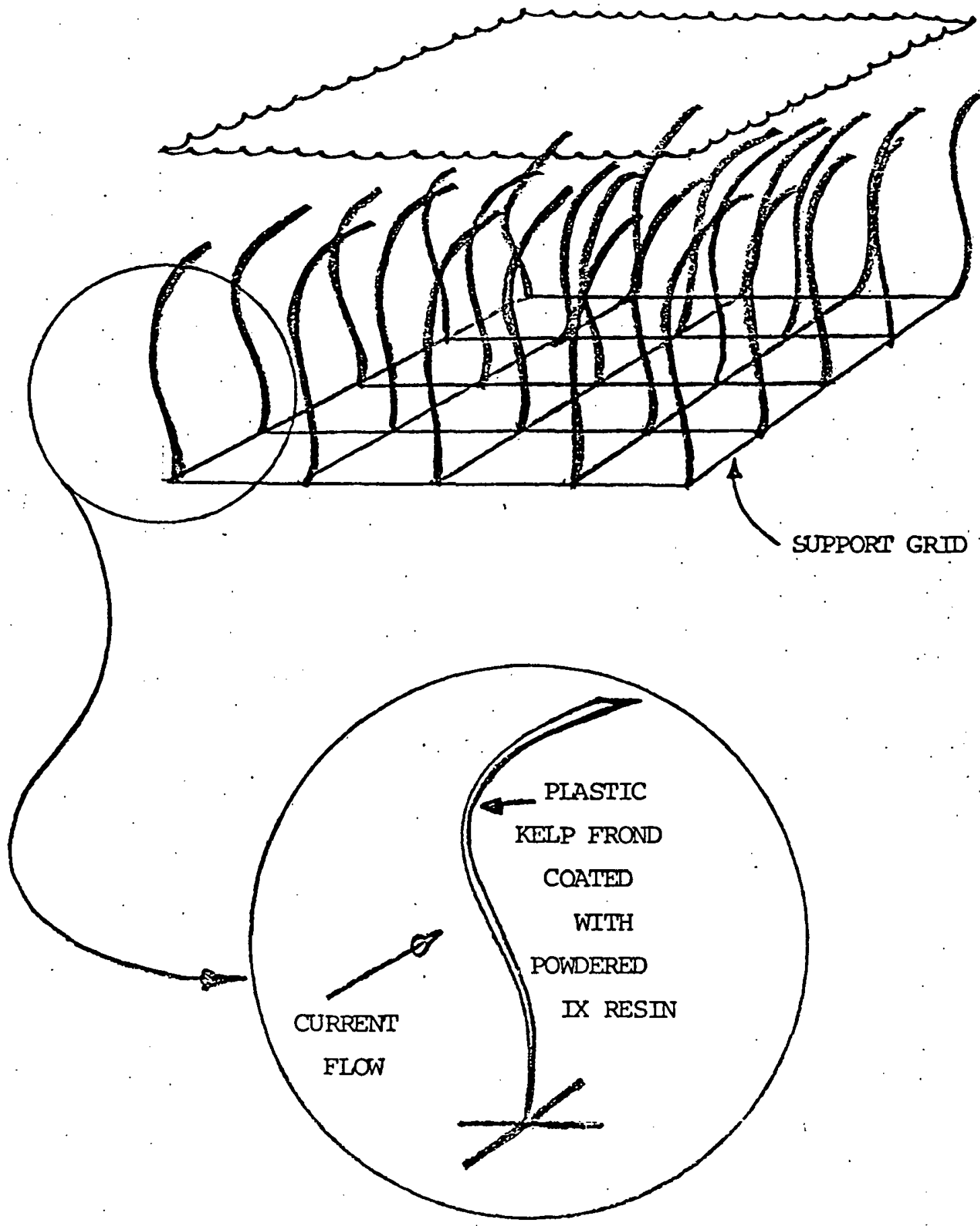

FOR EACH 1 GWE REACTOR ONE NEEDS A 1000 ACRE FARM OF KELP FRONDS ON A 1 FT $\times 1$ FT GRID, EACH FROND 1 FT WIDE $\times 100$ FT IONG

FIG. 2 PASSTVE CONCEPT BASED ON KELP FARM ANALOGY 
Chapter. 3

The Effect of System Improvements on

Uranium Recovery From seawater

by

F. R. Best (MIT) and M. J. Driscoll (MIT)

The reason for interest in the recovery of uranium from the world's oceans is clear: they contain on the order of 4000 million tons of $\mathrm{U}_{3} \mathrm{O}_{8}-$ enough to sustain thousands of LiWR for thousands of years without resort to plutonium recycle or the introduction of breeder reactors. The reasons for skepticism as to the prospects of this undertaking are also obvious: the low concentration of uranium in seawater ( $\sim 3.3 \mathrm{ppb}$ ) necessitates large flow rates and sorber bed areas--to sustain one large LWR the ocean water throughput must be about half the volumetric flow rate of the Mississippi river. To help resolve key points at issue, work has been carried out to:

(a) develop a model describing the engineering and economic performance characteristics of a generic system

(b) employ the model to predict $\mathrm{U}_{3} \mathrm{O}_{8}$ production costs using state-of-the art technology

(c) carry out sensitivity analyses, parametric studies and process optimizations to identify targets for $R d D$ efforts which could lead to a competitive system.

A computer program, URPE, was developed incorporating analytic models for adsorption and pressure drop in packed 
beds (or in stacked tubes), the use of actively-pumped or passive current-interception flow induction, and a multi-purpose plant to generate electricty to drive the seawater pumps, distill water and produce chemicals for use in bed elution. Unlike previous studies, whirh have been centered about the use of large terrestrial civil works (2), the present conceptual design assumes a modular sea-borne system. The adsorber used in the studies was hydrous titanium dioxide (HTO), the consensus choice of the various researchers worldwide who are pursuing the goal of uranium-fromseawater. In addition to calculating the kinetic behavior of the adsorption process, the program executes a complete mass and energy balance around the overall system, sizes all components and estimates all associated costs to arrive at a unit price of product, $\$ / 1 \mathrm{~b} \mathrm{U}_{3} \mathrm{O}_{8}$.

The program was benchmarked against previous studies by ORNL and. EXXON by inputting their system's characteristics to URPE. The cost breakdown for each subsystem generated by URPE ras either in good agreement with the corresponding ORNL and EXXON values, or the reason for the observed difference was apparent (e.g. the more sophisticated bed kinetics treatment in URPE and the large interest during construction term in the ExxON study). The results (in 1979\$) were, for ORNL: $627 \$ / 1 b \mathrm{U}_{3} \mathrm{O}_{8}$; for EXXON (without interest during construction): $740 \$ / 1 \mathrm{~b} \mathrm{U}_{3} \mathrm{O}_{8}$ and for MIT: 650-1322 $\$ / 1 \mathrm{~b} \mathrm{U} \mathrm{U}_{8} \mathrm{O}$. These values correspond to a terrestriallysited unit using proven technology, and not subjected to any substantial design optimization. They are clearly uncompetitive 
compared to the current price of $\mathrm{U}_{3} \mathrm{O}_{8}(30 \$ / 1 b)$ or even the projected breakeven price of $\mathrm{U}_{3} \mathrm{O}_{8}$ used in LWRs in competition with breeder reactors or coal-fired fossil units ( $2 i^{5} 0$ \$/lb).

In the next stage of the evaluation a sea-borne recovery system was iteratively optimized to deliver minimum cost $\mathrm{U}_{3} \mathrm{O}_{8}$. Table 1 summarizes both key input data and selected items from the computer output. As can be seen, the total price of $\mathrm{U}_{3} \mathrm{O}_{8}$. $316 \$ / 1 b$, is considerably lower than for the benchmark comparisons, but still not competitive. By tracking the variation of key parameters in the optimization process it was possible to establish a number of important generalizations:

(a) Actively pumped systems outperform passive current. interceptor systems

(b) Packed beds are superior to stacked tubes as a substrate for the adsorber film

(c). Optimum systems have thin beds (on the order of inches thick), small partirlea (on the order of $0.1 \mathrm{~mm}$ dia.). and thin adsorber coatings ( $25 \mu \mathrm{m})$

(d) The high cost of desalinated water in pre- and postelution bed washing operations is sufficiently large to warrant close attention to refinement of this step.

In the final phase of the work parameteric and sensitivity studies were carried out to identify targets of opportunity for future R\&D efforts, and to establish ultimate bounds on potential system performance. 
Table 1

Characteristics of an Optimized

state-of-the-Art Packed Bed System

\section{Parameter}

Value

I. Input specifications

Adsorber Properties:

Adsorber Capacity

Uranyl-HTO Equilibrium Constant

Diffusivity of Uranyl Species in HTO

$210 \mathrm{mg} \mathrm{U} / \mathrm{kg} \mathrm{Ti}$

$4.39 \times 10^{-16} \mathrm{~m}^{2} / \mathrm{s}$

Economic Conditions:

Fixed Charge Rate

Plant Capacity Factor

Lang Factor (System cost/component cost)

Annual Production Rate

$258 / y r$

$80 \%$

4.46

200 tons $\mathrm{U}_{3} \mathrm{O}_{8} / \mathrm{yr}$

II. Optimized Output

Superficial Velocity in the Bed

Particle Diameter

Bed Thickness

Loading Time

Coating Thickness

Bed Area

$1.08 \times 10^{-3} \mathrm{~m} / \mathrm{sec}$
$64.6 \mu \mathrm{m}$
$1.18 \times 10^{-2} \mathrm{~m}(0.5 \mathrm{in})$
$32 \mathrm{hrs}$
$5.3 \mu \mathrm{m}$
$3.10 \times 10^{6} \mathrm{~m}^{2}$

III. Costs

Aasorbent Losses

12

Chemical Make-up

39

water

63

Pumping Power

46.

Annualized Capital; Maintenance and Labor 156

Total (1979\$)/ib U $\mathrm{O}_{8}$

$\overline{316}$ 
Adsorption capacity and pumping power requirements are two of the most important and contested parameters in the analysis of uranium-from-seawater systems. Adsorotion capacity is important for obvious reasons. That the capacity of HTO for uranium is a contested property is clear from the wide range. of values reported for capacity. Although the pumping power required for any given system design is not disputed, the choice of system conceptual design to minimize pumping power requirements does depend on how important pumping power is considered to be by the designer.

A study of the effect of increasing adsorption capacity and pumping power was performed. in order to assess the impact of these items on optimized uranium production cost. The study was performed by starting from the optimized base case, increasing the item of interest, and re-optimizing the entire uranium recovery system design.

The adsorption capacity was varied, starting with the base case value of $8.68 \times 10^{-5} \mathrm{lb}$ U/lb HTO (210 $\mathrm{mg} \mathrm{U/kg} \mathrm{Ti),} \mathrm{and}$ increasing the capacity to a maximum value of $3 \times 10^{-2} \mathrm{lb} \mathrm{U} / 1 \mathrm{~b}$ HTO $(72,380 \mathrm{mg} \mathrm{U} / \mathrm{kg} \mathrm{Ti})$. This range includes all of the reported values of HTO capacity, including experiments in spiked seawater, and concludes with a capacity which might be typical of an ion exchange resin. Figure 1 shows the data plotted from the URPE output.

The data show the maximum improvement which might be expected as sorber capacity increases. Very large (but not phys- 


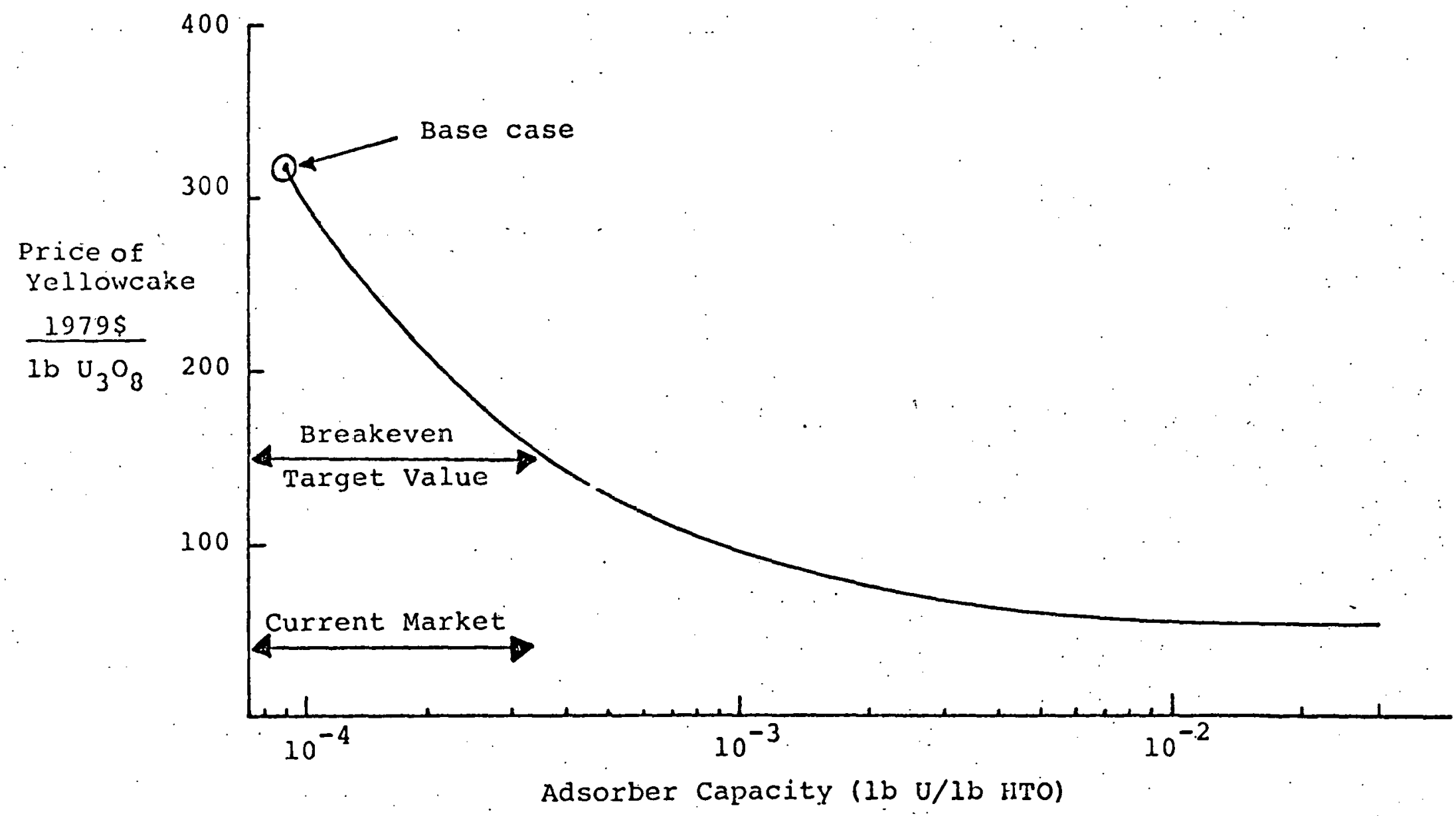

Fig. I Optimized $\mathrm{U}_{3} \mathrm{O}_{8}$ Cost as a Function of Adsorber Capacity 
ically impossible) increases in sorber capacity would be required to bring production price down to the range of the 1980 spot market price for $\mathrm{U}_{3} \mathrm{O}_{8}, 30 \mathrm{\$} / \mathrm{lb}$. However, the capacity' need only be increased to $3.5 \times 10^{-4} \mathrm{lb} \mathrm{U} / \mathrm{lb}$ HTO $(847 \mathrm{mg} \mathrm{U} / \mathrm{kg} \mathrm{Ti})$ in order to produce uranium at a price of $150 \$ / 1 \mathrm{~b} \mathrm{U}_{3} \mathrm{O}_{8}$, the breakeven price. It is recognized that it is unlikely that a single recovery system model could accurately predict production costs over such a wide range of sorber capacity. However, the trend of decreasing cost with increasing capacity is so strong that work to improve sorber capacity, or identify alternate adsorbers having a high capacity, should clearly be carried out.

The pumping power was varied from the base case value, to ten times the base case value. The results are plotted in Figure 2. This figure shows that the cost of uranium production increases much less than one-to-one with increasing pumping power requirements (due, for example, to the need for augmented prefiltering or excessive bed fouling) and could be offset by relatively smaller incleases in adsorber capacity.

Summary and Conclusions

As a result of running the URPE code over a wide range of bed operating conditions, it was found that $\mathrm{U}_{3} \mathrm{O}_{8}$ produced from seawater using state-of-the-art materials could not cost less than about $316 \$ / 1 b \mathrm{U}_{3} \mathrm{O}_{8}$ (1979 $\left.\$\right)$. This result is also supported by a comparison of URPE performance and economics models with ORNL and ExXON analyses. Inclusion of interest on capital during 


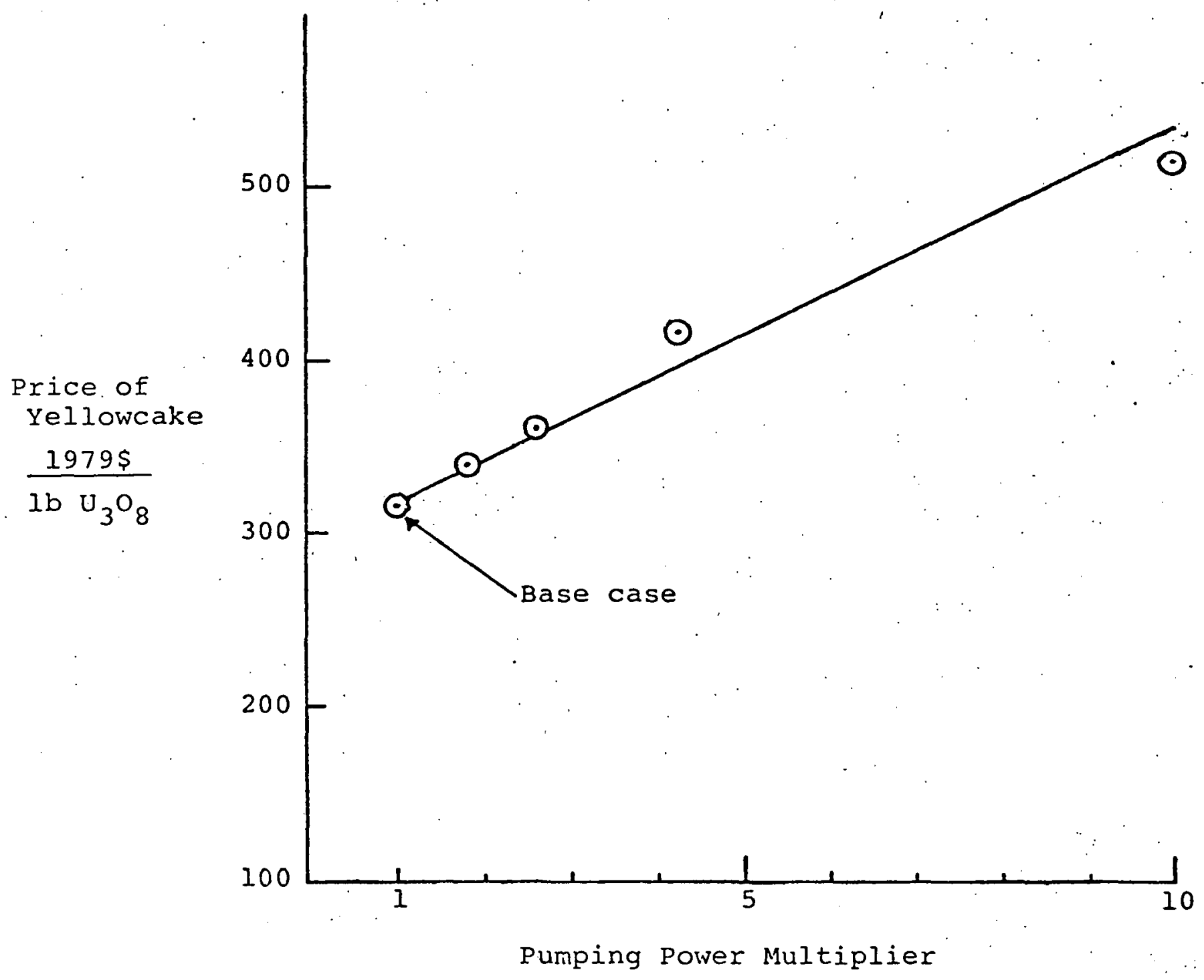

Fig. 2. Optimized $\mathrm{U}_{3} \mathrm{O}_{8}$ Price as a Function of the Increase in pumping Power Requirements 
construction would increase this value, but increases in sorber capacity would lead to offsetting cost reductions. The potential. of higher capacity adsorbers for reducing costs, together with development of an effective method of reducing the costs of chemicals expended during elution could bring the ultimate production price below $150 \$ / 1 b \mathrm{U}_{3} \mathrm{O}_{8}$. Indeed, this goal would appear assured if capacities typical of ion exchange resins could be demonstrated for uranium in seawater.

\section{$\underline{\text { References }}$}

1. F.R. Best., M. J. Driscoll, "The Recovery of Uranium From Seawater," MIT-EL 80-001, January 1980.

2. "Extraction of Uranium from Seawater," EXXON Nuclear Company, Reports XN-RT-14 and XN-RT-15, February 1979. 


\section{Chapter 4}

CONCEPTUAL DESIGN OF A SYSTEM TO

EXTRACT URANIUM FROM SEAWATER

by

M. J. Driscoll and L. G. Riniker

1. Introduction

A clear picture is now emerging of the general features demanded of a uranium-from-seawater system. (1) (2) (3) If settled sorber bed technology is to be employed, then thin beds of fine particles are greatly to be preferred: thin beds to keep pumping power requirements within practical bounds, and small diameter particles to enhance mass transfer. Consideration of these requirements led to selection of a barge-mounted filter system (exploiting concepts drawn from a number of areas faced with similar demands) for evaluation as a candidate approach to the task at hand.

\section{Background}

The need to process large volumes of water at modest pressure drops, while removing contaminants at trace element concentrations has been addressed in the field of condensate polishing as applied to large power plants. The use of thin beds of powdered ion exchange resin has proven to be effective. The major drawback for present purposes is the expensive structural arrangement used to support the beds. Here we can profit from another area of power station technology: the filter bags used to remove particulates from combustion gases discharged by coal-fired units ${ }^{(5)}$. These baghouse units process large volumetric flow rates through long cylindrical fiberglass filter 
bags, and are capable of $99+8$ retention of even extremely fine soot. Of particular interest here is their low capital cost and the ease with which a layer of particulate material can be laid down and removed. The proposed material for the filter bags is spunbonded polypropylene, marketed by du Pont under the trademark TYPAR (16). This material has been widely used in civil engineering applications (soil stabilization, drainage, dike construction and erosion control) which include long term exposure to seawater. Porosity and pressure drop data are available (and have been verified experimentally at MIT). The material is available commercially in large quantities, in rolls $16 \mathrm{ft}$ wide and $3,000 \mathrm{ft}$ long at a cost of roughly $70 \notin / \mathrm{yd}^{2}$ for a $15 \mathrm{mil}$ thick product weighing $4 \mathrm{oz} / \mathrm{yd}^{2}$.

Thus the concept to be evaluated here involves the use of baghouse-type filters to support a thin layer of fine sorber particles. Either ion exchange resin or hydrous titanium oxide can be employed as the filter bed medium, but our evaluation concentrates on the former because it is projected to have better overall properties in the long term. The filter modules are mounted on barges, which will permit operation in clean, warm water in biologically inactive areas sufficiently far from shore. The requisite pumping is provided by large low-head axial flow pumps currently under development for OTEC applications (7.). Energy is supplied by a coal-fired unit mounted on the barge. At the end of a loading cycle the resin is removed from the filter bags and returned to a shore-based chemical processing plant for uranium recovery and resin regeneration prior to reuse. Figure 1 is a sketch of the general concept envisioned. 


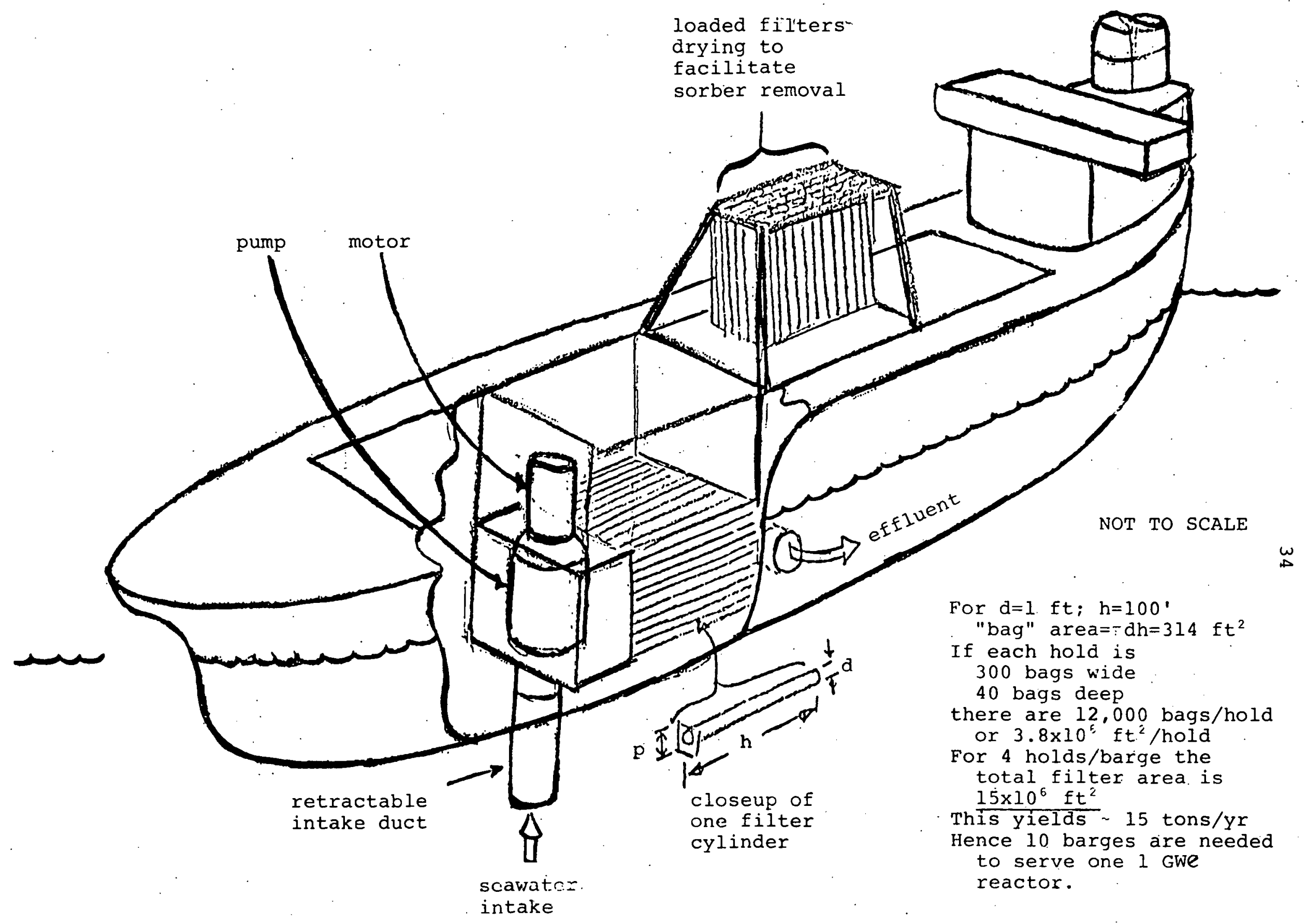

Figure 1 Schematic View of Barge-Mounted Baghouse-Type Filter Units 


\section{Key Characteristics}

Two sources of pertinent data can be drawn upon to develop information which will define the essential features of a filter system of the type envisioned here. 'First of all, there is extensive operating data from baghouse operation. Although the fluid handled is combustion gas $\left(\mathrm{N}_{2}, \mathrm{CO}_{2}, \mathrm{H}_{2} \mathrm{O}\right)$, it is similar in many respects to air, for which there is a long history of similitude studies as a surrogate for water. Thus we can directly translate the pressure drop versus flow rate data as a function of particle diameter and bed thickness into water-equivalent results. The calculational methodology assembled by Best (1) can then be used to estimate mass transfer coefficients and uranium recovery efficiency for the range of parameters of interest. In concert these results determine system size and material processing rates, which, in turn, can be used to develop estimates of the cost of the $\mathrm{U}_{3} \mathrm{O}_{8}$ product:

The ratio of water to yas pressure drops through the same filter bed is given by the simple relation:

$$
\frac{\Delta \mathrm{P}_{w}}{\Delta \mathrm{P}_{g}}=\left(\frac{\mu_{w}}{\mu_{g}}\right)\left(\frac{\mathrm{Q}_{w}}{\mathrm{Q}_{g}}\right) \equiv\left(\frac{\mu_{w}}{\mu_{g}}\right)\left(\frac{V_{w}}{V_{g}}\right)
$$

where $\left(\mu_{\mathrm{w}} / \dot{\mu}_{\mathrm{g}}\right)=$ ratio of water to gas viscosities $\approx 50$

$Q=$ volumetric flow loading, cfm per $f t^{2}$ $V=$ superficial velocity, ft/min 
Thus if we employ representative baghouse data $\left(\Delta \mathrm{P}_{\mathrm{g}}=0,14 \mathrm{psi}, \mathrm{Q}_{\mathrm{g}}=2 \mathrm{cfm}\right.$ per $\left.\mathrm{ft}^{2}\right)$, and permit $\Delta \mathrm{P}_{\mathrm{W}}=7 \mathrm{psi}$ in accord with Ref (1), which shows that values in this range are needed to assure a favorable overall energy balance, then Eq (I) shows that the superficial flow velocity of water passing through the bed, $V_{W}=2 \mathrm{ft} / \mathrm{min}$. This corresponds to a flow loading of roughly $15 \mathrm{gpm} / \mathrm{ft}^{2}$. Powdered ion exchange resin beds in condensate polishing service are operated at flow loadings this high, but at pressure drops near $40 \mathrm{psi}$. However, pressure drop is directly proportional to bed depth and inversely proportional to particle diameter squared; so that a bed design compatible with current requirements is readily achievable.

If the bed frontal area is $A$, then the uranium uptake by the bed over a period of $\mathrm{T}$ days is merely

$$
U=1.18\left(\frac{1440}{2000}\right) w \times V_{w} A n T \text {, tons } U_{3} O_{8}
$$

where $\mathrm{x}=$ concentration of uranium in unfiltered seawater ( $\left.3.3 \times 10^{-9} 1 \mathrm{~b} / 1 \mathrm{~b}\right)$

$w=$ density of seawater, $1 \mathrm{bs} / \mathrm{ft}^{3}(64)$

$n=$ bed efficiency, fraction of uranium removed, averaged over time $\mathrm{T}$

Best's computer program, URPE, has been used to determine $\eta$ as a function of flow rate, particle diameter and bed thickness for various exposure times. For parameter sets compatiblo with the present concept a typical value of $n$ is 20.5 for a cycle time, $T$, of 30 days, in which case Eq (2) predicts 
a uranium recovery of 0.084 tons of yellowcake for every. $10^{6} \mathrm{ft}^{2}$ of filter area, A, per month; or 1 ton per year, Hence the barge design sketched in Fig. 1, with its $15 \times 10^{6}$ $\mathrm{ft}^{2}$ filter area, can produce approximately 15 tons of uranium per year.

\section{Economic Prospects}

Sufficient information is now available to permit assembly of the various components of a cost-of-product estimate. Appendix A to this paper considers each element of such an analysis. The results are summarized in Table 1. The total of $113 \$ / 1 \mathrm{~b} \mathrm{U}_{3} \mathrm{O}_{8}$, while undoubtedly overoptimistic, is encouraging. This value, if attainable in practice, is attractive from a long range perspective: although today's spot market price is about $30 \$ / 1 \mathrm{~b}$, the breakeven price versus long range alternatives such as breeder reactors (and many other high technology options such as accelerator breeders, fusion-fission hybrid devices, and the like) is on the order of $150 \$ / 1 b \mathrm{U}_{3} \mathrm{O}_{8}(8)$.

\section{Discussion}

The scoping calculations completed to date indicate that the use of a barge-mounted, actively-pumped system based upon a baghouse filter analogy may be a promising approach 
to the extraction of uranium from seawater. If, after further reflection, this concept is judged to outperform the passive, current-interceptor systems currently under. evaluation at MIT and elsewhere (1), then increased attention will be in order.

The foremost requirement is for more sophisticated cost analyses. Since none of the elements of the system involve unproven technology, this would appear to be primarily a question of devoting sufficient effort to the task. The cost is most sensitive to the flow rate and integrated flow which can be sustained through the filters. Several limits constrain these parameters:

(1) The strength of the baghouse cloth. A hoop stress of $\Delta \mathrm{P} \cdot \mathrm{d} / 2=7 \mathrm{psi} \cdot 12 \mathrm{in} / 2=42 \mathrm{lbs}$ per linear foot, is indicated under the assumed conditions. This is severe, but within the capability of spunbonded polypropylene cloth (confirmed. experimentally at MIT).

(2) The ability to avoid fouling by particulates in seawater. This consideration motivated the use of a barge which can operate far from shore in biologically inactive zones. The achievable concentration of filterable matter will determine whether the filter beds have to be reclaimed more often than desired to restore their permeability.

(3) The performance characteristics of the sorber medium. Tests under prototypic conditions in natural seawater are yet to be performed. It must be shown that: 
(a) Mass transfer rates are as calculated at the bed thicknesses and particle diameters assumed (or equivalently at the pressure drops and flow loadings required):

(b) Sorber capacities are as high as presumed. Otherwise, regeneration must be performed more frequently.

Sorber research now underway at MIT (both in Cambridge and at Woods Hole); and at Rohm and Haas, and elsewhere in the world (2), should provide a firm data base for further parametric studies, leading to optimization of the proposed system, withjn the next year or so. 


\section{ACKNOWLEDGEMENTS}

The authors are grateful to Dr. Frederick R. Best and Ms. Cynthia K. Nitta for their review of, and constructive comments on, this manuscript. The contribution of Mr. David A. Surber to the cost-of-elution estimates is especially appreciated.

Finally, the authors are also grateful to the MIT Sea Grant program for providing funding via the MIT UROP office to Mr. Riniker during the period in which the research necessary for this paper was carried out. 


\section{REFERENCES}

1. F. R. Best and M. J. Driscoll

"Prospects for the Recovery of Uranium from Seawater" MIT-EL80-001, Jan. 1980.

2. F. R. Best and M. J. Driscoll (Eds.)

"Proceedings of a Topical Meeting on the Recovery of Uranium from Seawater"

MIT-EL80-031, Dec. 1980.

3. M. J. Driscoll et al

"Practical Constraints on Systems for the Extraction

of Uranium from Seawater"; in Ref. (1)

4. "Special Report: Ion Exchange" POWER, Vol. 124, No. 9, sept. 1980.

5. "Upsurge in Baghouse Development"

EPRI Journal, Vol 5, No. 9, Nov. 1980.

6. Private communication, D. C. Cannon, du Pont Technical Representative; forwarding TYPAR (B) product literature Wilmington, Delaware, March 1981.

7. T. E. Little, "Selection of Seawater Pumping systems for OTEC Power Plants," in proceedings of the Fifth OTEC Conference, Feb. 20-22, 1978, Miami Beach, Fla.

8. Report of the Nonproliferation Alternative Systems Assessment Program, DOE/NE-0001/1-9, June 1980. 
Table 1 - Cost of Product Summary

$\underline{\text { Item }}$

Filters

IX: Resin

Regeneration and Product Recovery

Barge Amortization

Barge Operation

Pumping system

Energy Consumption
Contribution,

$\$ / 1 \mathrm{~b} \quad \mathrm{U}_{3} \mathrm{O}_{8}$

6

2

26

13

39

3

24

TOTAL

$113 \$ / 1 \mathrm{~b} \quad \mathrm{U}_{3} \mathrm{O}_{8}$ 


\section{APPENDIX A: COST ESTIMATES}

The subsections in this appendix consider, term by term, the major cost components making up the subject uranium-from-seawater system.

\section{A. 1 Cost of Baghouse-Type Filters}

The contribution of the filter structure to the cost of product is obtained by dividing the annualized cost by the product production rate:

$$
U_{F}=\frac{\phi_{f} \gamma}{1.18(8766)(60) W x V_{W} n L} \quad \$ / 1 b U_{3} O_{8}
$$

where $\phi_{f}=$ annual carrying charge rate (assumed to have a service life of 5 years and zero salvage value) $\left(0.30 \mathrm{yr}^{-1}\right)$

$\gamma=$ installed cost of filter system, $\$ / f t^{2}$; spunbonded polypropylene bags will cost approximately $0.1 \$ / f t^{2}$, to which we add $1.9 \$ / f t^{2}$ for supporting structures.

$\dot{w}=$ density of seawater, $1 \mathrm{bs} / \mathrm{ft}^{3}(64)$

$\mathrm{x}=$ concentration of uranium in seawater, $1 \mathrm{bs} \mathrm{U} / \mathrm{lb}$ $\left(3.3 \times 10^{-9}\right)$

$\mathrm{V}_{\mathrm{w}}=$ superficial velocity of water traversing filter, $\mathrm{ft} / \min (2.0)$

$\eta$ = bed efficiency, fraction of incident uranium removed $(0.5)$

$I$ = plant capacity factor, fraction of year at full flow $(0.75)$ 
APPENDIX A: COST ESTIMATES (contd.2

For the quoted parameter values:

$$
U_{f}=6 \quad \$ / 1 \mathrm{~b} \mathrm{U} \mathrm{O}_{8}
$$

\section{A. 2 Cost of Resin Inventory and Makeup}

The weight per unit area of resin in a bed $\delta$ ft thick is just

$$
M_{R}=R \cdot \delta(1-E), \quad I b s / f t^{2}
$$

where $R=$ resin density, $1 b / f t^{3}(80)$

$$
E=\text { void fraction in bed (0.4) }
$$

Thus the annualized cost relative to the filter bag cost, again assuming a 5-year useful life is:

$$
U_{R}=:\left(\frac{C_{R} \cdot M_{R}}{\gamma}\right) \cdot U_{f} \quad \$ / 1 b U_{3} O_{8}
$$

For $\delta=10^{-2} \mathrm{ft}, \gamma=2 \$ / \mathrm{ft} t^{2}$,

$$
\begin{aligned}
& \mathrm{C}_{\mathrm{R}}=1 \$ / 1 \mathrm{~b} \text { and } \mathrm{U}_{\mathrm{f}}=6 \$ / 1 \mathrm{~b}: \\
& \mathrm{U}_{\mathrm{R}}=2 \$ / 1 \mathrm{~b} \mathrm{U}_{3} \mathrm{O}_{8}
\end{aligned}
$$

where we have rounded to the nearest dollar. Makeup has been allowed for by augmenting initial bed thickness to allow for losses such that the end-of-useful-life inventory is adequate.

\section{A. 3 Cost of Resin Regeneration and Product Recovery}

For a resin bed having a surface density of $M_{R}$ $1 \mathrm{~b} / \mathrm{ft}^{2}$, an elution chemical consumption of $\mathrm{z} \$ / 1 \mathrm{~b}$ resin and $\mathrm{n}$ regenerative cycles per year of operation, the expenditure relative to the filter bag cost is: 
APPENDIX A: COST ESTIMATES (Contd.)

$$
U_{C}=\frac{n Z R \cdot S(1-E)}{\phi_{f} \gamma} \cdot U_{f} \quad \$ / 1 b U_{l} O_{n}
$$

If $\mathrm{z}=2 \$ / 1 \mathrm{~b}$ and $\mathrm{n}=10 \mathrm{yr}^{-1}$, with other values as previously prescribed:

$$
\mathrm{U}_{\mathrm{C}}=16 \quad \$ / 1 \mathrm{~W} \mathrm{\textrm {U } _ { 3 } \mathrm { O } _ { 8 }}
$$

To this we add an additional $10 \$ / 1 b \quad U_{3} O_{B}$ to account for recovery of the final product from the elutant - by processes identical to those used in terrestrial milling operations.

\section{A. 4 Cost of Barge}

If the total area occuppied by a $1 \mathrm{ft}$. dia. filter bag cell is $2 \mathrm{ft}^{2}$ :

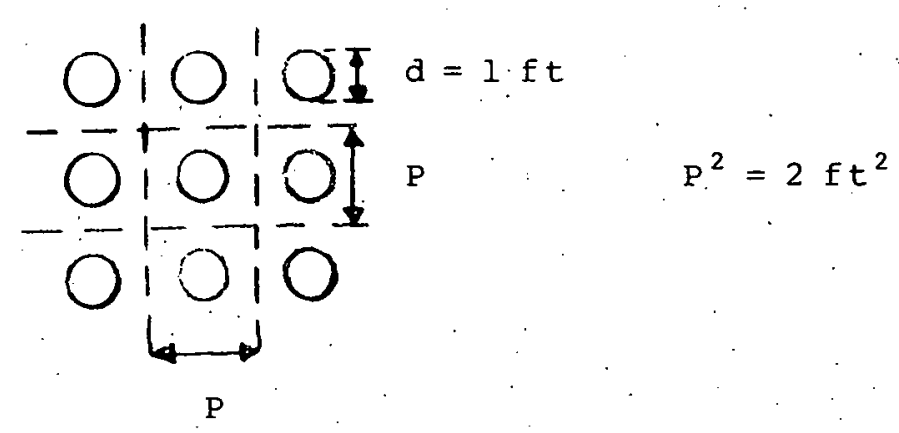

and the active length of each bag is $h=100 \mathrm{ft}$, so that the surface area per bag is $a_{s}=\pi d h \equiv 314 \mathrm{ft}^{2}$, then a barge containing $A=15 \times 10^{6} \mathrm{ft}^{2}$ of total filter surface will require $\mathrm{N}=\mathrm{A} / \mathrm{a}_{\mathrm{s}}=4.8 \times 10^{4}$ bags. These can be contained in a hold volume, $Q=\mathrm{N} \cdot \mathrm{p}^{2} \cdot \mathrm{h}=9.6 \times 10^{6} \mathrm{ft} \mathrm{t}^{3}$. 
APPENDIX A: COST ESTIMATES (Contd.

For a barge costing $\mathrm{C} \$ / \mathrm{ft}^{3}$ of useful hold volume, the annualized cost per unit area of filter is:

$$
\phi_{\mathrm{b}} \frac{\mathrm{CQ}}{\mathrm{A}}=\phi_{\mathrm{b}} \mathrm{C} \frac{\mathrm{P}^{2}}{\pi \mathrm{d}} \quad \mathrm{S} / \mathrm{Yr} \cdot \mathrm{ft} \mathrm{t}^{2}
$$

where $\phi_{\mathrm{b}}=$ annual carrying charge rate for barge (assumed to have a service life of 20 years and zero salvage value) $\left(0.20 \mathrm{yr}^{-1}\right)$

Relative to the filter bag cost, the allocated barge cost is:

$$
\mathrm{U}_{\mathrm{b}}=\left(\frac{\phi_{\mathrm{b}}}{\phi_{\mathrm{f}}}\right) \frac{\mathrm{c}}{\gamma} \frac{\mathrm{p}^{2}}{\pi \mathrm{d}} \cdot \mathrm{u}_{\mathrm{f}} \quad \$ / I \mathrm{~b} \mathrm{U}_{3} \mathrm{O}_{8}
$$

For $c=10 \$ / f t^{3}$, and the other costs as already stated:

$$
\mathrm{U}_{\mathrm{b}}=13 \quad \$ / 1 \mathrm{~b} \quad \mathrm{U}_{3} \mathrm{O}_{8}
$$

\section{A. 5 Cost of Barge Operations}

Based upon experience from merchant ship and barge operations, the running cost is approximately three times the annualized capital cost: This includes all labor, replenishment and repairs.

$$
\mathrm{U}_{\mathrm{o}}=3.0 \quad \mathrm{Ub} \quad, \$ / 1 \mathrm{~b} \mathrm{U} \mathrm{U}_{3}
$$

For the data quoted:

$$
\mathrm{U}_{\mathrm{O}}=39 \quad \$ / 1 \mathrm{~b} \quad \mathrm{U}_{3} \mathrm{O}_{8}
$$

This corresponds to an annual cost:

$$
\mathrm{O}_{\mathrm{b}}=\frac{\mathrm{U}_{\mathrm{O}}}{\mathrm{U}_{\mathrm{b}}} \phi_{\mathrm{b}} \mathrm{C} \mathrm{O}=57.6 \times 10^{6} \mathrm{~s} / \mathrm{yr}
$$




\section{APPENDIX A: COST ESTIMATES (Contd.)}

A. 6 Cost of Pumping Power and Energy Generation

The pumping power can be calculated from the flow rate and pressure drop:

$$
P=2.26 \times 10^{-5}\left[\rho \cdot \mathrm{A} \cdot \mathrm{V}_{\mathrm{W}} / \mathrm{n}_{\mathrm{p}}\right] \mathrm{kW}
$$

where $n_{p}$ is the motor/pump efficiency $(0.8)$. For $\rho=641 \mathrm{~b} / \mathrm{ft}^{3}$ $A=15 \times 10^{6} \mathrm{ft}, V_{W}=2 \mathrm{ft} / \mathrm{sec}$ one obtains:

$$
P=54,240 \mathrm{kw}
$$

The annual energy consumption is

$$
\mathrm{E}=8766 \mathrm{PL} \quad \mathrm{KWhr} / \mathrm{Yr}
$$

The numerical data given corresponds to

$$
\mathrm{E}=3.57 \times 10^{8} \quad \mathrm{Kwhr} / \mathrm{Yr}
$$

If the pump and drive-motor capital cost is Ip $=400 \mathrm{~s} / \mathrm{kw}$ installed, the contribution to the cost of product is:

$$
U_{\mathrm{P}}=\left(\frac{{ }_{\mathrm{p}} \mathrm{P}}{\mathrm{CQ}}\right) \mathrm{Ub}_{\mathrm{b}}, \quad \$ / 1 \mathrm{~b} \mathrm{U}_{3} \mathrm{O}_{8}
$$

For the data quoted

$$
\mathrm{U}_{\mathrm{p}}=3 \quad \$ / 1 \mathrm{~b} \quad \mathrm{U}_{3} \mathrm{O}_{8}
$$

A small coal fired power plant of the rating required would have a levelized lifetime cost of electrical energy, $e \simeq 0.1 \$ /$ Kwhr .

This contributes to the cost of product as follows:

$$
\mathrm{U}_{\mathbf{e}}=\left(\frac{\mathrm{eE}}{\mathrm{O}_{\mathrm{b}}}\right) \cdot \mathrm{U}_{\mathrm{O}} \quad \mathrm{\$} / 1 \mathrm{~b} \quad \mathrm{U}_{3} \mathrm{O}_{8}
$$

which yields: $U_{e}=24 \quad \$ / 1 b \quad \mathrm{U}_{3} \mathrm{O}_{8}$ 
by

M. J. Driscoll and J. L. Whaley

\section{Introduction}

The benefits and difficulties of extracting uranium from seawater are by now well appreciated (I). Approaches to this task can be categorized as either actively pumped or passively current-driven (2); the latter mode is of present concern. Reference (3) outlines the general features demanded of a system of this type: a relatively transparent current-interceptor structure, a large surface area, and thin sorber particles or film. Consideration of these requirements led to selection of a "plastic kelp farm" as a concept deserving further evaluation. This paper outlines the basic features of a generic system of this type and presents some preliminary cost estimates.

\section{Background}

Experience with (and analyses of) oceanic kelp farming are relevant to the present study because of several aspects of direct analogy: kelp growth rates are limited by dilute ionic nutrient transport from seawater to the frond surfaces, hence nature has already carried out field trials to arrive at an efficient configuration -- thin strips of matter up to $100 \mathrm{ft}$ long which prosper in several knot currents (4); and harvesting costs are likely to be quite similar for both. natural and artificial materials. Perhaps even more 
relevantly; the Gas Research Institute is currently sponsoring research into kelp farming as a source of biomass for conversion into synthetic fuels (5). Their work includes installation and operation of open ocean farms of California Giant Kelp. Commercial harvesting of natural kelp fields has been practiced since the turn of the century.

A second area of related research is the use of synthetic. seaweed (patented and marketed under the trade name SEASCAPE) to control shoreline erosion (6): This product is currently undergoing sea trials in several locations, under conditions far more severe than contemplated for the present use. It is fábricated from spunbonded polypropylene sheet (sold by du Pont under the trade name TYPAR ${ }^{B}$ ). "This material has been widely used in civil engineering applications (soil stabilization, drainage, erosion control, dike construction) which include long term exposure to seawater. This material is resistant to the rhemicals used in sorber regeneration and to biological attack in situ. The physical strength of this material exceeds that demanded by the present application. The thermally-bonded filamentous material is porous, and is readily permeated by water. The material is available commercially in large quantities at a cost of roughly $70 \not / \mathrm{yd}^{2}$ for a $15 \mathrm{mil}$ thick product weighing $4 \mathrm{oz} / \mathrm{yd}^{2}$ (7).

The most promising sorbers, hydrous titanium oxide and advanced ion exchange (IX). media, can both be produced in fine particulate form (1). Here we will proceed on the basis of 
utilization of powdered IX resin, similar to that frequently used to purify condensate in power generating stations (8). The one missing ingredient is the demonstration that plastic sheet can be coated with IX resin lor, alternatively surfaceactivated with functional groups). Before carrying out or encouraging research into this area, however, a study of the sort reported here is in order to quantify the incentives for successful pursuit of this goal.

\section{General Features}

The general features of a passive sorber model are quite simple in concept: a wide mesh "fisnnet" is suspended vertically across a current stream, moored at the bottom and supported by floats at the top. Plastic kelp fronds are attached to the top and bottom web (and/or sides) of each internodal web making up the mesh, as shown in Fig. 1. As indicated in the cloșe-up view, each blade has narrou fronds, which will have a better mass transier coefficient than an uninterrupted: plane surface; and the pattern is such that a sheet can be cut into many fronded blades without wastage.

For a net of width $W$ and height $H$, with a node spaced every $\mathbf{S}$ feet, supporting blades of thin plastic strips of width $b$ and length $L$; the total (two-sided) surface exposed to seawater is approximately:

$$
A=b L\left(\frac{W H}{s^{2}}\right), \quad f t^{2}
$$




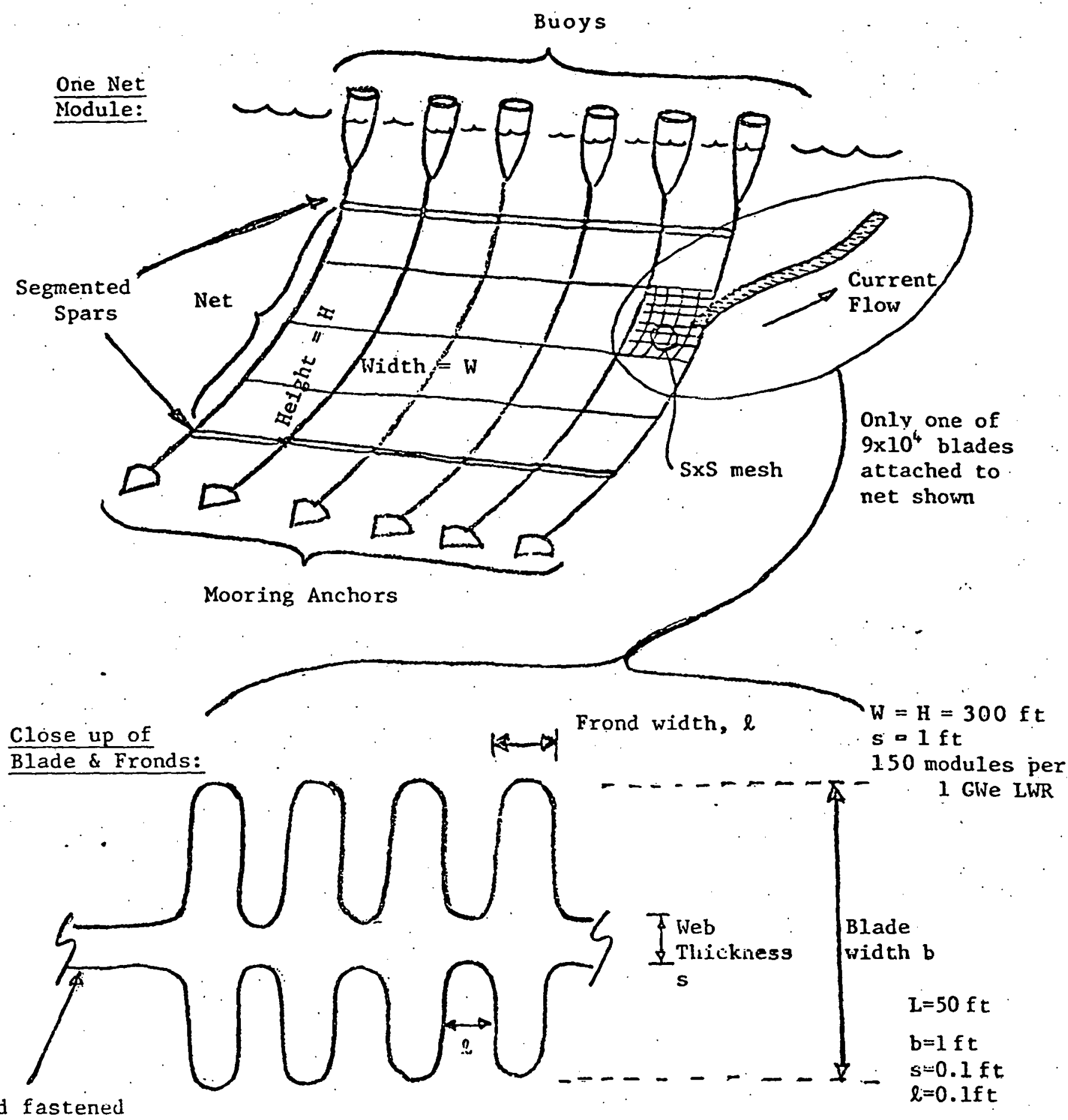

End fastened to net

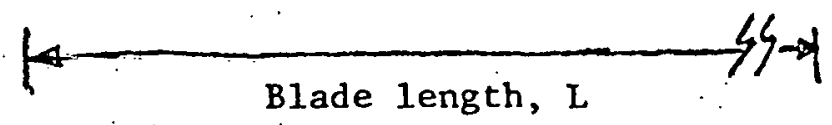


Thus, if $b=1 \mathrm{ft}, L=50 \mathrm{ft}, \quad w=H=300 \mathrm{ft}$ and $s=1 \mathrm{ft}$, $A$ is $4.5 \times 10^{6} \mathrm{ft}^{2}$.

Nets of this size are well within the capabilities of modern fishing vessels to deploy and recover. Stern trawlexs and purse seiners are accustomed to handling nets as large as $1000 \times 3000 \mathrm{ft}$; and vertical surface nets $30 \mathrm{ft}$ tall and 10 miles long are routinely set and hauled (in sections).

The rate of uranium uptake by such a structure is merely:

$$
\frac{U}{T}=1.18\left(\frac{8766}{2000}\right) \mathrm{KA} \text { tons } \mathrm{U}_{3} \mathrm{O}_{3} / \mathrm{Yr}
$$

where $\mathrm{K}$ is the mass transfer coefficient $\left(4 \times 10^{-8} \mathrm{lb} \mathrm{U} / \mathrm{hr} \mathrm{ft}^{2}-\right.$ see Eq (6)). For this value of $K$ and $A=4.5 \times 10^{6} \mathrm{ft}^{2}, \mathrm{U} / \mathrm{T}$ is 1. ton/yr. Hence on the order of 150 nets of the type just described would be required to sustain a single 1000 MWe LWR. 
The mass of plastic kelp substrate required for this structure is just:

$$
M_{k}=\frac{R \cdot A \cdot \Delta}{2(2000)} \text { tons }
$$

where $\mathrm{R}=$ density of plastic $\left(60 \mathrm{lbs} / \mathrm{ft}^{3}\right)$

$$
\Delta=\text { thickness of plastic }\left(10 \mathrm{mils}=8.3 \times 10^{-4} \mathrm{ft}\right)
$$

For these values and $A=4.5 \times 10^{6} \mathrm{ft}^{2}, M_{R}=56$ tons.

A similar analysis for the sorber coating yields

$$
M_{a}=\frac{r \cdot A \cdot \delta}{(2000)} \text { tons }
$$

where $r=$ density of sorber $\left(\sim 100 \mathrm{lbs} / \mathrm{ft}^{3}\right)$

$\delta=$ thickness of sorber film $\left(2 \mathrm{mils}=16.6 \times 10^{-5} \mathrm{ft}\right)$

in which case $M_{a}=37$ tons, for a total weight, $M_{k}+M_{a}$ of

93 tons.

The mass of kelp to be handled is within the capabilities of modern fishing vessels. The material has essentially neutral buoyancy, and should be easy to pull aboard a sternloading vessel. Whaling vessels, for example, bring 100 ton carcasses aboard in this manner. The hold capacities of representative fishing vessels are also in the range required, that is several hundred tons.

If $\mathrm{C}$ is the saturated capacity of sorber ( $\mathrm{lb} \mathrm{b} / \mathrm{lb}$ sorber) in natural seawater ( $(03.3 \mathrm{ppb} \mathrm{U})$, then we have a constraint on Eq (2), namely that:

$$
\mathrm{U} \leq 1.18 \mathrm{C} \mathrm{M} \text { tons } \mathrm{U}_{3} \mathrm{O}_{3}
$$




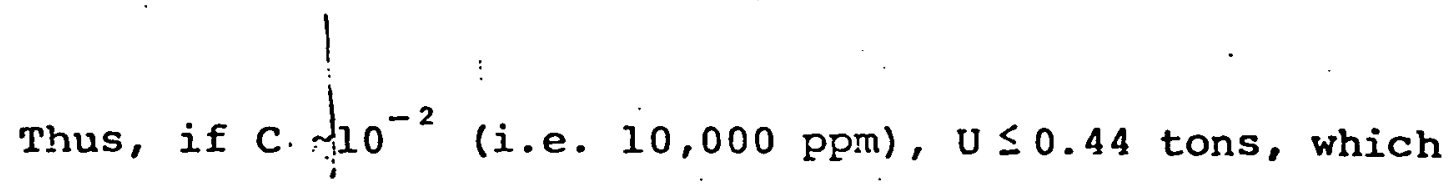
in conjunction with Eq. (2), would indicate an exposure duration of about 3 months.

The mass transfer coefficient required in Eq. (2) can be estimated from well-known correlations (9). For turbulent flow over a flat plate, considering only fluid side resistance:

$$
K=(x p)\left[\begin{array}{lll}
133 & \mathrm{~V} S c^{-2 / 3} & \mathrm{Re}-3 / 5
\end{array}\right] \mathrm{lb} / \mathrm{hr} \cdot \mathrm{ft} \mathrm{t}^{2}
$$

$$
\begin{aligned}
& \text { where } x^{\prime}=\text { concentration of uranium in seawater, } \\
& 1 \mathrm{~b} / 1 \mathrm{~b}\left(3.3 \times 10^{-9}\right) \\
& \rho=\text { density of seawater, } 1 b / f t^{3}(64) \\
& S C=\text { Schmidt Number }=\mu / \rho D \text { (7560) } \\
& \mu=\text { viscosity of seawater, } 1 \mathrm{~b} / \mathrm{ft} \sec \left(1.04 \times 10^{-3}\right) \\
& D=\text { diffusivity of uranyl tricarbonate in seawater } \\
& \left(2.15 \times 10^{-9} \mathrm{ft}^{2} / \mathrm{sec}\right) \\
& \text { Re }=\text { Reynolds Number }=V \rho \ell / \mu\left(2.7 \times 10^{4}\right) \\
& \rho=\text { length of plate (here width of frond) }(0.1 \mathrm{ft}) \\
& \mathrm{v}=\text { velocity of current }(3 \mathrm{mph}=4.4 \mathrm{ft} / \mathrm{sec})
\end{aligned}
$$

For the values quoted, $\mathrm{K}=4 \times 10^{-8} \mathrm{Ib} / \mathrm{hr} \mathrm{ft}^{2}$

It must be stressed that this value of $K$ does not take into account solid side resistance, which can easily reduce the overall mass transfer rate by a factor of 10 to 100 . One can, however, approach the fluid-only limit by using a thin porous film of sorber. 
Note that Eq (6) ignores the effect of uranium depletion in the water as the current traverses the sorber array an approximation which is readily justified; if all incident uranium were collected one would have:

$$
\frac{\mathrm{U}}{\mathrm{T}}=1.18\left[\frac{8766(5280) \mathrm{VWHx \rho}}{2000}\right] \text { tons } \mathrm{U}_{3} \mathrm{O}_{8} / \mathrm{Yr}
$$

which would give $U / T=1557$ tons/yr, three orders of magnitude larger than the actual removal rate.

\section{Hydrodynamic Aspects}

Plastic strips were towed singly and in arrays at various speeds in the towing tank at MIT to check on the valididty of drag calculations and to verify that strips could be deployed without being subjected to damage due to fluttering, and that they did not possess an inherent tendency to stick together or tangle. These tests were all highly successful and argue for surcessful deployability of a net-supported field of plastic kelp.

The turbulent regime drag equation (10) was verified to give a conservative value in these tests:

$$
a=0.036 A_{s} \dot{v}^{2}\left(\frac{\rho}{g_{c}}\right) r_{e}-1 / s \quad 1 b s
$$

where $A_{S}=$ (two-sided) surface area of kelp blade, $f t^{2}(50)$ 
For the reference conditions quoted, the drag on a single kelp strip is $9 \mathrm{lbs}$. For the wH/ $\mathrm{s}^{2}$ strips on the net the total drag would be 400 tons, which is a challenging, but not impossible mooring problem. The stress on the web of an individual strip:

$$
\sigma=\frac{\mathrm{d}}{144 \mathrm{~s} \Delta}=750 \mathrm{psi}
$$

(where $\mathbf{s}=$ width of web, ft $(0.2))$. can be withstood by the material under consideration for this task; as experimentally verified. This is not surprising since real kelp plants withstand even more severe stresses.

\section{Economic Prospects}

Although lacking in detail, the concept outlined in the preceding section has been sufficiently characterized to permit rough cost estimates to be made. Three categories will be considered: The annualized cost of capital expenditures, bed deployment and harvesting costs, and uranium recovery by elution. The capital cost contribution is given by:

$$
\mathrm{U}_{\mathrm{C}}=\frac{\phi \gamma}{1.18(8766) \mathrm{KL}} \quad \$ / 1 \mathrm{~b} \mathrm{U}_{3} \mathrm{O}_{\mathrm{g}}
$$

where $\phi=$ annual carrying charge rate for the investment in the bed (assumed to have a service life of 5 years and zero salvage worth); for investor-owned utility financing a representative value would be $\phi \sim 0.30 \mathrm{yr}^{-1}$.

$L=$ capacity factor, fraction of time the collector is on station (0.75) 
$\gamma=$ unit cost of kelp bed, s/ft, as-built, including materials and fabrication costs $\left(0.1 \$ / \mathrm{ft}^{2}\right.$ )

For the reference parameter values quoted, one finds that $\mathrm{U}_{\mathrm{C}}=100 \$ / \mathrm{Ib} \mathrm{U}_{3} \mathrm{O}_{8}$.

The second cost center is the operating expense associated with bed deployment and harvesting. Here we can appropriate experiential data on biomass kelp collection. Assuming that deployment costs (not involved in natural kelp farming) are equal to harvesting costs, we have for $n$ harvests per year (here 4):

$$
\dot{U}_{\mathrm{d}, \mathrm{h}}=\frac{\mathrm{n}(\mathrm{R} . \Delta+r . \delta) \mathrm{B}}{1.18(2000)(8766) \mathrm{KL}}
$$

where $\mathrm{B}=$ Biomass kelp harvesting cost, $\$ /($ wet $)$ ton $(-40)$ For the representative costs cited, $U_{d, h}=16 \$ / 1 b U_{3} O_{8}$, a quite tolerable value.

This value of the harvesting cost can also be supported using a fishing vessel analogy. For a total cost (amortization plus operating expenses) of $\$ 8,000$ per week and a weekly haul of 200 tons ( 2 nets deployed, 2 recovered), the value of B would again come to $40 \$ /$ ton.

Incidentally, biomass kelp at $40 \$ /$ wet ton would yield a combustible product at almost 280 \$/diy ton, an order of magnitude higher than current coal costs: In the present application 1 ton of plastic kelp, worth about $\$ 3000$, might contain as much as 8 Ibs of $\mathrm{U}_{3} \mathrm{O}_{8}$, worth around $\$ 800$. 
The final major cost category is that covering the elution step. Use of a $10 \%$ sulfuric acid wash to remove the sorbed uranium from the ion exchange resin is postulated, preceded and followed by fresh water washes. The uranium is then recovered from the elutant using conventional terrestrial milling plant practices.

A cost function which includes terms proportional to substrate, sorber and uranium masses and to kelp surface area is employed to permit rational apportionment of the costs of freshwater washing, consumption and loss of elutant chemicals; and product recovery:

$$
\cdot U_{r}=\frac{\left\{c+\frac{2000}{A}\left[C_{2} M_{k}+C_{3} M_{a}\right]\right\} n}{1.18(8766) K L}+C_{4} \quad \$ / 1 b_{3} O_{8}
$$

where $c_{1}\left(10^{-3} \$ / f t^{2}\right), c_{2}\left(10^{-2} \$ / 1 b\right), c_{3}\left(10^{-1} \$ / 1 b\right)$ and $\mathrm{C}_{4}\left(10 \$ / 1 \mathrm{~b} \mathrm{U}_{3} \mathrm{O}_{8}\right)$ are constants characterizing the process costs, and $n$ is the number of regenerations per year (here 4) Using the numerical values previously cited:

$$
\mathrm{u}_{\mathrm{r}}=47 \$ / \mathrm{Lbu}_{3} \mathrm{O}_{8}
$$

The total cost of yellowcake from the sea in the example we have been carrying along is then:

$$
\mathrm{U}=\mathrm{U}_{\mathrm{C}}+\mathrm{U}_{\mathrm{d}, \mathrm{h}}+\mathrm{U}_{\mathrm{r}} \$ / 1 \mathrm{~b} \mathrm{U}_{3} \mathrm{O}_{8} \text {, or } 163 \$ / 1 \mathrm{~b} \mathrm{U}_{3} \mathrm{O}_{8}
$$


This value if attainable in practice, is attractive from a long range perspective: although today's spot market price is about $30 \$ / 1 \mathrm{~b}$, the breakeven price versus long range alternatives such as breeder reactors (and many other high technology options such as accelerator breeders, fusionfission hybrid devices, and the like) is on the order of $150 \$ / 1 \mathrm{~b} \mathrm{U}_{3} \mathrm{O}_{8}(11)$.

\section{Developmental Aspects}

clearly the focus must be on bonding sorber to the substrate or otherwise incorporating it into the material, followed by uranium uptake testing. The physical nature of the sorbing surface is open to refinement. If the fibrous and porous structure of the spunbonded polypropylene can be retained, then a substantial augmentation of the effective surface area can be attained: Recent Japanese tests with fiber-configuration sorbers have given evidence of exceptional performance in terms of both rate of sorption and effective capacity.

It should also be noted that the overall configuration of the artificial "kelp" blades, their fronds and the supporting structure has not been optimized. TYPAR sheet is available in rolls approximately $16 \mathrm{ft}$ wide and $30.00 \mathrm{ft}$ long, hence a wide variety of sorber surface arrangements could be contemplated. Attention should be paid to simplification of the 
mooring structure. In the limit the "plastic kelp plants." could be individuaily moored, as are their natural counterparts, without appreciably increasing harvesting costs: as shown by the analyses in section 5 of this paper, there is ample room for engineering a favorable trade-off between sorber system capital costs and harvesting costs. The patented SEASCAPE ${ }^{T M}$ design, in which a pocket is sewn into the bottom of the seaweed units, and filled with sand or gravel to moor the device, should be considered for the present application, as should be the use of flotation strips at the ends of the kelp blades to increase their buoyancy - again emulating SEASCAPE ${ }^{\mathrm{TM}}$.

- Finally, the elution and recovery costs embodied in Eq. (12) are preliminary and speculative in that not even laboratory scale tests have been conducted as a basis for parameter estimation. While not a great deal can be done until sorber configurations have been fabricated and loaded with uranium, some useful experiments on parasitic chemical and fresh water expenditures due to incomplete drainage and washing of the TYPAR ${ }^{\mathbb{B}}$ substrate could be carried out. 


\section{Concluding Observations}

The scoping calculations completed to date indicate that the use of a passive collection system based on a kelp farm analogy may be a promising approach to the extraction of uranium from seawater. If, after further reflection, this concept is judged to outperform the actively-pumped systems currently under evaluation at MIT and elsewhere (1), then increased attention will be in order.

The weakest link in the present analysis is the assumption that a durable, ultra-high capacity coating of active sorber can be applied, or impregnated within, the plastic kelp. Clearly, this as yet unproven aspect requires R\&D work. It may be possible, for example, to use a bonded multilayer plastic sandwich and then treat the composite film to impiant active ion exchange groups in the outer layer, while the inner layer retains and provides the requisite strength and flexibility. Also, while the proposed substrate material has a useful life in seawater an order of magnitude longer than needed, it is not yet proven that a sorber can survive the 5 years of service assumed (during which time twenty or more elutions would be experienced). Finally, the entire edifice rests upon the premise that mass transfer coefficients approaching the theoretical maximum value can be attained. While it is not clear that this can be accomplished, other tactics may be employed to compensate for any shortfall - for example (again mimicing nature) a ciliate (hairy) frond surface could bc employed. 


\section{Acknowledgements}

The authors are grateful to $\mathrm{Dr}$. Frederick R. Best and Ms. Cynthia K. Nitta for their review of, and constructive comments on, this manuscript. The contributions of $\mathrm{Mr}$. David A. Surber to the cost-of-elution estimates are especially appreciated. 


\section{References}

1. F. R. Best and M. J. Driscoll (Eds.) "Proceedings of a Topical Meeting on the Recovery of Uranium from Seawater," MIT-ELBO-081, December 1980.

2. F. R. Best and M. J. Driscoll, "Prospects for the Recovery of Uranium from Seawater," MIT-EL80-001, January 1980.

3. M. J. Driscoll et al, "Practical Constraints on Systems for the Extraction of Uranium from Seawater,"; in Ref (1).

4. G. A. Jackson and W. J. North "Concerning the Selection of Seaweeds Suitable for Mass Cultivation..." , W. M. Keck Laboratories, California Institute of Technology. 15 October, 1973.

5. "Long-Term Biomass Research," EPRI Journal, Vol. 6, No. 2, March 1981.

6. Private communication, William L. Garrett, Greenville, Delaware, April 1981.

7. Private communication, D. C. Cannon, duPont Technical Representative; forwarding TYPAR $\Theta$ product literature, Wilmington, Delaware, March 1981.

8. "Special-Report: Ion Exchange" PONER, Vol. 124, No. 9, September 1980.

9. T. K. Sherwood, R. L. Pigford, C. R. Wilke, "Mass Transfer" McGraw Hill, New York, 1975.

10. J. H. Perry, ed. "Chemical Engineers Handbook" 4th edition, P 5-54, McGraw Hill, New York 1963.

11. Report of the Nonproliferation Alternative Systems Assessment Program, DOE/NE-0001/1-9, June 1980. 
AN IMPROVED

CONCEPTUAL DESIGN OF A SYSTEM TO

EXTRACT URANIUM FROM SEAWATER

by

M. J. Driscoll, F. R. Best and C. K. Nitta

\section{Introduction}

A clear picture is now emerging of the general features demanded of a uranium-from-seawater system [B1, B2, D1]. If settled sorber bed technology is to be employed, then thin beds of fine particles are greatly to be preferred: thin beds to keep pumping power requirements within practical bounds, and small diameter particles to enhance mass transfer. Consideration of these requirements led to selection of a ship-mounted filter system (exploiting concepts drawn from a number of areas faced with similar demands) for evaluation as a candidate approach to the task at hand.

2. Background

The need to process large volumes of water at modest pressurc drops, while removing contaminants at trace element concentrations has been addressed in the field of condensate polishing as applied to large power plants. The use of thin beds of powdered ion exchange resin (mass mean particle diameter $\sim 20$ microns) has proven to be effective [P1]. The major drawback for present purposes is the expensive structural arrangement used to support the beds. Here we can profit from another area of power station technology: the filter bags used to remove particulates from combustion gases discharged by coal-fired units [E1]. These baghouse units process large volumetric flow rates through long cylindrical fiberglass filter bags, and are capable of $99+\%$ retention of even extremely fine soot (mass mean particle diameter $\sim 20$ 
microns). Of central interest here is their low capital cost and the ease with which a layer of particulate material can be laid down and removed. The proposed material for the filter bags in the present application is spunbonded polypropylene: for example, the product line marketed by Du Pont under the trademark TYPAR ${ }^{R}$ [C1]. This material has been widely used in civil engineering applications (soil stabilization, drainage, dike construction and erosion control) which include long-term exposure to seawater. Porosity and pressure drop data are available (and have been re-determined experimentally at MIT). The material is available commercially in large quantities, in rolls $16 \mathrm{ft}$ wide and $3,000 \mathrm{ft}$ long at a cost of roughly $70 \mathrm{c} / \mathrm{yd}^{2}$ for a $15-\mathrm{mil}$ thick product weighing $4 \mathrm{oz} / \mathrm{yd}^{2}$. Variations on the above ideas are commonplace in the industrial practice of filtration in other applications as well (O1).

\section{Conceptual System Design}

The concept to be evaluated here involves the use of baghouse-type filters to support a thin layer of fine sorber particles. Either ion exchange resin or hydrous titanium oxide can be employed as the filter bed medium, but our evaluation concentrates on the former because it is projected to have better overall properties in the long term. 'l'he filter modules are mounted on board a ship or barge, which will permit operation in clean, warm water in biologically inactivc arcas sufficiently far from shore. The requisite pumping can be provided by large low-head axial flow pumps such as those currently under development for OTEC applications [L1], or commercially available pumps used for various civil engineering projects [B3, B4]. Energy is supplied by the ship's normal propulsion plant: here an electric drive unit burning powdered coal. At the end of a loading cycle the resin is removed from the filter bags and ultimately returned to a shore-based chemical processing plant for uranium recovery and resin regeneration prior to re-use. 
Figures 1 and 2 sketch the general concept envisioned; Fig. 2 shows one unit (of several dozen) designed to be mounted in a hold of a supertanker-type vessel (Fig. 1).

A supertanker (very large crude carrier, VLCC) design has been used as the prototype hull for the present application for several reasons:

(a) A single vessel on the order of 200,000 dwt displacement can readily accommodate enough filter beds to support a $1000 \mathrm{MWe}$ LWR. While a larger number of smaller units could be used, the economy of scale realized through use of a single ship is decidedly advantageous.

(b) Considerable experience exists in the construction and operation of such ships - over. seven hundred VLCC's have been commissioned to date worldwide. Hence they represent proven technology having well known costs. Since ultra-large crude carriers, ULCC, exceeding 500, $000 \mathrm{dwt}$ have been built, we are not even at the forefront of the state-of-the-art in the present instance.

(c) The normal ship's propulsion plant is approximately of the correct rating to power the scawater pumps needed to supply the sorber beds. ULCC main propulsion ratings of 45, 000 SHP (equivalent to 33.6 $\mathrm{MWe}$ ) are commonplace.

(d) While there is a current slack in the tanker market, large bulk carriers and coal colliers approaching the VLCC size are now on the drawing boards or under construction, which assures the existence of a continuing engineering base.

(e) While not decisive, this also makes for an interesting comparison, since a single 200,000 dwt oil tanker making approximately eight round trips per year could sustain one $1000 \mathrm{MWe}$ oil-fired central station. 


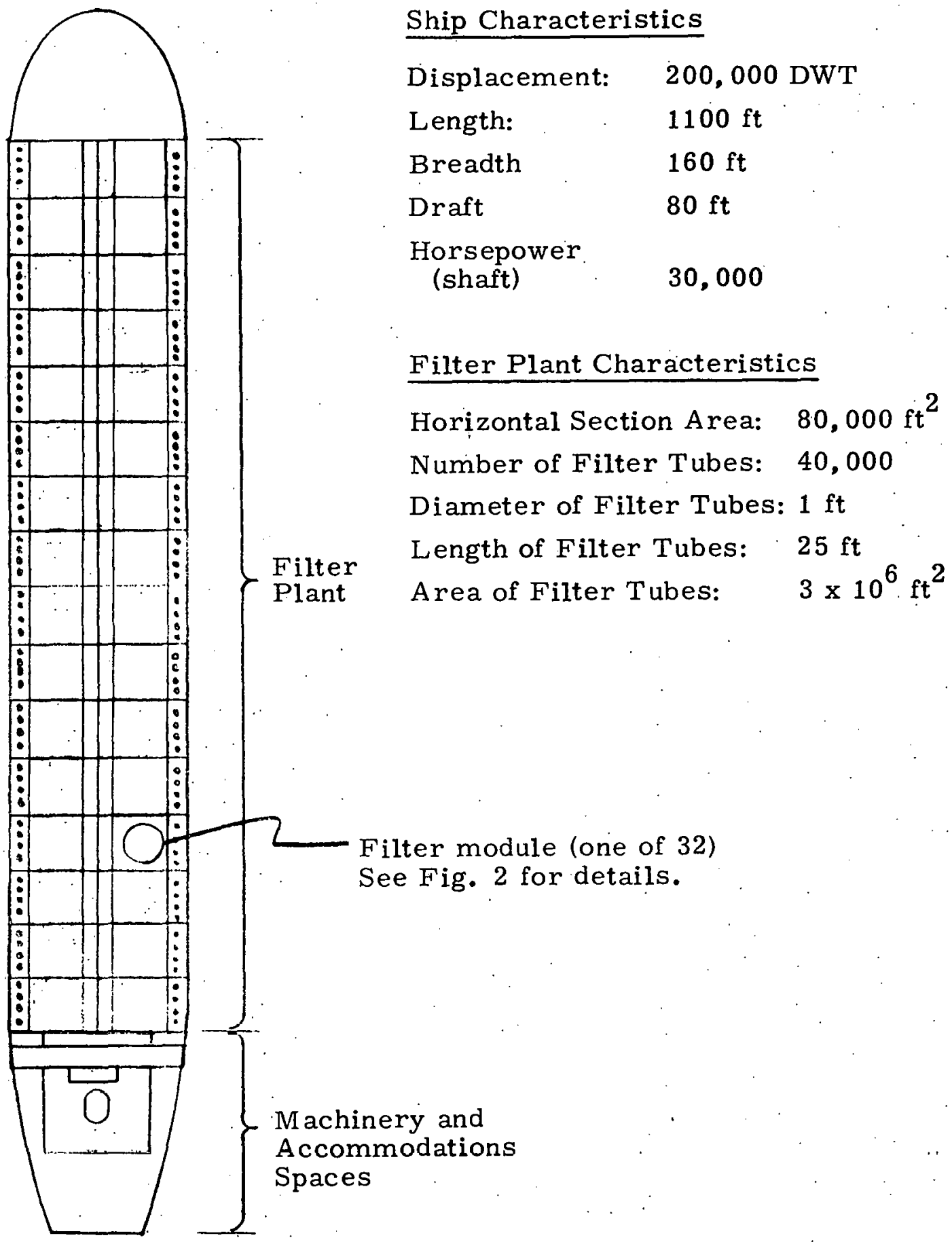

Fig. 1 Schematic of ship-mounted filtration plant. 

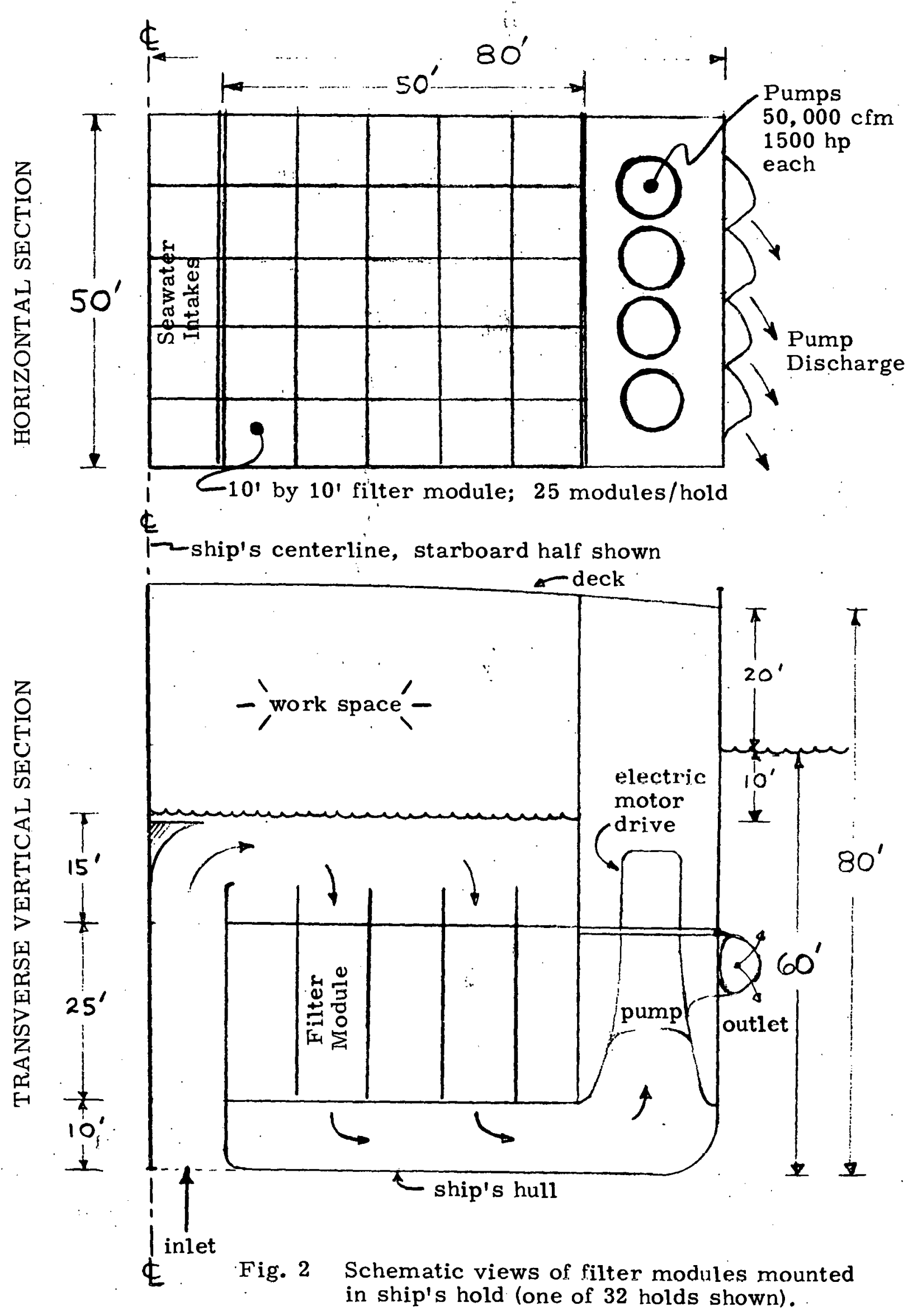
The filter module sketched in Fig. 2 is similar in many respects to the designs used in stack-gas service. As noted in Appendix B, flow similitude exists between the gas conditions in such service and the water flow parameters in the present case. The pressure drop is considerably higher, however, and hence a more rugged support structure is needed.

The filter tubes are arranged vertically to help insure that sorber will load symmetrically around their periphery and to avoid gravity-induced problems during no-flow conditions. Downflow is employed, being a more natural choice than the upflow used in stack-gas applications. This permits access to the filter inlet tubes from above for loading and unloading operations.

Also as shown in Fig. 2, several seawater pumps are employed per unit. This insures reliability. In addition, pumps rated up to roughly 1 MWe are commercially available, which insures the use of proven technology and a lower cost due to production economies. The pump discharge is directed aft, to provide thrust sufficient to move the ship slowly forward, into undepleted seawater.

To load the filters, powdered resin is merely dumped into the pool of water at the top of the unit, with the seawater pumps running. Over a period of 15-30 minutes the coating operation will proceed in much the same fashion as a fly-ash loading cycle in a stack-gas baghouse.' Once loaded, the bed will remain in operation for a uranium-uptake cycle, here presumed to last one week. At the end of the cycle the seawater flow is stopped, resin is scoured from the filter cloth using a water and/or air lance to form a slurry which can be pumped to a settling/storage tank for subsequent reprocessing. A fresh batch of resin can then be added to repeat the cycle.

At the present time a 90-day campaign is envisioned in which some 13 weekly cycles could be accomplished. No resin reprocessing would be attempted aboard ship, but the accumulated material would be returned to 
port for uranium recovery, and regeneration of the resin for subsequent re-use. Although there would be sufficient room for an on-board elution facility, it was considered that a shore-based system would be preferable due to the greater availability of inexpensive fresh water and less expensive labor. These advantages must of course be traded off against the cost of maintaining a much larger resin inventory.

4. Key Design Characteristics

Appendix B contains detailed calculations in support of major design decisions; Ref. [D1] provides relevent supplementary backup. Here.only a few essential features will be reviewed.

If the bed frontal area is $A$, then the uranium uptake by the bed over a period of ' $\mathrm{T}$ days is merely:

$$
\mathrm{U}=1.18\left(\frac{1440}{2000}\right) \mathrm{WxV}_{\mathrm{W}} \mathrm{A} \overline{\mathrm{f}} \mathrm{TL} \text { tons } \mathrm{U}_{3} \mathrm{O}_{8}
$$

where

$\mathrm{x}=$ concentration of uranium in unfiltered seawater $\left(3.3 \times 10^{-9} \mathrm{lb} / \mathrm{lb}\right)$

$\mathrm{W}=$ density of seawater, $1 \mathrm{bs} / \mathrm{ft}^{3}(64)$

$\overline{\mathrm{f}}=$ bed efficiency, fraction of uranium removed, averaged over time $\mathrm{T}(0.5)$

$\mathrm{L}=$ overall system capacity factor $(0.75)$

In one year, Eq. (1) indicates that a filter bed having a total surface arca $\Lambda=3 \times 10^{6} \mathrm{ft}^{2}$ can produce 147 tons of $U_{3} \mathrm{O}_{8}$, enough to sustain one 1000 MWe LWR for one year (using an extended burnup; once-through fuel cycle).

The only complicated parameter in this overal system equation is the fractional recovery, $\bar{f}$. System optimization can be viewed as the manipulation of the independent variables to determine a value of $\bar{f}$ which minimizes the total cost of product (i. e., $\$ / 1 \mathrm{~b} \mathrm{U} \mathrm{U}_{3} \mathrm{O}_{8}$ ). This involves a tradeoff among 
several variables, the most important of which are flow loading, sorber bed thickness and particle diameter. Table 1 displays the functional dependence of several of the more important dependent variables.

As can be seen in the table, a high flow loading reduces bed frontal area, which leads to lower costs; but, on the other hand, a higher flow loading requires a higher pumping power and shortens the cycle time, which leads to higher costs.

A thicker bed improves efficiency and reduces bed area without penalizing pumping power - to first order for thin beds. However, in the limit as the recovery fraction, $\overline{\mathrm{f}}$, approaches unity, one finds that pumping power becomes proportional to bed thickness and hence there is a compromise to be made here as well.

Finally, reducing particle diameter improves recovery efficiency and reduces bed area; unfortunately this is at the expense of a higher pumping power and a shorter cycle length. Again, an optimum value is to be sought.

Based upon our work to date and inferences from similar industrial. processes, the range of interest appears to be:

$$
\begin{aligned}
& 1.0 \leq \mathrm{G} \leq 20 \mathrm{gpm} / \mathrm{ft}^{2} \\
& 10 \leq \mathrm{d} \leq 100 \mathrm{microns} \\
& 5 \leq \mathrm{t} \leq 20 \mathrm{~mm}
\end{aligned}
$$

\section{Economic Prospects}

Sufficient information is now available to permit assembly of the various components of a cost-of-product estimate. Appendix A to this paper considers each element of such an analysis. The results are summarized in Table 2. The total of $200 \$ / 1 \mathrm{~b} \mathrm{U} \mathrm{U}_{8}$ may be attractive from a long-range perspective: although today's spot market price is about $30 \$ / 1 \mathrm{~b}$, the breakeven price versus long-range alternatives such as breeder reactors (and many other high tech- 
Table 1

Functional Dependence of Key Parameters

\begin{tabular}{|c|c|}
\hline Parameter & Dependence \\
\hline $\begin{array}{l}\text { Fraction of uranium } \\
\text { recovered by bed }\end{array}$ & $f \sim \frac{t}{G^{1 / 2} d^{3 / 2}} \quad($ for $f \ll 1.0)$ \\
\hline Bed area & $A \sim \frac{1}{f G} \rightarrow \frac{d^{3 / 2}}{G^{1 / 2} t}$ \\
\hline $\begin{array}{l}\text { Cycle length, or bed } \\
\text { volume or cost }\end{array}$ & $T \sim \frac{t}{f G} \rightarrow \frac{d^{3 / 2}}{G^{1 / 2}}$. \\
\hline Bed pressure drop & $\Delta p \sim \frac{G t}{d^{2}}$ \\
\hline $\begin{array}{l}\text { Pumping power or ratio } \\
\text { of energy expended to } \\
\text { that produced }\end{array}$ & $P \sim G A \Delta p \rightarrow \frac{G^{3 / 2}}{d^{1 / 2}}$ \\
\hline
\end{tabular}

* Independent Variables are:

$\mathrm{G}=$ flow loading, $\mathrm{gpm} / \mathrm{ft}^{2} ; \propto$ water velocity, $\mathrm{V}_{\mathrm{w}}$

$\mathrm{d}=$ particle diameter, microns

$t=$ bed thickness, $\mathrm{mm}$ 
Table 2

Cost of Product Summary

\begin{tabular}{|c|c|c|}
\hline Item & & $\begin{array}{l}\text { ontribution } \\
\$ / 1 b \mathrm{U}_{3} \mathrm{O}_{8}\end{array}$ \\
\hline Filters & $\therefore$ & 6 \\
\hline IX Resin & . & 69 \\
\hline Regeneration and Product Recove & ry & 53 \\
\hline Ship Amortization & & 41 \\
\hline Ship Operation & & 4 \\
\hline Pumping System & & 13 \\
\hline Energy Consumption & & 18 \\
\hline & TOTAL: & $\$ 204$ \\
\hline
\end{tabular}

* See Appendix A for supporting calculations; values are rounded to the nearest whole dollar. 
nology options such as accelerator breeders, fusion-fission hybrid devices, and the like) is on the order of $150 \$ / 1 b \mathrm{U}_{3} \mathrm{O}_{8}$ [N1].

This cost breakdown also provides a framework for examination of potential improvements, which could lead to lower costs. Some of the more important are:

(a) Development of a more cost effective ship design. Here we have merely adapted a VLCC hull based on the need for a horizontal hold area of roughly $80,000 \mathrm{ft}^{2}$. The weight of the present "cargo", however, is only half of the carrying capacity of a ship of $200,000 \mathrm{dwt}$. This implies that a more "barge-like" hull (broader beam, shallower draft) might as much as double the supportable filter area.

(b) The filter area could be doubled again if 6-inch diameter bags were used in place of the current 12 -inch diameter bags. It might also be possible to extend the length of the bags from the present $25 \mathrm{ft}$ to 30 or $40 \mathrm{ft}$. This latter option, however, would considerably increase the fluid velocity in the bags.

(c) The cost of using a small supply ship (which may be needed anyway) to transport sorber to and from the filter ship should be investigated as an alternative to maintaining a large and costly on-board inventory. On-board reprocessing is also worth examining.

(d) The development of an ultra-high-capacity ion exchange resin would provide substantial benefits by reducing the expenditures for resin loading/unloading and regeneration, and would reduce the inventory of resin needed on board.

(e) A detailed sub-optimization, allowing flow loading, particle 
diameter and bed thickness to vary is also in order.

Finally, Japanese workers in this field have also published conceptual designs and cost estimates for uranium from seawater plants based on the use of filter trays supported by pier-like structures [K1]. Estimated yellowcake costs as low as $161 \$ / 1 b \mathrm{U}_{3} \mathrm{O}_{8}(1976 \$)$ have been quoted.

\section{Discussion}

The scoping calculations completed to date indicate that the use of a shipboard-mounted, actively-pumped system based upon a baghouse filter analogy may be a promising approach to the extraction of uranium from seawater. This design will therefore serve as the frame of reference for further work at MIT. In the next stage of this effort the foremost requirement is for more sophisticated cost analyses. Since none of the elements of the system involve unproven technology, this would appear to be primarily a question of devoting sufficient effort to the task. The cost is most sensitive to the flow rate and the integrated flow which can be sustained through the filters. Several limits constrain these parameters:

(1) The ability to avoid fouling by particulates in seawater. This consideration motivated the use of a ship or barge which can operate far from shore in biologically inactive zones. The achievable concentration of filterable matter will determine whether the filter beds have to be reclaimed more often than desired to restore their permeability. It should be noted that bed restoration need not include resin regeneration, if the bed is fouled before its capacity is exhausted.

(2) The performance characteristics of the sorber medium. It 
must be shown that:

(a) Mass transfer rates are as calculated at the bed thicknesses and particle diameters assumed (or equivalently at the pressure drops and flow loadings required).

(b) Sorber capacities are as high as presumed. Otherwise, regeneration must be performed more frequently.

Sorber research now underway at MIT (both in Cambridge and at Woods Hole) and at Rohm and Haas, and elsewhere in the world [B2], should provide a firm data base for further parametric studies, leading to optimization of the proposed system, within the next year or so. German workers [S1] have already reported resin capacities (2400 ppm) considerably in excess of the value used here (1500 ppm).

\section{Acknowledgements}

The authors are grateful to Lance Riniker for his work in support of an earlier version of this manuscript, and to the MIT Sea Grant Program for providing funding via the MIT UROP office to Mr. Kiniker during the period in which his part of this research was carried out. 


\section{References}

[B1] F. R. Best and M. J. Driscoll

"Prospects for the Recovery of Uranium from Seawater" MIT-EL80-001, Jan. 1980.

[B2] F. R. Best and M. J. Driscoll (Eds)

"Proceedings of a Topical Meeting on the Recovery of Uranium from Seawater"

MIT-EL80-031, Dec. 1980.

[B3] M. R. Broussard

"Alternative Energy Systems: Application to the Extraction of Uranium from Seawater"

SM Thesis, MIT Nuclear Engineering Department, May 1978.

[B4] N. A. Brooks

"Process Design Evaluation for the Recovery of Uranium from Seawater"

SM Thesis, MIT Nuclear Engineering Department, August 1976.

[C1] D. C. Cannon, Du Pont Technical Representative

Private communication, forwarding TYPAK $R$ literature, Wilmington, Delaware, March 1981.

[C2] J. J. Carberry, "Chemical and Catalytic Reaction Engineering", McGraw-Hill, New York (1976).

[D1] M. J. Driscoll et al.

"Practical Constraints on Systems for the Extraction of

Uranium from Seawater"

In'Ref. [B1].

[E1] "Upsurge in Baghouse Development"

EPRI Journal, Vol. 5, No. 9, Nov. 1980.

[G1] R. J. Gibbs, "Suspended Solids in Water", Plenum Press, New York (1974).

[K1] M. Kanno

"Japanese Studies on Extraction of Uranium from Seawater" Symposium on Separation Science and Technology for Energy Applications, Gatlinburg, Tennessee, May 5-8, 1981.

[L1] T. E. Little

"Selection of Seawater Pumping Systems for OTEC Power Plants" in Proceedings of the Fifth OTEC Conference, Feb. 20-22, 1978, Miami Beach, Fla.

[M1] G. H. Mansfield, "Some Measurements of Particulate Fouling of Cation Exchange Resins", Chemistry and Industry, Issue No. 18, 20 September, 1980. 
78

[N1] Report of the Nonproliferation Alternative Systems Assessment Program $\mathrm{DOE} / \mathrm{NE}-0001 / 1-9$, June 1980 .

[O1] C. Orr, "Filtration Principles and Practices" Marcel Dekker, Inc., New York (1977)

[P1] "Special Report: Ion Exchange" POWER, Vol. 124, No. 9, September 1980.

[S1] K. Schwochau et al., "Studies on Complexing Resins Accumulating Uranium from Seawater", in Ref. [B2].

[W1] P. B. Weisz

"Sorption-Diffusion in Heterogeneous Systems, Parts 1-3", Trans. Faraday Soc., Vol. 63, pp 1801-1823 (1967); also see CHEMTECH, April 1980, p. 207, and May 1980, p. 267. 
$\underline{\text { Appendix A }}$

\section{Cost Estimates}

The subsections in this appendix consider, term by term, the major cost components making up the subject uranium-from-seawater system.

\section{A. 1. Cost of Baghouse-Type Filters}

The contribution of the filter structure to the cost of product is obtained by dividing the annualized cost by the production rate:

$$
\mathrm{U}_{\mathrm{f}}=\frac{\varphi_{\mathrm{f}} \gamma}{1.18(8766)(60) \mathrm{WxV}_{\mathrm{w}} \eta \mathrm{L}} \$ / 1 \mathrm{~b} \mathrm{U} \mathrm{U}_{3}
$$

where

$\varphi_{\mathrm{f}}=$ annual carrying charge rate (the filter assemblies are assumed to have a service life of 5 years and zero salvage value) $\left(0.30 \mathrm{yr}^{-1}\right)$

$\gamma=$ installed cost of filter system, $\$ / \mathrm{ft}^{2}$; spunbonded polypropylene bags wlll cost approximately $0.1 \$ / \mathrm{ft}^{2}$, to which we add $1.9 \$ / \mathrm{ft}^{2}$ for supporting structures.

$\mathrm{W}=$ density of seawater, $\mathrm{lb} / \mathrm{ft}^{3}(64)$

$x=$ concentration of uranium in seawater, $1 \mathrm{lb} U / \mathrm{lb}$ water $\left(3,3 \times 10^{-9}\right)$

$\mathrm{V}_{\mathrm{w}}=$ superficial velocity of water traversing filter, $\mathrm{ft} / \mathrm{min} \cdot(2.0)$

$\eta=$ bed efficiency, fraction of incident uranium removed (0.5).

$\mathrm{L}=$ plant capacity factor, fraction of year at full flow (0.75)

For the quoted parameter values:

$$
\mathrm{U}_{\mathrm{f}}=6.10 \$ / \mathrm{lb} \mathrm{U} \mathrm{U}_{8}
$$




\section{A. 2 Cost of Resin Inventory and Make-up}

The weight per unit area of resin in a bed $\delta \mathrm{ft}$ thick is just:

$$
M_{r}=R \cdot \delta(1-\epsilon) 1 b s / \mathrm{ft}^{2}
$$

where

$$
\begin{aligned}
& \mathrm{R}=\text { resin density, } 1 \mathrm{~b} / \mathrm{ft}^{3}(80) \\
& \epsilon \quad=\text { void fraction in bed }(0.4)
\end{aligned}
$$

Thus the annualized cost relative to the filter bag cost, again. assuming a 5 -year useful life is:

$$
\mathrm{U}_{\mathrm{r}}=\left(\frac{\mathrm{C}_{\mathrm{R}}^{\mathrm{m} \mathrm{M}_{\mathrm{R}}}}{\gamma}\right) \cdot \mathrm{U}_{\mathrm{f}} \$ / 1 \mathrm{~b} \mathrm{\textrm {U } _ { 3 } \mathrm { O } _ { 8 }}
$$

where

$$
\begin{gathered}
\mathrm{m}=\text { number of bed inventories on hand }(13 \text {, enough to } \\
\text { operate for } 4 \text { months on a weekly cycle without } \\
\text { replenishment) }
\end{gathered}
$$

For

$$
\begin{aligned}
& \delta=11 \mathrm{~mm}=3.6 \times 10^{-2} \mathrm{ft} . \gamma=2 \$ / \mathrm{ft}^{2} . \\
& C_{R}=1 \$ / 1 \mathrm{~b} \text { and } U_{f}=6.10 \$ / 1 \mathrm{~b} \text {, we have } \mathrm{M}_{\mathrm{r}}=1.73 \mathrm{lbs} / \mathrm{ft}^{2}
\end{aligned}
$$

and $\mathrm{U}_{\mathrm{r}}=68.59 \$ / 1 \mathrm{~b} \mathrm{U} \mathrm{U}_{3} \mathrm{O}_{8}$

Make-up has been allowed for by augmenting initial bed thickness by $10 \%$ to allow for losses such that the end-of-useful-life inventory is adequate.

The total resin inventory on board is $\mathrm{M}_{\mathrm{r}} \cdot \mathrm{A} \cdot \mathrm{m} / 2000 \approx 34,000$ tons, which is large, but tolerable.

\section{A. 3. Cost of Resin Regeneration and Product Recovery}

For a resin bed having a surface density of $M_{r} 1 b / \mathrm{ft}^{2}$, an elution chemical consumption of $Z \$ / 1 b$ resin and $n$ regenerative cycles per year 
of operation, the expenditure relative to the filter bag cost is:

$$
\mathrm{U}_{\mathrm{c}}=\frac{\mathrm{nZM_{ \textrm {R } }}}{\varphi_{\mathrm{f}} \gamma} \cdot \mathrm{U}_{\mathrm{f}} \$ / \mathrm{lb} \mathrm{U}_{3} \mathrm{O}_{8}
$$

If $\mathrm{Z}=0.5 \$ / \mathrm{lb}$ and $\mathrm{n}=50 \mathrm{yr}^{-1}$ (i. e., approximately 50 weekly cycles per year), with other values as previously prescribed:

$$
\mathrm{U}_{\mathrm{c}}=43.21 \$ / \mathrm{lb} \mathrm{U}_{3} \mathrm{O}_{8}
$$

To this we add an additional $10 \$ / \mathrm{lb} \mathrm{U}_{3} \mathrm{O}_{8}$ to account for recovery of the final product from the elutant - by processes identical to those used in terrestrial milling operations.

\section{A. 4 Cost of Ship}

If the total area occupied by a $1 \mathrm{ft}$ diameter filter bag cell is $2 \mathrm{ft}^{2}$ :

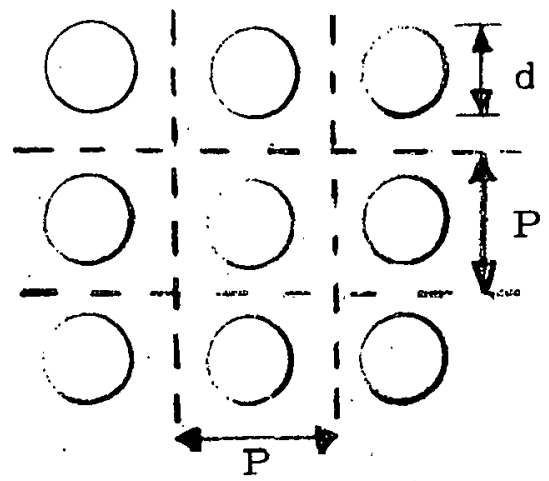

$$
\mathrm{P}^{2}=2 \mathrm{ft}^{2}
$$

and the active length of each bag is $h=25 \mathrm{ft}$, so that the surface area per bag is $a_{s}=\pi d \cdot h \cong 78.5 \mathrm{ft}^{2}$, then barges containing $A=3 \times 10^{6} \mathrm{ft}^{2}$ of total filter surface will require $\mathrm{N}=\mathrm{A} / \mathrm{a}_{\mathrm{S}}=3.8 \times 10^{4}$ bags. These can be contained in a hold volume, $Q=N \cdot p^{2} \cdot h=1.9 \times 10^{6} \mathrm{ft}^{3}$. Allowing an equal volume of fluid in the inlet and outlet plenums gives a volume of $3.8 \times 10^{6} \mathrm{ft}^{3}$, which corresponds to roughly 120,000 tons of seawater.

On the bases of this computation a 200,000 dwt supertanker type ship is selected. If the initial capital cost of the ship is I dollars, then the allocated ship cost relative to the filter bag cost is: 


$$
\mathrm{U}_{\mathrm{S}}=\left(\frac{\varphi_{\mathrm{s}}}{\varphi_{\mathrm{f}}}\right)\left(\frac{\mathrm{I}}{\gamma \mathrm{A}}\right) \cdot \mathrm{U}_{\mathrm{f}} \quad \$ / \mathrm{lb} \mathrm{U}_{3} \mathrm{O}_{8}
$$

where $\varphi_{S}$ is the annual carrying charge rate for the ship (assumed to have a service life of 20 years and negligible salvage value).

For a ship costing $300 \$$ per dwt, $I=60 \times 10^{6} \$$ and $\varphi_{S}=0.20$ year $^{-1}$, and the other values as already noted:

$$
\dot{U}_{S}=40.67 \$ / 1 \mathrm{~b} \mathrm{U} \mathrm{U}_{3}
$$

\section{A. 5 Cost of Ship Operations}

A running cost including all labor, replenishment and repairs (but excluding fuel costs) of $10 \%$ of the initial cost is assumed.

This gives an annual cost of operations:

$$
\mathrm{U}_{\mathrm{o}}=4.07 \$ / 1 \mathrm{~b} \mathrm{U} \mathrm{U}_{3} \mathrm{O}_{8}
$$

\section{A. 6 Cost of Pumping Power and Energy Generation}

The pumping power can be calculated from the flow rate and pressure drop:

$$
\mathrm{P}=3.25 \times 10^{-3}\left[\Delta \mathrm{P} \cdot \mathrm{A} \cdot \mathrm{V}_{\mathrm{w}} / \eta_{\mathrm{p}}\right] \mathrm{kW}
$$

where $\eta_{\mathrm{p}}$ is the motor/pump efficiency (0.8). For $\mathrm{A}=3 \times 10^{6} \mathrm{ft}^{2}$, $\mathrm{V}_{\mathrm{w}}=2 \mathrm{ft} / \mathrm{min}$ and $\Delta \mathrm{P}=2 \mathrm{psi}$, one obtains:

$$
P=48,750 \mathrm{~kW}
$$

The annual consumption of energy is:

$$
\mathrm{E}=8766 \mathrm{PL} \mathrm{kWh/yr}
$$

The numerical data given corresponds to:

$$
E=3.2 \times 10^{8} \mathrm{kWh} / \mathrm{yr}
$$


If the pump and drive-motor capital cost is Ip $=400 \$ / \mathrm{kW}$ (installed), the contribution to the cost of product is:

$$
U_{p}=\left(\frac{{ }_{p} P}{I}\right) U_{s}, \quad \$ / 1 b U_{3} O_{8}
$$

For the data quoted:

$$
\mathrm{U}_{\mathrm{p}}=13.22 \$ / 1 \mathrm{~b} \cdot \mathrm{U}_{3} \mathrm{O}_{8}
$$

A specific fuel consumption of 10 tons coal/mwe day is assumed to operate the ship while in transit or on station. The annual cost of fuel to generate electricity is therefore:

$$
\mathrm{O}_{\mathrm{e}}=10^{-2} \cdot \mathrm{Y}(365.25) \mathrm{PL} \cdot \$ / \mathrm{yr}
$$

where $Y$ is the cost of coal, $\$ /$ ton $(40)$.

The cost per unit of yellowcake produced is:

$$
\mathrm{U}_{\mathrm{e}}=\frac{\mathrm{O}_{\mathrm{e}}}{\varphi_{\mathrm{S}} \mathrm{I}} \cdot \mathrm{U}_{\mathrm{s}} \$ / 1 \mathrm{~b} \mathrm{U}_{3} \mathrm{O}_{8}
$$

which for the values quoted gives

$$
\mathrm{U}_{\mathrm{e}}=18.10 \$ / 1 \mathrm{~b} \mathrm{U} \mathrm{U}_{3} \mathrm{O}_{8}
$$

The total coal inventory on board for 90 days of full power operation is roughly $10^{-2} \mathrm{P}(90) \approx 43,875$ tons, a large but manageable bunker volume. In this regard it should be noted that for a given amount of energy coal requires roughly twice the volume of oil. 


\section{Appendix B}

Filter Bed Performance

\section{B. 1 Pressure Drop Characteristics}

The well-known relation for pressure drop across a packed bed of spherical particles (D2) gives, for seawater, a bed void fraction of 0.4 , and units convenient for present purposes:

$$
\Delta \mathrm{P}_{\mathrm{b}}=150 \frac{\mathrm{Gt}}{\mathrm{d}^{2}}, \text { psi }
$$

where

$\Delta \mathrm{P}_{\mathrm{b}}=$ pressure drop across the bed, psi

$\mathrm{G}=$ flow loading, $\mathrm{gpm} / \mathrm{ft}^{2}$

$\mathrm{t}_{\mathrm{o}}=$ void-free bed thickness, $\mathrm{mm}$

$\mathrm{d}=$ particle diameter, microns

Thus for $\mathrm{G}=15 \mathrm{gpm} / \mathrm{ft}^{2}, \mathrm{t}_{\mathrm{o}}=6 \mathrm{~mm}$, and $\mathrm{d}=100 \mu, \Delta \mathrm{P}_{\mathrm{b}}=1.35 \mathrm{psi}$, which is considerably less than the upper limit of $\sim 6$ psi for a practical system (based on energy balance considerations).

To this value must be added the pressure drop across the retention screen, here spunbonded polypropylene. Laboratory measurements using Du Pont TYPAR ${ }^{\mathrm{R}}\left(4 \mathrm{oz} / \mathrm{yd}^{2}\right.$, type 3407$)$ at MIT can be represented by:

$$
\Delta \mathrm{P}_{\mathrm{S}}=x \mathrm{G}, \mathrm{psi}
$$

where $x$ was measured to be $0.05 \mathrm{psi} / \mathrm{gpm} / \mathrm{ft}^{2}$, or $\Delta \mathrm{P} \approx 0.75 \mathrm{psi}$ for $\mathrm{G}=15 \mathrm{gpm} / \mathrm{ft}^{2}$. Thus the pressure drop across the retention screen itself will be tolerable, with a substantial margin left over for bed and screen fouling.

Manufacturer's data on the spunbonded polypropylene sheet used in our laboratory tests indicate the capability for retention of particles 
larger than about $150 \mu$. This parameter could be altered in manufacture to improve retention (and, of course, the pressure drop characteristics would also be changed). Du Pont reports a considerably lower pressure drop than found in our tests. Thus further work is needed in this area, using retention cloth tailored to meet our specific requirements. Since baghouse filter cloth has the capability to achieve $99.8 \%$ retention on particles down to a few microns in diameter, and with pressure drop characteristics suitable for our current application, it is not felt that any insurmountable problems are likely to arise in this area.

\section{B. 2 Uranium Removal Efficiency}

The computer program developed by Best (B1) has been upgraded to handle ion exchange resin, and used to compute removal efficiency under conditions of current interest. Some pertinent results (under conditions which are roughly, but not exactly, comparable to ours) are tabulated below; they serve to substantiate the performance estimates used in the body of the text.

Superficial velocity $\mathrm{V}, \mathrm{ft} / \mathrm{min}$ 2. 0

Flow loading $\mathrm{G}$, gpm/ $\mathrm{ft}^{2}$

Particle diameter $d$, microns 100

Bed thickness (actual) $t, \mathrm{~mm}$

Resin capacity, C, ppm U

Rcsin deneity, $1 \mathrm{~b} / \mathrm{ft}^{3}$

Duration of exposure, $T$, days

Recovery efficiency, $\eta$ 48. $1 \%$

I.nading, $\mathcal{L}$ $94.1 \%$

Uranium production rate, $\mathrm{MT} \mathrm{U}_{3} \mathrm{O}_{8} / \mathrm{yr}$ 200

Bed surface area

$5.6 \times 10^{6} \mathrm{ft}^{2}$ 
A somewhat simplistic model of the sorption process, which considers only fluid-side resistance, can be used to illustrate in a rough manner how bed performance will vary as a function of key design parameters (C2). For an inexhaustible bed the fraction of incident solute sorbed is:

$$
\eta=1-\mathrm{e}^{-\mathrm{NTU}}
$$

where NTU, the number of transfer units, is given by:

$$
\mathrm{NTU}=\frac{6 \rho \mathrm{t}_{\mathrm{o}} \mathrm{D}}{60 \mathrm{wGd^{2 }}} \cdot \mathrm{Sh} \equiv 1750\left(\frac{\mathrm{t}_{\mathrm{o}}}{\mathrm{Gd}^{2}}\right) \cdot \mathrm{Sh}
$$

and $\mathrm{Sh}$ is the Sherwood Number, or mass-transfer Nusselt Number; in the present instance, for uranyl tricarbonate in seawater under conditions of laminar flow:

$$
\mathrm{Sh}=2.0+0.86 \sqrt{\mathrm{dG}}
$$

For $\mathrm{d}=100 \mu$ and $\mathrm{G}=15 \mathrm{gpm} / \mathrm{ft}^{2}$, we have $\mathrm{Sh}=24.7, \mathrm{NTU}=1.7 \mathrm{~s}$. $\dot{\eta}=0.82$. : Note, however, that the preceding relations apply to a bed of fixed thickness. $t_{0}$. If the bed is modeled as a layer which decreases in thickness as a sharply-defined wave front of progressive depletion moves through it, from the inlet toward the outlet, then an average removal fraction can be defined:

$$
\bar{f}=\frac{\int_{t o}^{(1-2) t} o f(t) d t}{\int_{t_{0}}^{(1-2) t} d t}
$$

which gives: 


$$
\bar{f}=1-e^{-N T U_{0}}\left\{\frac{e^{\mathcal{L} \cdot N T U_{0}}-1}{\mathcal{L} \cdot N T U_{0}}\right\}
$$

(Actually this result does not depend on the shape of the depletion profile so long as free and depleted sites are unaffected by each other's presence, in which case effective bed thickness depends only on the average population of remaining free sites.)

For the representative parameter values previously cited and a loading fraction, $\mathcal{L}$, of $77 \%$ (see below), Eq. (B. 5 ) gives for $\overline{\mathrm{f}}$ a value of 0.62.. This is larger than the value predicted by the more detailed analysis using Best's computer model. In any event, experience with powdered ion exchange resins in condensate polishing service suggests that the fractional removal value of $50 \%$ used in the present analysis is undoubtedly conservative.

A material balance on the incident seawater and the sorber bed can be used to relate the loading $(\mathcal{L})$, the fraction of bed capacity exhausted, and the recovery fraction, $\eta$ :

$$
\eta=\frac{\text { CR } t_{0} \mathcal{L}}{(304.8)(1440) \times w G T}
$$

where

$$
\begin{aligned}
& \mathrm{C}=\text { resin capacity, } \mathrm{lb} \mathrm{U} / \mathrm{lb} \operatorname{resin}\left(1.5 \times 10^{-3}\right) \\
& \mathrm{R}=\text { vold-free density of resin, } \mathrm{lb} / \mathrm{ft}^{3},(80) \\
& \mathrm{t}_{0}=\text { vold-free lhickness of bed, } \mathrm{mm}
\end{aligned}
$$


$\mathrm{x}=$ concentration of $\mathrm{U}$ in seawater, $\mathrm{Ib} U / \mathrm{lb}$ water

$\left(3.3 \times 10^{-9}\right)$

$\mathrm{w}=$ density of seawater, lb/gal (8.55)

$\mathrm{G}=$ flow loading, $\mathrm{Gpm} / \mathrm{ft}^{2}$. (15)

$\mathrm{T}$ = exposure duration, days (6)

For the variables cited:

$\eta=0.65 \mathfrak{L}$

Thus $50 \%$ recovery would exhaust $0.50 / 0.65=77 \%$ of the available sites.

In the preceding analysis it has been assumed that fluid-side transport was the controlling resistance. This is not necessarily the case. Weisz (W1) has characterized the solid-side diffusion in a particularly useful way; he finds for the time for a sorber to reach half-saturation:

$$
T_{h}=u^{2} \frac{d^{2} b}{4 D} \frac{C}{p x}
$$

where $u$ is a constant ranging, in the case of a sphere, between 0.175 and 0.136 in the limits of weak and strong sorption, respectively. Weisz shows that these limits include behavior described by the Nernst, Freundlich and Langmuir isotherms. The other parameters are:

$\mathrm{b}=$ tortuosity factor, usually $\leq \sqrt{ } 3$

$\mathrm{p}=$ porosity fraction in sorber particle $(\sim 0.5)$

and as before:

$\mathrm{d}=$ particle diameter (100 microns)

$\mathrm{C}=$ concentration at equilibrium in sorber (1500 ppm)

$\mathrm{x}=$ concentration in solution $(3.3 \mathrm{ppb})$

For the above parameter values, and strong sorption, $\mathrm{T}_{\mathrm{h}}=100 \mathrm{hrs}$ $\cong 4$ days, which suggests that the uranium uptake may not be reduced substantially by solid-side resistance in the present case. However, 
this process must be taken into account in more detailed calculations. The considerable benefit of an even smaller particle diameter is readily seen, in view of the $d^{2}$ dependence. Finally, note that the above prescription applies to diffusion through the liquid phase inside a porous solid. Diffusion in the solid itself is too slow to be of appreciable help: values of the diffusivity, $D$, in solids are typically several orders of magnitude less than those in liquids.

\section{B. 3 Pressure Drop Down the Length of the Filter Tube}

The pressure drop down the baghouse cylinders can be estimated as follows. For a flow loading $\mathrm{G}, \mathrm{gpm} / \mathrm{ft}^{2}$, through the filter cloth, the Reynolds number at the entrance to the tube is:

$$
\operatorname{Re}=1140\left(\frac{\mathrm{L}}{\mathrm{D}}\right) \cdot \mathrm{G}
$$

where

$L=$ length of tube $(25 \mathrm{ft})$

$D=$ diameter of tube $(1 \mathrm{ft})$

For the above-quoted values and $G=15 \mathrm{gpm} / \mathrm{ft}^{2}, \mathrm{Re}=427,500$, well into the turbulent regime.

If the velocity down the length of the tube decreases linearly (because of the leakage of fluid through the filter walls), then the net pressure drop over the length of the tube is approximately one-third that of a solid-wall tube:

$$
\Delta P=\frac{4}{3} f\left(\frac{L}{D}\right)^{3} \frac{G^{2}}{1.83 \times 10^{6}}, p s i
$$

We will approximate the friction factor for a rough-walled pipe as being constant with a value of 0.0024 ; for this and the previously noted parameter values, $\Delta \mathrm{P}=0.006 \mathrm{psi}$.

This value of the pressure drop is sufficiently less than that 
through the walls to insure a uniform flow distribution. Note in Eq. (B. 9) the strong dependence of $\Delta P$ on $L$ and $G$ : this serves to limit the useful length of the baghouse tubes; we have restricted our choice to be within the range of state-of-the-art experience with stack-gas filters.

\section{B. 4 A Design Option}

While individual filter bags can be fabricated as in the conventional stack-gas baghouse applications, it may be more economical to produce them in modules directly from commercially-available polypropylene sheet:

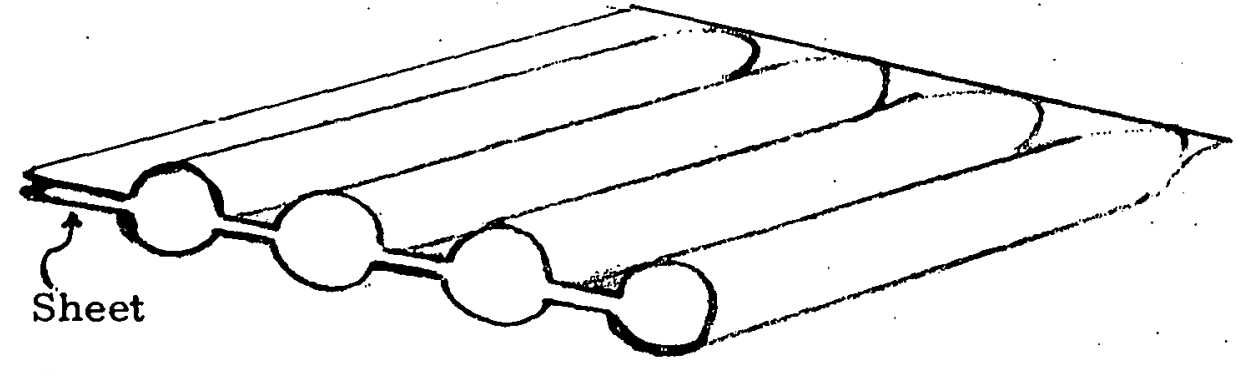

folded over and stitched and/or sealed together in strips to form rows of tubes.

A unit cell becomes.

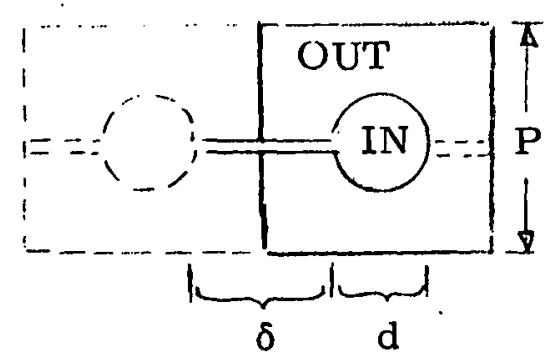

The length of sheet per tube is:

$$
\mathrm{S}=2 \delta+\pi \mathrm{d}
$$
The ratio of flow areas, out/in, $\xi=\frac{p^{2}-\frac{\pi}{4} d^{2}}{\frac{\pi}{4} d^{2}} \cdot$ Since $p=d+\delta$, one
can show that:

$$
\frac{\delta}{d}=\sqrt{\frac{\pi}{4}(1+\xi)}-1
$$

Hence if $\dot{\xi}=1, \delta \approx 0.25 \mathrm{~d}$, and if $\mathrm{d}=1 \mathrm{ft}, \mathrm{S}=3.5 \mathrm{ft}$.

TYPAR ${ }^{R}$ is available from Du Pont in standard 197 inch (16 ft) 
wide rolls, which would permit fabrication of four-bag modules. If $25 \mathrm{ft}$ wide rolls could be obtained, then any number of bags could be webbed together, since rolls are available in 1,000 yard lengths. (Du Pont indicates that custom widths are available upon request.)

\section{B. 5 Length of Loading Cycle}

A parameter of decisive importance is the cycle time - the time between successive bed regenerations. This can be estimated by computing the time to exhaust the effective capacity of the ion exchange resin (one minus the loading fraction times the ultimate equilibrium capacity:

$$
\mathrm{T}_{\mathrm{c}}=\frac{\mathrm{C} \cdot \mathrm{R} \mathrm{t}_{\mathrm{o}}}{(304.8)(1440) \mathrm{w} \times \eta \mathrm{G}} \text { days }
$$

where

$\mathrm{C}=$ effective resin capacity for uranium, $\mathrm{lb} \mathrm{U} / \mathrm{lb}$ resin, $\left(1.5 \times 10^{-3}\right.$, i.e. $\left.1500 \mathrm{ppm}\right)$

$\mathrm{G}=$ flow loading, $\mathrm{gpm} / \mathrm{ft}^{2}$ (15)

$\mathrm{R}=$ resin density, $1 \mathrm{~b} / \mathrm{ft}^{3}(60)$

$t_{0}=$ void-free thickness of sorber bed, $\mathrm{mm}(6)$

$\mathrm{w}=$ density of seawater, $\mathrm{lb} / \mathrm{gal}(8.55)$

$\eta \quad=\quad$ efficiency of recovery $(0.5)$

$\mathbf{x}:=$ concentration of uranium in seawater, $1 \mathrm{~b} U / \mathrm{lb}$ water $\left(3.3 \times 10^{-9}\right)$

For the representative values in parentheses, $T_{c}=6$ days under fullflow conditions.

Hence a weekly load/reload cycle is indicated. Longer cycle times would be desirable, since this would reduce the required resin inventory, chemical consumption, and operating labor. As can be seen, the cycle time is set by the resin capacity. Values for ion exchange 
resin as high as 2500 ppm have been reported for uranium-fromseawater applications. Hence longer exposures may be feasible. However, the filters will also remove suspended solids from the water being processed, which will require periodic refurbishment of the bed in any event to avoid excessive pressure drop and the consequent diminution of throughput.

\section{B. 6 Extrapolation from Analogous Experience}

Two sources of pertinent data can be drawn upon to develop information which will help define the essential features of a filter system of the type envisioned here. First of all, there is extensive operating data from baghouse operation. 'Although the fluid handled is combustion gas $\left(\mathrm{N}_{2}, \mathrm{CO}_{2}, \mathrm{H}_{2} \mathrm{O}\right)$, it is similar in many respects to air, for which there is a long history of similitude studies as a surrogate for water. Thus we can directly translate pressure drop versus flow rate data as a function of particle diameter and bed thickness into waterequivalent results.

The ratio of water to gas pressure drops through the same filter bed is given by the simple relation:

$$
\frac{\Delta \mathrm{P}_{\mathrm{w}}}{\Delta \mathrm{P}_{\mathrm{g}}}=\left(\frac{\mu_{\mathrm{w}}}{\mu_{\mathrm{g}}}\right)\left(\frac{\mathrm{Q}_{\mathrm{w}}}{\mathrm{Q}_{\mathrm{g}}}\right) \equiv\left(\frac{\mu_{\mathrm{w}}}{\mu_{\mathrm{g}}}\right)\left(\frac{\mathrm{V}_{\mathrm{w}}}{\mathrm{V}_{\mathrm{g}}}\right)
$$

where $\left(\mu_{\mathrm{w}} / \mu_{\mathrm{g}}\right)=$ ratio of water to gas viscosities $\approx 50$

$\mathrm{Q} \quad=$ volumetric flow loading, cfm per $\mathrm{ft}^{2}$

$\mathrm{V} \quad=$ superficial velocity, $\mathrm{ft} / \mathrm{min}$

Thus if we employ representative baghouse data $\left(\Delta P_{g}=0.14 \mathrm{psi}\right.$, $\mathrm{Q}_{\mathrm{g}}=2 \mathrm{cfm}$ per $\mathrm{ft}^{2}$ ), and permit $\Delta \mathrm{P}_{\mathrm{w}} \leq 7 \mathrm{psi}$ in accord with Ref. (B1), which shows that values in this range are needed to assure a favorable 
overall energy balance, then Eq. (B. 11) shows that the superficial flow velocity of water passing through the bed, $V_{w} \leq 2 \mathrm{ft} / \mathrm{min}$. This corres ponds to a flow loading of roughly $15 \mathrm{gpm} / \mathrm{ft}^{2}$. Powdered ion exchange resin beds in condensate polishing service are operated at flow loadings this high in beds $3-6 \mathrm{~mm}$ thick, but at pressure drops near 40 psi. However, pressure drop is directly proportional to bed depth and inversely proportional to particle-diameter squared, so that a bed design compatible with current requirements is readily achievable by adjusting these parameters. For example, mass-mean particle diameters for both fly ash and powdered ion exchange resins are approximately 20 microns, while optimum sorber particle diameter in the present instance as determined by Best (B1), is closer to 60 microns.

\section{B. 7 Stress on Filter Cloth}

It must be recognized that the filter cloth is under considerable stress (compared to stack-gas service) due to the large pressure drop sustained across the filter bed.

The maximum hoop stress is

$$
\sigma=\Delta \bar{P} \cdot \frac{12 d}{2}, \text { lb per linear foot }
$$

where

$\Delta \mathrm{P}=$ maximum pressure drop across the filter bed, psi (7)

$\mathrm{d}=$ diameter of cylindrical filter bag, ft (1)

Hence for the quoted parameter values $\sigma \leq 42 \mathrm{lb}$ per linear foot. This is severe, but experimentally confirmed to be within the capability of spunbonded polypropylene cloth on the order of 15 mils thick.

Compared to stack gas service, in which the filters are subjected to a load/fly ash removal cycle every 30 minutes or so, the current 
application, in which a weekly cycle is contemplated, should be more benign in other respects.

\section{B. 8 Bed Fouling}

An inherent limit on cycle length is set by water purity. Since sorber beds of the present type are excellent filters, it must be assumed that essentially all suspended matter in seawater will be removed, at the expense of a gradual buildup in pressure drop. The time to foul the bed can be expressed in the prescription:

$$
\mathrm{T}_{\mathrm{f}}=\frac{\mu}{(304.8)(1440) \mathrm{y} \mathrm{w}} \text {, days }
$$

where

$$
\begin{aligned}
& \mathrm{y}=\text { concentration of suspended matter in seawater, } 1 \mathrm{bs} / 1 \mathrm{~b}\left(10^{-7}\right) \\
& \mathrm{w}=\text { density of seawater, } 1 \mathrm{bs} / \mathrm{gal}(8.55) \\
& \mathrm{G}=\text { flow loading, } \mathrm{gpm} / \mathrm{ft}^{2}(15)
\end{aligned}
$$

and

$$
\mu=\text { allowable crud loading on bed, } \mathrm{lbs} / \mathrm{ft}^{2}(0.1)
$$

For the parametcr values quoted, $\mathrm{T}_{\Gamma}=8,5$ days. which assures that the weekly cycle postulated in the present instance is practicable. It must be noted, however, that this is predicated on the use of clean ocean water. Concentrations of suspended material less than $100 \mu \mathrm{g} / \mathrm{liter}$ are apparently readily attainable in the open ocean (G1), but one can not necessarily be assured of achieving more than about a factor of two less than this. Similarly, the amount of solids which will cause an intolerable increase in pressure drop can only be approximately specified (M1), but is in the range employed here. 
Chapter 7

Advanced Particle Bed Configurations for the Extraction of Uranium from Seawater

by

M. J. Driscoll

1. Introduction

Design studies on more-or-less straightforward approaches to the recovery of uranium from seawater indicate that even fairly thoroughly optimized systems evaluated under optimistic assumptions can at best produce $\mathrm{U}_{3} \mathrm{O}_{8}$ in the cost range of $150-200 \$ / \mathrm{lb}[\mathrm{B} 1, \mathrm{~K} 1]$. While this is approximately the breakeven cost for LWR units competing with fast breeder reactors or other advanced energy options [N1], it is still sufficiently high to discourage short-term interest in the exploitation of oceanic uranium reserves. It is clear, therefore, that fuller advantage must be taken of known means to improve system performance. The approach suggested here is to adopt an expanded bed design, as might be achieved, for example, through use of sorber media configured as fibrous mats (e.g. "steel wool"), bent wire chaff, or other similar packing. Numerous chemical engineering unit operations already use such fill, and for many of the same reasons as motivate the present suggestion.

\section{Technical Bases}

While prescriptions vary somewhat among researchers in the field, the pressurc drop through a bed of material is conceded to vary strongly with void fraction, $\epsilon$, for example [O1]: 


$$
\begin{aligned}
& \left(\frac{\Delta \mathrm{P}_{2}}{\Delta \mathrm{P}_{1}}\right)=\left(\frac{\epsilon_{1}}{\epsilon_{2}}\right)^{3}\left(\frac{1-\varepsilon_{2}}{1-\varepsilon_{1}}\right) \text {, for particle beds } \\
& \left(\frac{\Delta \mathrm{P}_{2}}{\Delta \mathrm{P}_{1}}\right)=\left(\frac{1-\epsilon_{2}}{1-\epsilon_{1}}\right)^{\frac{1}{2}}\left[\frac{1+56\left(1-\epsilon_{2}\right)^{3}}{1+56\left(1-\varepsilon_{1}\right)^{3}}\right] \text {, for fibrous mats }
\end{aligned}
$$

The above equations are for beds having all essential features the same (particle size, total bed mass, superficial fluid velocity); hence the true thickness, $t$, and the void-free (i. e. "crushed") thickness $t_{0}$ are related by:

$$
t_{0}=t(1-\epsilon)
$$

Settled sorber beds for the recovery of uranium from seawater typically have void fractions of $40 \%$; this is readily increased to $80 \%$ (or even more) in an expanded bed, in which case a decrease in pressure drop by a factor of between 16 (Eq. (1b)) and 24 (Eq. (1a)) is to be anticipated.

On the other hand, mass transfer coefficient correlations predict a variation bracketed by $[\mathrm{C} 1][\mathrm{P} 1]$ :

$$
\frac{\epsilon_{1}}{\epsilon_{2}}<\frac{\mathrm{k}_{2}}{\mathrm{k}_{1}}<\sqrt{\frac{\epsilon_{1}}{\epsilon_{2}}}
$$

Hence the mass transfer coefficient will decrease by a factor somewhere between 0.5 and 0.7 when the void fraction is increased from $40 \%$ to $80 \%$. This is not a substantial penalty to pay for such a large reduction in pressure drop, and moreover the loss is easily recovered by increasing the mass flow rate, $G\left(\mathrm{gpm} / \mathrm{ft}^{2}\right)$, since $\mathrm{k} \sim \sqrt{\mathrm{G}}[\mathrm{D} 1]$.

The trade-off is further constrained by the desirability of keeping the efficiency of the bed approximately constant. The fraction of the incident uranium removed by the bed is determined by the number of 
transfer units. In terms of the variables of interest [D1]:

$$
\text { NTU } \sim \frac{k t_{o}}{G} \sim \frac{t_{o}}{\sqrt{G}}
$$

We also have:

$$
\Delta \mathrm{p} \sim \mathrm{Gt}_{\mathrm{o}} \sim \mathrm{G}^{3 / 2}
$$

Thus recouping a factor of 24 in $\Delta p$ would permit an increase in flow by roughly a factor of 8 . The corresponding increase in $t_{0}$ is a factor of 3 .

Since pump work is proportional to $G \cdot \Delta p$ and uranium recovery is also proportional to $G$ (for fixed bed efficiency), the energy expended per unit mass of product is unchanged. Likewise, for a fixed sorber capacity the consumption of chemicals should not change appreciably (per $1 b$ of product) so long as the bed is well drained prior and subsequent to regeneration. The cycle time will be shorter, however, since it is proportional to $t_{0} / G$ : for the above example a reduction by a factor of $3 / 8$ is indicated.

Overall, then, the major impact of the use of an expanded bed will be the large increase in flow loading, which (for a fixed rate of production) will substantially reduce the size of the physical plant and hence greatly reduce capital expenditures.

\section{Other Considerations}

The use of a fiber mesh bed introduces a number of features which should contribute to the overall effectiveness of the design. In particular:

(a) The higher void fraction should reduce the susceptibility of the bed to plugging by suspended solids in the seawater.

(b) Retention screens can be of a very coarse mesh, and hence 
contribute a negligible pressure drop.

(c) Material losses due to bed attrition should be lower than for beds of small movable granular particles.

(d) An expanded mesh bed should realize most of the advantages of a fluidized bed, but be able to operate at much higher flow loadings - beyond the point at which fluidized bed particles would be swept away.

The major disadvantage of the expanded bed, of course, is the need to develop a suitable packing. To date none of the leading candidate sorber materials (hydrous titanium oxide (HTO) and ion exchange resins) has been fabricated in a suitable configuration. Plastic packing has been fabricated in satisfactory shapes for other mass transfer applications. Perhaps the appropriate functional groups can be added to form an ion exchange resin without excessive degradation of the material's structural properties. HTO has also been implanted in a plastic carrier, which may be suitable for subsequent fabrication.

A final possibility would bc the coating of a suitable substrate with active sorber. All of thcse approaches would require an $R \& D$ effort. The payoff, however, would be substantial, and could be carried out on a small scale, since the results are readily extrapolable to full scale.

\section{Conclusions and Recommendations}

It has become increasingly evident that resort must be made to a higher level of technical sophistication in the development of a suitable sorber configuration for uranium recovery from seawater. One approach is suggested here - the use of an open mesh bed. It was shown that as much as a factor of eight reduction in sorber bed frontal surface area might be achievable. This would greatly reduce plant capital costs, 
which are currently the dominant contributor to the production cost of yellowcake from the sea.

To pursue this goal several subtasks are indicated:

(a) Verification of the generalized mass transfer and pressure drop correlations on the candidate configuration. This can be done without specific involvement of the uranium sorption process. This is worthwhile since the generalized correlations are only good to within $\pm 20 \%[\mathrm{P} 1]$.

(b) Fabrication and test in the laboratory of candidate sorber media in uraniferous seawater. The addition of functional groups to prefabricated plastic shapes would appear to be the most promising approach.

(c) Refinement and cost analysis of a detailed overall design to better define the ultimate cost of product if all R\&D goals were to be achieved.

Subtasks (a) and (c) can be completed in short order; subtask (b) must await the achievement of satisfactory ion exchange resin performance In its more conventional bead or granular form. 


\section{References}

[B1] F. R. Best and M. J. Driscoll (eds), "Proceedings of a Topical Meeting on the Recovery of Uranium from Seawater", MIT-EL80-031, December 1980.

[C1] J. J. Carberry, "Chemical and Catalytic Reaction Engineering", McGraw-Hill, NY (1976).

[D1] M. J. Driscoll et al., "Practical Constraints on Systems for the Extraction of Uranium from Seawater", in Ref. [B1].

[K1] M. Kanno, "Japanese Studies on Extraction of Uranium from Seawater". Symposium on Separation Science and Technology for Energy Applications, Gatlinburg, Tennessee, May 5-8, 1981 .

[N1] Nuclear Proliferation and Civilian Nuclear Power: Report of the Nonproliferation Alternative Systems Assessment Program, DOE/NE-0001/1-9, June 1980.

[O1] C. Orr, "Filtration Principles and Practices", Marcel Dekker, Inc., NY (1977).

[P1] D. K. Pandey and S. N. Upadhyay, "Mass Transfer Between the Particles and the Fluid in Fluidized Beds of Large Particles", Int. J. Heat Mass T'ransfer, Vol. 24, No. 7, July 1981. 


\section{Appendix A}

Notes on Interpretation of Correlations.

\section{A. 1 Mass Transfer}

Mass transfer in packed and fluidized beds is almost always correlated in the form:

$$
S h=a+b R e^{m} S c^{n}
$$

where

$$
\begin{aligned}
\text { Sh } & =\text { Sherwood Number (mass transfer Nusselt Number) } \\
& =\left(\frac{\mathrm{kd}}{\rho \mathrm{D}}\right) \\
\mathrm{Re} & =\text { Reynolds Number }=\left(\frac{\mathrm{dG}}{\mu}\right) \\
\mathrm{Sc} & =\text { Schmidt Number }=\left(\frac{\mu}{\rho \mathrm{D}}\right) \\
\mathrm{k} & =\text { mass transfer coefficient } \\
\mathrm{d} & =\text { characteristic diameter of sorber particle } \\
\mathrm{D} & =\text { diffusivity of species to be sorbed } \\
\mu, \rho & =\text { fluid viscosity, density } \\
\mathrm{G} & =\text { flow loading }
\end{aligned}
$$

The coefficient $m$ ranges between 0.5 and 1.0. For cases of current interest the flow rate is high enough that the second term in Eq. (A. 1) will dominate.

Of interest herc is the dependence of mass transfer coefficient, $k$, on the bed volume fraction voids, $\varepsilon$. The latter parameter can enter the correlation in several ways:

1. In a bed the true velocity of the fluid is higher than the superficial (i. e., empty tube) velocity which leads to the relation

$$
\mathrm{G}=\mathrm{G}_{0} / \epsilon
$$


Hence one often finds a modified Reynolds number used to correlate data:

$$
\operatorname{Re}=\frac{\mathrm{dG}_{\mathrm{O}}}{\mu \epsilon}
$$

2. The sorber particle diameter, $d$, can be either the physical diameter of an (equivalent) sphere (or cylinder), or, especially when the analogy to heat transfer is in mind, the hydraulic diameter of the flow channel, given by the relation:

$$
d_{h}=\frac{4 V_{s}}{S_{p}}
$$

where $V_{f}=$ volume of fluid

$$
S_{p}=\text { surface area of particle }
$$

For spherical particles we have

$$
d_{h}=\frac{(4 / 3) \pi\left(\frac{d}{2}\right)^{3} /(1-\epsilon)}{4 \pi(d / 2)^{2}}=\frac{d}{6(1-\epsilon)}
$$

This approach gives the $(1-\epsilon)$ sometimes encountered, as in

$$
\text { Re }=\frac{\mathrm{dG}}{\mu(1-\varepsilon)}=\frac{\mathrm{dG}_{\mathrm{o}}}{\mu \epsilon(1-\epsilon)}
$$

Hopefully investigators will be consistent in their use of $d$ or $d_{h}$ on both sides of Eq. (A.1); if particle diameter $\mathrm{d}$ is used one would expect to find:

$$
\mathrm{k} \sim \frac{1}{\epsilon^{\mathrm{m}}}=\left\{\begin{array}{l}
>1 / \sqrt{ } \epsilon \\
51 / \epsilon
\end{array} \quad \text { since } \frac{1}{2}<\mathrm{m}<1\right.
$$

F'urther thought is necessary if the hydraulic diameter is employed.

The mass transfer coefficient $k$ is the mass of material transferred into a unit area of sorber per unit time per unit concentration difference; it has the units of (mass) (length) $)^{-2}$ (time) $^{-1}$. The diffusivity $D$ has the units of (length) ${ }^{2}$ (time) $)^{-1}$ and fluid density $\rho$ is mass (length) ${ }^{-3}$; 
hence with $\mathrm{d}$ having the units of length, $\mathrm{Sh}$ is a dimensionless parameter. To divine the correct $d$ for use in the correlation we need to invoke the physics involved. The diffusivity $\mathrm{D}$ is proportional to the velocity of the diffusing species and its mean free path in the fluid. The mass transfer coefficient, $k$, applies to diffusion through the thin fluid boundary layer surrounding the sorber particles, while $\rho$ refers to the density of the fluid phase only. Thus one can argue that $d$ should measure the fluid volume available per unit area of sorber particle - i. e. the hydraulic diameter, in which case:

$$
\mathrm{k} \sim \frac{(1-\epsilon)^{1-\mathrm{m}}}{\epsilon^{\mathrm{m}}}=\left\{\begin{array}{l}
>\sqrt{\frac{1-\epsilon}{\epsilon}} \\
<1 / \epsilon
\end{array} \text { since } \frac{1}{2}<\mathrm{m}<1\right.
$$

Since the $\sqrt{1-\varepsilon}$ factor would imply the physically unrealistic condition $k \rightarrow 0$ as $\epsilon \rightarrow 1.0$, this limit is rejected. The remaining limits support the use of Eq. (A.7) to bound the dependence of $k$ on $\epsilon$, as was done in the body of this paper.

Researchers may choose to correlate their data using a mixture of conventions; if so, other dependencies could be encountered; e.g. :

$\begin{array}{ccc}\frac{\text { LHS (Sh) }}{d_{h}} & \frac{\text { RHS (Re) }}{d} & \frac{k \text { dependence }}{\frac{(1-\epsilon)}{\epsilon^{m}}} \\ d & \frac{1}{[\epsilon(1-\epsilon)]^{m}}\end{array}$

Since neither result approaches a physically meaningful limit when $\epsilon$ approaches 1.0 , they were both rejected as plausible dependencies.

In the preceding development it was assumed that fluid-side resistance dominated and that the Reynolds Number was moderately large. 
To the extent that solid side diffusion controls or the flow approaches creep-flow conditions, the dependence on void fraction will be less pronounced than in the preceding analyses. Reference $(G-1)$ presents a comprehensive review of the field, leading to the development of a comprehensive correlation which suggests the following void fraction dependence at low and moderate values of the Reynolds number

$$
\frac{k(\varepsilon)}{k(1)}=\frac{\operatorname{Sh}(\epsilon)}{\operatorname{Sh}(1)}=\frac{7-10 \epsilon+5 \epsilon^{2}}{2}
$$

Figure A. 1 compares this relation to the dependence predicted in Eq. A.7, namely:

$$
\frac{k(\varepsilon)}{k(1)}=\left\{\begin{array}{l}
1 / \sqrt{\epsilon} \\
1 / \varepsilon
\end{array}\right.
$$

As can be seen from the figure, something less than a factor of 2 penalty in mass transfer coefficient is to be anticipated when an expanded bed is used in place of a settled bed (which typically has $\sim 40 \%$ voids). This is easily recouped by increasing the flow rate.

\section{A. 2 Pressure Drop}

In principle the dependence of pressure drop on void fraction can be deduced from general principles - by treating the bed as a bundle of sinuous flow tubes - as is done in many standard references (K1).

For a fixed bed mass (i. e. void-free thickness), this approach gives:

$$
\Delta P \propto \frac{(1-\epsilon)}{\epsilon^{3}}
$$

This expression was the basis for inferring a factor of 24 reduction in pressure drop if the void fraction were increased from $40 \%$ to $80 \%$. The powers of $\varepsilon$ in the denominator arise naturally from the conversion 
from superficial to actual fluid velocity and from hydraulic diameter to particle diameter.

The picture becomes more complicated, however, when one turns to a second source of information - the filtration literature $(\mathrm{J} 1, \mathrm{~W} 1)$. If one employs correlations from these references, pressure drop values a factor of two higher or lower than predicted by Eq. (A.10) are predicted. In some cases, however, the applicability of these prescriptions to highly compacted beds is in question; similarly the applicability of Eq. (A.10) to very dispersed beds is uncertain. Unfortunately there is no simple $100 \%$ void limit which can be invoked as in the case of mass transfer. Fortunately, pressure drop is amenable to experimental determination using rather unsophisticated apparatus. Thus it is recommended that candidate sorber configurations be investigated experimentally using readily available surrogate media such as steel wool. 


\section{References}

(G1) D. J. Gunn, "Tranśfer of Heat or Mass to Particles in Fixed and Fluidised Beds", Int. J. Heat Mass. Transfer, Vol. 21, No.4, April 1978.

(J1) R. A. Jaisinghani and G. S. Sprenger, "Resistance to Flow of Liquids in Fibrous Beds Applied to Cartridge Filtration", Filtration and Separation, Vol. 18, No.2, March/April 1981.

(K1) J. M. Kay and R. M. Nedderman, "An Introduction to Fluid Mechanics and Heat Transfer", 3rd Edition, Cambridge University Press, 1974.

(Wi) A.'J. Wishart and J. Gregory, "Filtration of Aqueous Suspensions through Fibrous Media", Filtration and Separation, Vol. 18, No. 3, May/June 1981. 


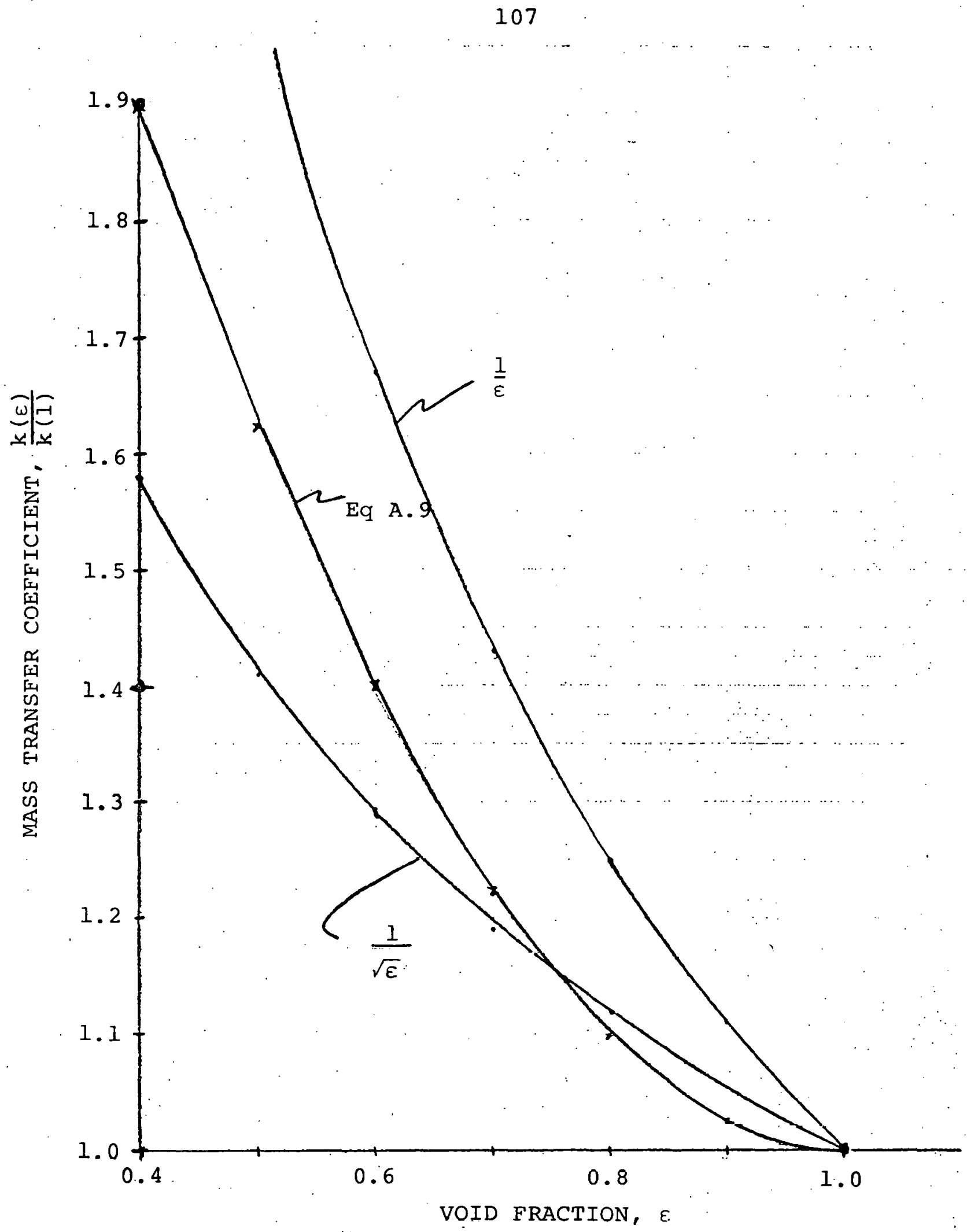

Figure A.l Mass Transfer Coefficient Relative to Isolated Particle value 


\section{Chapter 8}

A High Performance System for Uranium Extraction from Seawater

by

M. J. Driscoll and F. R. Best

\section{Introduction}

A series of system studies performed during the course of this research project has inexorably led to the conclusion that attractive economic performance can come only through exploitation of very high flow rates, which in turn are practical with respect to pumping power requirements only if an expanded bed having high voidage is utilized. Several other changes in the conceptual design of the system have also been incorporated to take into account lessons learned from critiquing earlier versions.

\section{System Description}

As in all of our recent design studies. the recovery process is focused around the use of ship or barge-mounted actively pumped sorber beds. Figure 1 illustrates the salient features of the current version of this concept; to be noted are:

* The use of a catamaran configuration to take advantage of its ability to avoid recirculation of depleted seawater back through the intakes. Here water is drawn from the region between the hulls and discharged into the unconfined region outside the hulls. The filter units are located on the sheltered inboard side of the hulls.

* The catamaran is also very stable against roll and pitch, which is desirable in a free-surface system such as the one employed here. 

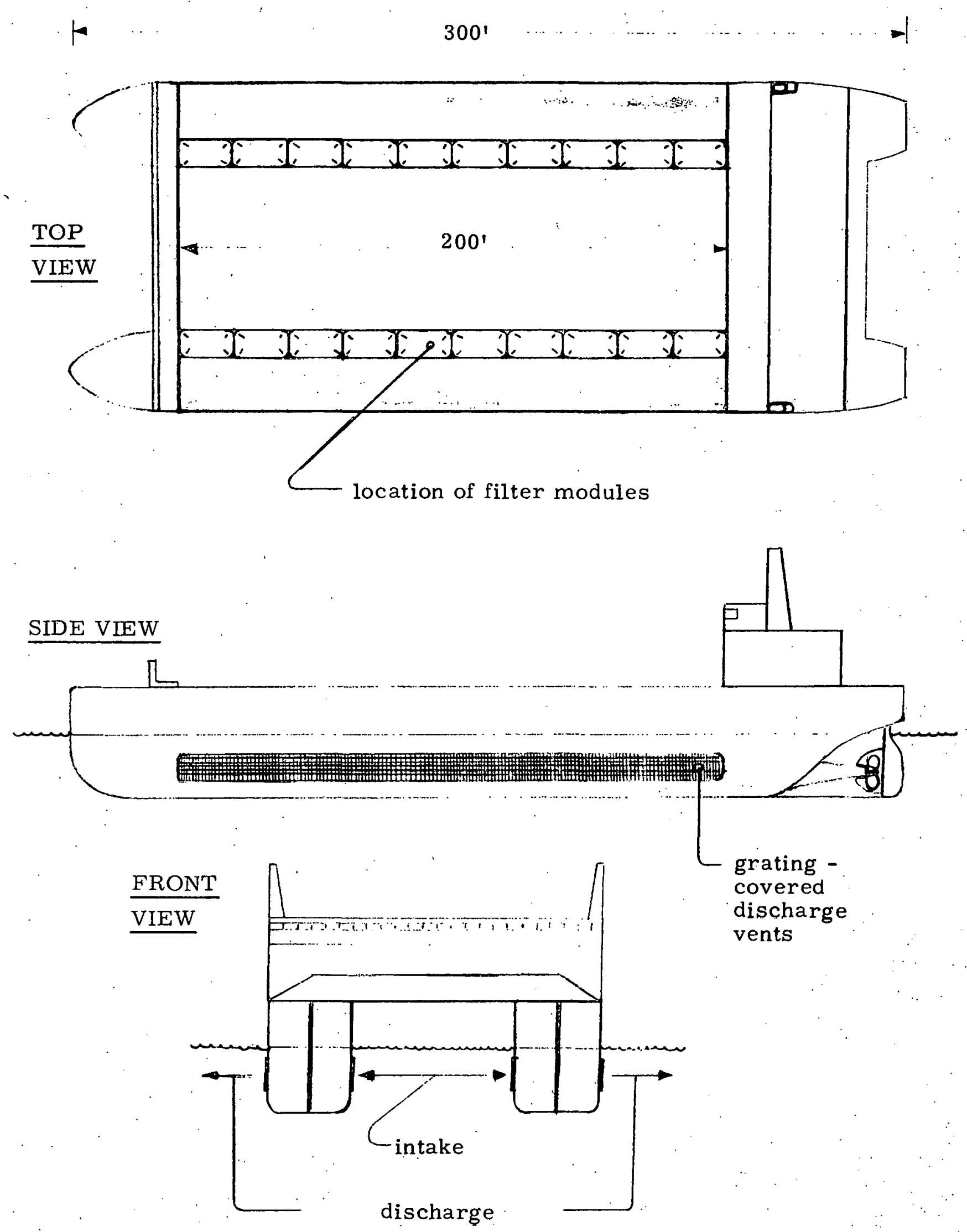

Fig. 1 Configuration of pump-ship for extraction of uranium from seawater. 
This layout permits a short straight-line flow path, which will minimize parasitic pressure drop losses due to changes in direction, duct wall friction, etc. The use of a $\mathbf{W}$-shaped arrangement for the filter leaves (see Fig. 2 for details), which doubles the useful surface area compared to a $\amalg$ configuration, and also provides an inherent truss-like structural rigidity to withstand the large flow forces associated with the high fluid throughput. The use of ion exchange media in the form of fibrous mats which permits the void fraction to be large enough to mitigate the pressure drop (which varies roughly as the -3 power of the void fraction) and thereby permits very high flow rates, while avoiding the particle attrition and carryover-loss problems associated with fluidized beds (the other obvious candidate for low $\Delta P$ service). The low-head, high flow rate axial pumps are located downstream of the filter. This protects the pumpe against ingcstion of ocean-borne trash and facilitates the problem of sealing the filter module to the pump inlet plenum. Filter pressure drop is sufficiently low and submergence depth sufficiently deep to preclude pump NPSH problems. The selection of a number of smaller barges (to serve each 1 Gwe nuclear unit) instead of a single super-size vehicle: the smaller barges are better suited (shallower draft, etc.) for operation out of a large number of unimproved port facilities with respect to navigation, drydocking and the like; in addition the customary advantages of redundancy are achieved (high 
overall load factor, insurance against catastrophic loss, etc.). Multiple filter-ship units operating as close as possible to shore also fit in well with a number of inherent process requirements: ** Attainable ion exchange capacities appear to be limited to a range which will require regeneration after a few days on line - thus negating any advantages which larger units might have with respect to sustained operation far at sea.

** A short-trip fishing-boat type of operation should make it easier to crew the units, and will keep on-board inventory costs low.

** It appears highly desirable to have the regeneration facilities based on shore to take advantage of economies of scale and easier access to key consumables such as fresh water, ammonia and carbon dioxide.

Figure 2 shows some details of the filter modules. Points of interest include:

* Each ship contains 20 modules, which in turn house 20 filter leaves. The modules are of a size (L, $\mathrm{W}, \mathrm{H}=20^{\prime}, 10^{\prime}, 10^{\prime}$ : roughly that of a trailer truck body) readily handled by a dockside crane, which should permit removal and replacement of the entire complement in one working shift. Commercial equipment exists for handling containers of this size for both ship and railroad applications.

* Each filter leaf is of a size $\left(10^{\prime}\right.$ by $10^{\prime}$ : roughly that of a living room rug) which can be handled by a few men. The two-foot wide vertical entrance/exit slots permit access for inspection, 
112

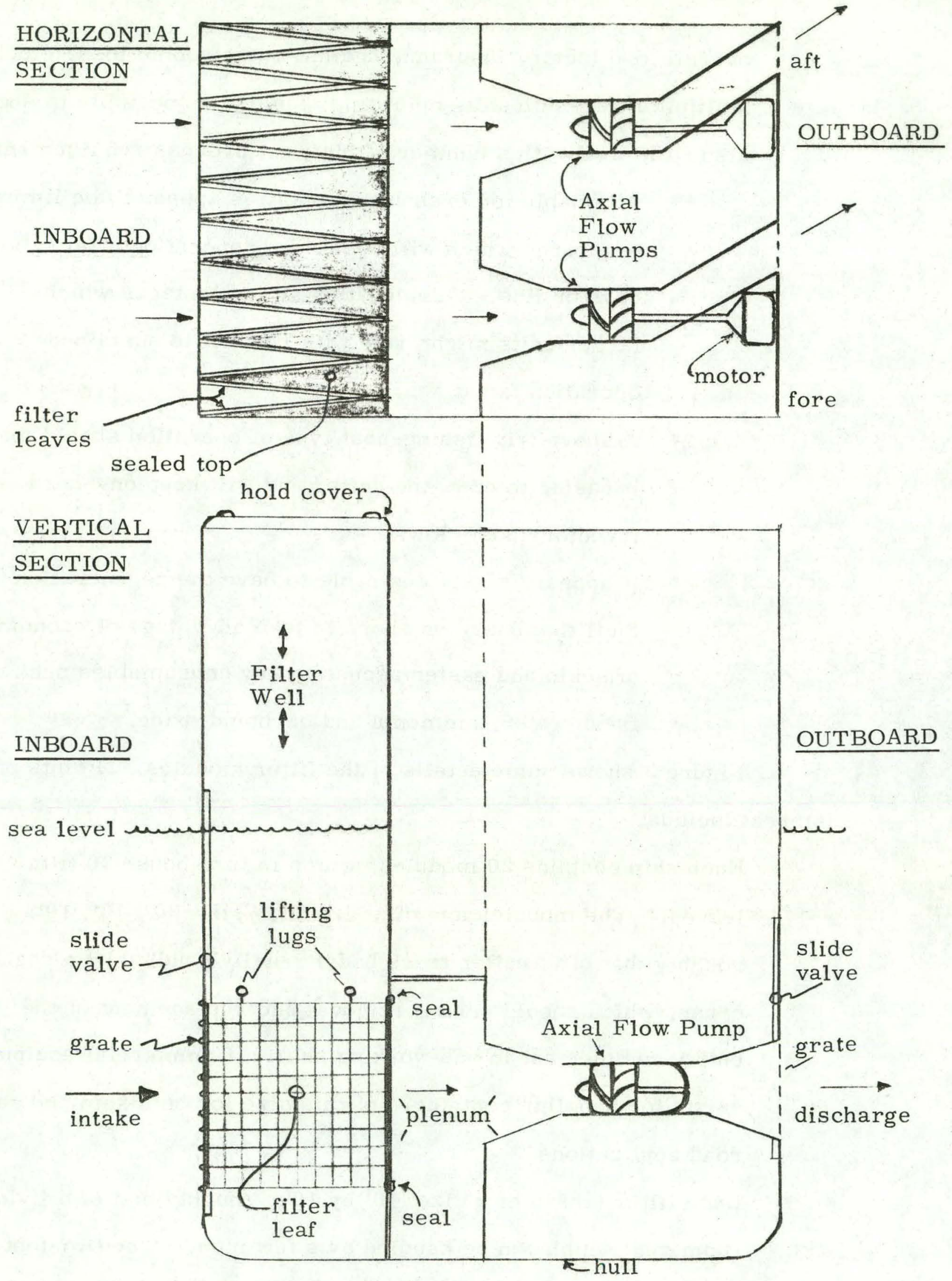

Fig. 2 Details of filter module as mounted in ship's hull. 
cleaning and minor repairs in place.

* Each filter leaf accommodates a grid of individual filter mats sandwiched between coarse wire netting (e.g. mesh wire fence). The leaf structure is permanent and can be disassembled for periodic replacement of the mats (conservatively assumed to be yearly in the present analysis). See Fig. 3 for details.

* The surface of each leaf can be covered with a disposable fiberglass mat prefilter to skim off most of the suspended matter in the influent.

* Although there is a water-air interface inside the module, a top cover is used to keep the interior in the dark, to discourage biological growth.

* The act of unloading a module is the first step in product recovery and resin regeneration since it drains the seawater from the module as a prelude to washing the filter media with fresh water. This should be more effective than the saltwater/freshwater displacement scheme employed in some process flowsheets devised for sorber bed elution. In the present case a freshwater shower bath could also be used as an alternative to immersion in the next step in the sequence which should further conserve on water usage.

Table 1 contains a summary of the principal design and performance features of the subject recovery system. Attention is called to the high flow loading, which is at the upper limit of commercial usage when bed-type ion exchange media are used, but which should be compatible with the more open fiber mat arrangement. Most other characteristics follow directly from this factor - in particular the relatively compact 


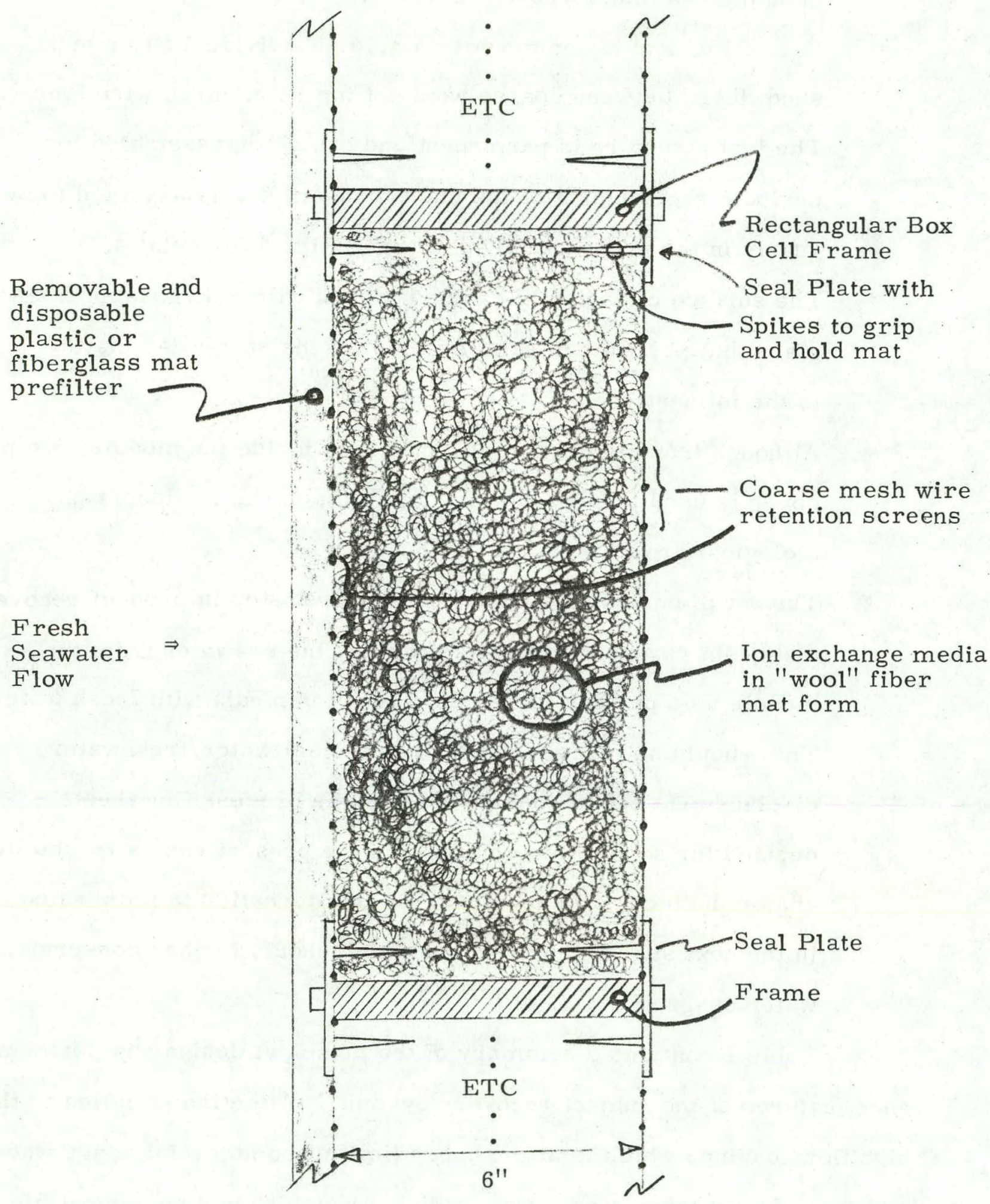

Fig. 3 Transverse section through filter leaf showing a typical cell. 
Table 1

Sorber Ship Characteristics ${ }^{*}$

Length of ship

Displacement

Modules per ship

Filter leaves per module

Frontal area of each leaf

Total filter area

flow loading

A rea density of sorber medium

Effective capacity

Bed loading time at full flow

Annual production per ship

(at a $75 \%$ capacity factor)

Ships per $1000 \mathrm{M}$ we LWR

Ship's power plant rating
300 feet

10,000 tons

20

20

$100 \mathrm{ft}^{2}$

$40,000 \mathrm{ft}^{2}$

$120 \mathrm{gpm} / \mathrm{ft}^{2}$

$2 \mathrm{lbs} / \mathrm{ft}^{2}$

5000 ppm U

3 days

16 tons $\mathrm{U}_{3} \mathrm{O}_{8}$

10

$70 \cap 0 \mathrm{HP}$

*See Appendix B for supporting calculations. 
size of the totality of the sorber beds compared to other conceptual designs. Tests have been performed on a pressure drop rig at MIT using steel wool having a mass mean fiber diameter of 84 microns at flow loadings up to $200 \mathrm{gpm} / \mathrm{ft}^{2}$ to confirm that the proposed design can indeed meet the goal of $\leq 1$ psi filter pressure drop. Similarly, tests on a prefilter mat have shown that satisfactory performance can be achieved at the expense of a (negligible) head loss of a few inches of water.

\section{Economic Evaluation}

Appendix A documents a step-by-step evaluation of the key cost components of the proposed system. This follows very nearly the same format as in earlier studies, with a few important exceptions.

One noteworthy difference is the decision to treat the ion exchange media as an expensed consumable rather than as a capitalized and depreciated item. Although in conventional service ion exchange resin can last for many years, it is common practice, for example, to expense this item when assessing the costs associated with centrul station electric generating units, whether nuclear or fossil [O-1]. Furthermore, in the present application, which employs an uncommon form for this sorber (fibrous mat) under fairly severe operating conditions, a useful life of only fifty cycles has been assumed.

Table 1 summarizes the cost breakdown obtained for the process design in question. The results are quoted in terms of an equivalent yellowcake cost, $\$ / \mathrm{lb}_{3} \mathrm{O}_{8}$, for both initial-year and lifetime-levelized scenarios; it is appropriate to compare the former to current spotmarket prices for $\mathrm{U}_{3} \mathrm{O}_{8}$ and the latter to a discounted average of projected prices over the next twenty years. 
Table 2

Cost of Product Summary

\begin{tabular}{|c|c|c|}
\hline Item & $\begin{array}{c}\text { Contribution } \\
(1981 \$)^{*}\end{array}$ & $\begin{array}{l}\$ / \text { lb } \mathrm{U}_{3} \mathrm{O}_{3} \\
\text { (lifetime) }\end{array}$ \\
\hline Filters & 6 & 6 \\
\hline IX Resin and Prefilter Mats & 16 & 30 \\
\hline Regeneration and Product Recovery & 35 & 66 \\
\hline Ship Amortization & 32 & 32 \\
\hline Ship Operation & 3 & 6 \\
\hline Pumping System & 13 & 13 \\
\hline \multirow[t]{2}{*}{ Energy Consumption } & 18 & 34 \\
\hline & LS: 123 & .187 \\
\hline
\end{tabular}

* See Appendix A for supporting calculations; values are rounded to the nearest whole dollar. Lifetime value is levelized over 20 years: initial annual operating costs are multiplied by $\left(\frac{1+X T}{1+X_{o} T}\right)$, where: $\mathrm{T}=20 . \mathrm{yrs} ; \mathrm{X}, \mathrm{X}_{\mathrm{o}}=$ market and deflated discount rates, respectively, equal to 0.10 and $0.03 \mathrm{yr}^{-1}$. 
The quoted prices are clearly not competitive with terrestrial uranium in the near term marketplace. However, in the longer term the benchmark for comparison should really be a value of on the order of $150 \$ / 1 b \mathrm{U}_{3} \mathrm{O}_{8}$ (in $1981 \$$ ), which represents a breakeven value for LWR units in competition with breeder reactors or other advanced power systems $[\mathrm{N}-1]$.

4. Conclusions and Recommendations

Based upon the results of this somewhat crude cost analysis, it appears that a high performance sorber system may have sufficient promise as a long-term energy option to deserve continuing research and development efforts. A number of obvious tasks remain before this concept merits a major commitment in terms of national or international. energy programs.

* Confirmation of the ability of ion exchange media to reliably exceed an effective capacity substantially exceeding $1000 \mathrm{ppm}$ uranium in actual sea trials.

* Vemonstration of the capability to produce ion exchange beds in a fibrous mat configuration.

* Greater detail and refinement in process design and cost estimation.

Following the successful completion of such work, the operation of pilot-scale facilities such as those now planned by Japanese researchers for their hydrous titanium sorber would be in order [K-1].

In conclusion, the Iure of uranium-from-the-sea endures. The $4,000,000,000$ tons of oceanic uranium is sufficient to support thousands of light water reactors for thousands of years - surely enough for this option to deserve consideration as another inexhaustible energy resource. 


\section{References}

[K1] M. Kanno, "Japanese Studies on Extraction of Uranium from Seawater", Symposium on Separation Science and Technology for Energy Applications, Gatlinburg, Tennessee, May 5-8, 1981.

[N1] Report of the Nonproliferation Alternative Systems Assessment Program, DOE/NE-0001/1-9, June 1980.

[O1] "A Procedure for Estimating Nonfuel Operating and Maintenance Costs for Large Steam-Electric Power Plants", ERDA-76-37, October 1975 . 
Appendix A

Cost Estimates

The subsections in this appendix consider, term by term, the major cost components making up the subject uranium-from-seawater system.

\section{A. 1. Cost of Filter Assemblies}

The contribution of the filter structure to the cost of product is obtained by dividing the annualized cost by the production rate:

$$
\mathrm{U}_{\mathrm{f}}=\frac{\varphi_{\mathrm{f}} \gamma}{1.18(8766)(60) \mathrm{WxV}_{\mathrm{w}} \eta \mathrm{L}} \$ / \mathrm{lb} \mathrm{U}_{3} \mathrm{O}_{8}
$$

where

$$
\begin{aligned}
& \varphi_{\mathrm{f}}=\text { annual carrying charge rate (the filter assemblies are } \\
& \gamma=\text { cost of filter frames } \$ / \mathrm{ft}^{2}(10) \\
& \mathrm{W}=\text { density of seawater, } 1 \mathrm{~b} / \mathrm{ft}^{3}(64) \\
& \mathrm{x}=\text { concentration of uranium in seawater, } \mathrm{lb} U / \mathrm{lb} \text { water } \\
& \left(3.3 \times 10^{-9}\right) \\
& \mathrm{V}_{\mathrm{w}}=\text { superficial velocity of water traversing filter, } \mathrm{ft} / \mathrm{min}(16) \\
& \text { ( }=0.134 \mathrm{G} \text {, where } \mathrm{G}=\text { flow loading, } \mathrm{gpm} / \mathrm{ft}^{2}=120 \text { ) } \\
& \eta=\text { bed efficiency, fraction of incident uranium removed (0.5) } \\
& \mathrm{L}=\text { plant capacity factor, fraction of year at full flow (0.75) }
\end{aligned}
$$

For the quoted parameter values:

$$
\mathrm{U}_{\mathrm{f}}=3.18 \$ / 1 \mathrm{~b} \mathrm{U} \mathrm{U}_{3}
$$

This value will be doubled to account for the filter modules being processed on shore, or held in inventory as spares. 
A. 2 Cost of Resin

The resin will be expensed as a consumable item (as is the custom for the ion exchange resins used in power plant service), rather than capitalized and depreciated (as are the filter frames).

The contribution to the cost of product is given by:

$$
\mathrm{U}_{\mathrm{r}}=\frac{\mathrm{C}_{\mathrm{r}}}{1.18 \mathrm{C} \cdot \mathrm{L} \cdot \mathrm{n}} \$ / 1 \mathrm{~b} \mathrm{U}_{3} \mathrm{O}_{8}
$$

where $C_{r}=$ cost of resin in fibrous matform, $\$ / 1 b(2)$

$\mathrm{C}=$ useful capacity of resin, lbs $U / \mathrm{lb}$ resin $\left(5 \times 10^{-3}\right)$

$\mathscr{L}=$ fraction of bed capacity exhausted in loading cycle (0.7)

$\mathrm{n}=$ number of loading cycles, useful life of resin (50)

For the above parameters:

$\mathrm{U}_{\mathrm{r}}=9.69 \$ / 1 \mathrm{~b} \mathrm{U} \mathrm{U}_{3} \mathrm{O}_{8}$

To this must be added the cost of the prefilter mats, which are discarded after each cycle:

$$
U_{p}=\frac{{ }^{n} C_{p}}{M_{r} C_{r}} \cdot U_{r}
$$

where $\mathrm{C}_{\mathrm{p}}=$ cost of prefilter mat, $\$ / \mathrm{ft}^{2}(0.05)$

$M_{r}=$ wcight of resin per unit area (see next section) $\mathrm{bb} / \mathrm{ft}^{2}(2)$

From which:

$$
\mathrm{U}_{\mathrm{p}}=6.06 \$ / 1 \mathrm{~b} \mathrm{U} \mathrm{U}_{3} \mathrm{O}_{8}
$$

\section{A. 3 Cost of Resin Regeneration and Product Recovery}

For a resin bed having a surface density of $\mathrm{M}_{\mathrm{r}} \mathrm{lb} / \mathrm{ft}^{2}$, an elution chemical consumption of $Z \$ / 1 b$ resin and $m$ regenerative cycles per year 
of operation, the expenditure relative to. the filter frame cost is:

$$
\mathrm{U}_{\mathrm{c}}=\frac{\mathrm{m} Z \mathrm{M}_{\mathrm{r}}}{\varphi_{\mathrm{f}} \gamma} \cdot \mathrm{U}_{\mathrm{f}} \$ / \mathrm{lb} \mathrm{U}_{3} \mathrm{O}_{8}
$$

The weight per unit area of resin in a bed $\delta \mathrm{ft}$ thick is just:

$$
M_{r}=R \cdot \delta(1-\epsilon) \mathrm{lbs} / \mathrm{ft}^{2}
$$

where

$R=$ resin density, $1 \mathrm{~b} / \mathrm{ft}^{3}(80)$

$\epsilon \quad=\quad$ void fraction in bed (0.95)

$\delta=$ thickness of bed, ft $(0.5)$

Hence $\mathrm{M}_{\mathrm{r}}=2 \mathrm{lbs} / \mathrm{ft}^{2}$.

If $\mathrm{Z}=0.1 \$ / \mathrm{lb}$ and $\mathrm{m}=100 \mathrm{yr}^{-1}$ (i. e., approximately 50

bi-weekly cycles per year), with other values as previously prescribed:

$$
\mathrm{U}_{\mathrm{c}}=25.44 \$ / 1 \mathrm{~b} \mathrm{\textrm {U } _ { 3 } \mathrm { O } _ { 8 }}
$$

To this we add an additional $10 \$ / 1 b \mathrm{U}_{3} \mathrm{O}_{8}$ to account for recovery of the final product from the elutant - by processes identical to those used in terrestrial milling operations.

The total resin inventory on board is $\mathrm{II}_{\mathrm{r}} \cdot \mathrm{A} / 2000 \approx 40$ tons, which is a very modest quantity.

\section{A. 4 Cost of Ship}

The estimated displacement of each ship is 10,000 tons. At a cost of $500 \$ / d w t$, the initial cost per ship is $I=5 \times 10^{6} \$$. If the initial capital cost of the ship is I dollars, then the allocated ship cost relative to the filter cost is:

$$
\mathrm{U}_{\mathrm{S}}=\left(\frac{\varphi_{\mathrm{s}}}{\varphi_{\mathrm{f}}}\right)\left(\frac{\mathrm{I}}{\gamma \mathrm{A}}\right) \cdot \mathrm{U}_{\mathrm{f}} \$ / 1 \mathrm{~b} \mathrm{U}_{3} \mathrm{O}_{8}
$$

where $\varphi_{\mathbf{S}}$ is the annual carrying charge rate for the ship (assumed to have a service life of 20 years and negligible salvage value).

For $I=5 \times 10^{6} \$$ and $\varphi_{S}=0.20$ year $^{-1}$, and the other values as 
already noted:

$$
\mathrm{U}_{\mathrm{S}}=31.80 \$ / \mathrm{lb} \mathrm{U}_{3} \mathrm{O}_{8}
$$

\section{A. 5. Cost of Ship Operations}

A running cost including all labor, replenishment and repairs (but excluding fuel costs) of $10 \%$ of the initial cost is assumed.

This gives an annual cost of operations:

$$
\mathrm{U}_{\mathrm{o}}=3.18 \$ / 1 \mathrm{~b} \mathrm{U}_{3} \mathrm{O}_{8}
$$

\section{A. 6 Cost of Pumping Power and Energy Generation}

The pumping power can be calculated from the flow rate and pressure drop:

$$
\mathrm{P}=3.25 \times 10^{-3}\left[\Delta \mathrm{P} \cdot \mathrm{A} \cdot \mathrm{V}_{\mathrm{w}} / \eta_{\mathrm{p}}\right] \mathrm{kW}
$$

where $\eta_{p}$ is the motor/pump efficiency (0.8). For $A=4 \times 10^{4} \mathrm{ft}^{2}$, $\mathrm{V}_{\mathrm{W}}=16 \mathrm{ft} / \mathrm{min}$ and $\Delta \mathrm{P}=2 \mathrm{psi}$, one obtains:

$$
\mathrm{P}=5,200 \mathrm{~kW} \approx 7000 \mathrm{HP}
$$

The annual consumption of energy is:

$$
\mathrm{E}=8766 \mathrm{PL} \mathrm{kWh/yr}
$$

The numerical data given corresponds to:

$$
\mathrm{E}=3.42 \times 10^{7} \mathrm{kWh} / \mathrm{yr}
$$

If the pump and drive-motor rapital cost is I $-1.00 \$ / \mathrm{kW}$ (installed), the contribution to the cost of product is:

$$
U_{p}=\left(\frac{{ }_{p} p^{P}}{I}\right) U_{s}, \$ / l b U_{3} O_{8}
$$


For the data quoted:

$$
\mathrm{U}_{\mathrm{p}}=13.23 \$ / 1 \mathrm{~b} \mathrm{U} \mathrm{U}_{3} \mathrm{O}_{8}
$$

A specific fuel consumption of 10 tons coal/mwe day is assumed to operate the ship while in transit or on station. The annual cost of fuel to generate electricity is therefore:

$$
\mathrm{O}_{\mathrm{e}}=10^{-2} \cdot \mathrm{Y}(365.25) \mathrm{PL} \$ / \mathrm{yr}
$$

where $Y$ is the cost of coal, $\$ /$ ton $(40)$.

The cost per unit of yellowcake produced is:

$$
\mathrm{U}_{\mathrm{e}}=\frac{\mathrm{O}_{\mathrm{e}}}{\varphi_{\mathrm{s}} \mathrm{I}} \cdot \mathrm{U}_{\mathrm{s}} \cdot \$ / 1 \mathrm{lb} \mathrm{U}_{3} \mathrm{O}_{8}
$$

which for the values quoted gives

$$
\mathrm{U}_{\mathrm{e}}=18.13 \$ / 1 \mathrm{~b} \mathrm{\textrm {U } _ { 3 }} \mathrm{O}_{8}
$$

The total coal inventory on board for 7 days of full power operation is roughly $10^{-2} \mathrm{P}(7) \approx 364$ tons, a readily manageable bunker volume. In this regard it should be noted that (for a given amount of energy) coal requires roughly twice the volume of oil. 


\section{Appendix B \\ Performance-Related Calculations}

This appendix contains calculations in support of major design decisions; Ref. [D1] provides relevant supplementary backup.

B. 1 Production Capability

If the bed frontal area is $A$, then the uranium uptake by the bed over a period of $\mathrm{T}$ days is merely:

$$
\mathrm{U}=1.18\left(\frac{1440}{2000}\right) \mathrm{WxV}_{\mathrm{w}} \mathrm{A} \overline{\mathrm{f}} \mathrm{TL} \text { tons } \mathrm{U}_{3} \mathrm{O}_{8}
$$

where

$$
\begin{aligned}
& \mathrm{x}=\text { concentration of uranium in unfiltered seawater } \\
& \left(3.3 \times 10^{-9} \mathrm{lb} / \mathrm{lb}\right) \\
& \mathrm{W}=\text { density of seawater, } \mathrm{lbs} / \mathrm{ft}^{3}(64) \\
& \mathrm{V}_{\mathrm{W}}=\text { superficial velocity of water traversing filter, } \mathrm{ft} / \mathrm{min}(16) \\
& \bar{f}=\text { bed efficiency, fraction of uranium removed, averaged } \\
& \text { over time } \mathrm{T}(0.5) \\
& \mathrm{L}=\text { overall system capacity factor }(0.75) \\
& \text { In one year, Eq. (B. 1) indicates that a filter bed having a total } \\
& \text { surface area } A=4 \times 10^{4} \mathrm{ft}^{2} \text { can produce } 15.7 \text { tons of } \mathrm{U}_{3} \mathrm{O}_{8} \text {; ten such }
\end{aligned}
$$$$
\text { systems could sustain one } 1000 \mathrm{MWe} \text { LWR for one year (using an extended }
$$$$
\text { burnup, once-through fuel cycle). }
$$

B. 2 Length of Loading Cycle

A parameter of decisive importance is the cycle time - the time

[D1] M. J. Driscoll et al.

"Practical Constraints on Systems for the Extraction of Uranium from Seawater", in F. R. Best and M. J. Driscoll (Editors), "Proceedings of a Topical Meeting on the Recovery of Uranium from Seawater", MIT-EL80-031, December 1880. 
between successive bed regenerations. This can be estimated by computing the time to exhaust the effective capacity of the ion exchange resin (one minus the loading fraction times the ultimate equilibrium capacity):

$$
\mathrm{T}_{\mathrm{c}}=\frac{\mathscr{L} \mathrm{C} \cdot \mathrm{M}_{\mathrm{r}}}{(1440) \mathrm{w} \times \eta \mathrm{G}} \text { days }
$$

where

$\mathrm{C}=$ effective resin capacity for uranium, $\mathrm{lb} \mathrm{U} / \mathrm{lb}$ resin, $\left(5 \times 10^{-3}\right.$, i. e. $\left.5000 \mathrm{ppm}\right)$

$\mathcal{L}=$ fraction of bed capacity loaded $(0.7)$

$\mathrm{G}=$ flow loading, $\mathrm{gpm} / \mathrm{ft}^{2}(120)$

$\mathrm{M}_{\mathrm{r}}=$ weight per unit area of resin, $\mathrm{lb} / \mathrm{ft}^{2}(2)$

$\mathrm{w}=$ density of seawater, lb/gal (8.55)

$\eta=$ efficiency of recovery $(0.5)$

$\mathrm{x}=$ concentration of uranium in seawater, $\mathrm{lb} \mathrm{U} / \mathrm{lb}$ water $\left(3.3 \times 10^{-9}\right)$

For the representative values in parentheses, $T_{c}=2.9$ days under fullflow conditions. A longer operating cycle would be preferable (i.e. closer to 5 days - one workweek). This could be achieved if a higher resin capacity is attained, or if a thicker bed and/or lower flow loading is selected. 


\author{
Chapter 9 \\ Current Reference Design
}

by

M.J. Driscoll

Figures 9.1 and 9.2 illustrate the reference design as of Fall 1981. The basic configuration is similar to that in the catamaran concept discussed in chapter 8 . However, rearrangement of the layout now permits the installation of three times as many filter modules in the same size barge.

The barge and propulsion unit have also been separated so that we now have something very similar to a conventional barge and tug system. The advantages are several:

(a) It may be possible to achieve a higher capacity factor for the tug -- which is the most expensive part of the system -- by permitting it to leave one barge in port for processing, and immediately set out to sea for another loading cycle with a fresh barge.

(b) Credible estimates for a large fraction of the overall system costs can be made by benchmarking one's results against conventional, readily available freight rates (1.e.; $\dot{c} /$ ton-mile). This $1 \mathrm{n}-$ cludes the capital costs of barge and tug, and their operating costs (fuel plus labor); only the added expenses of the filters, sorber, pumps and 
TOP SECTION VIEW OF ONE HOLD

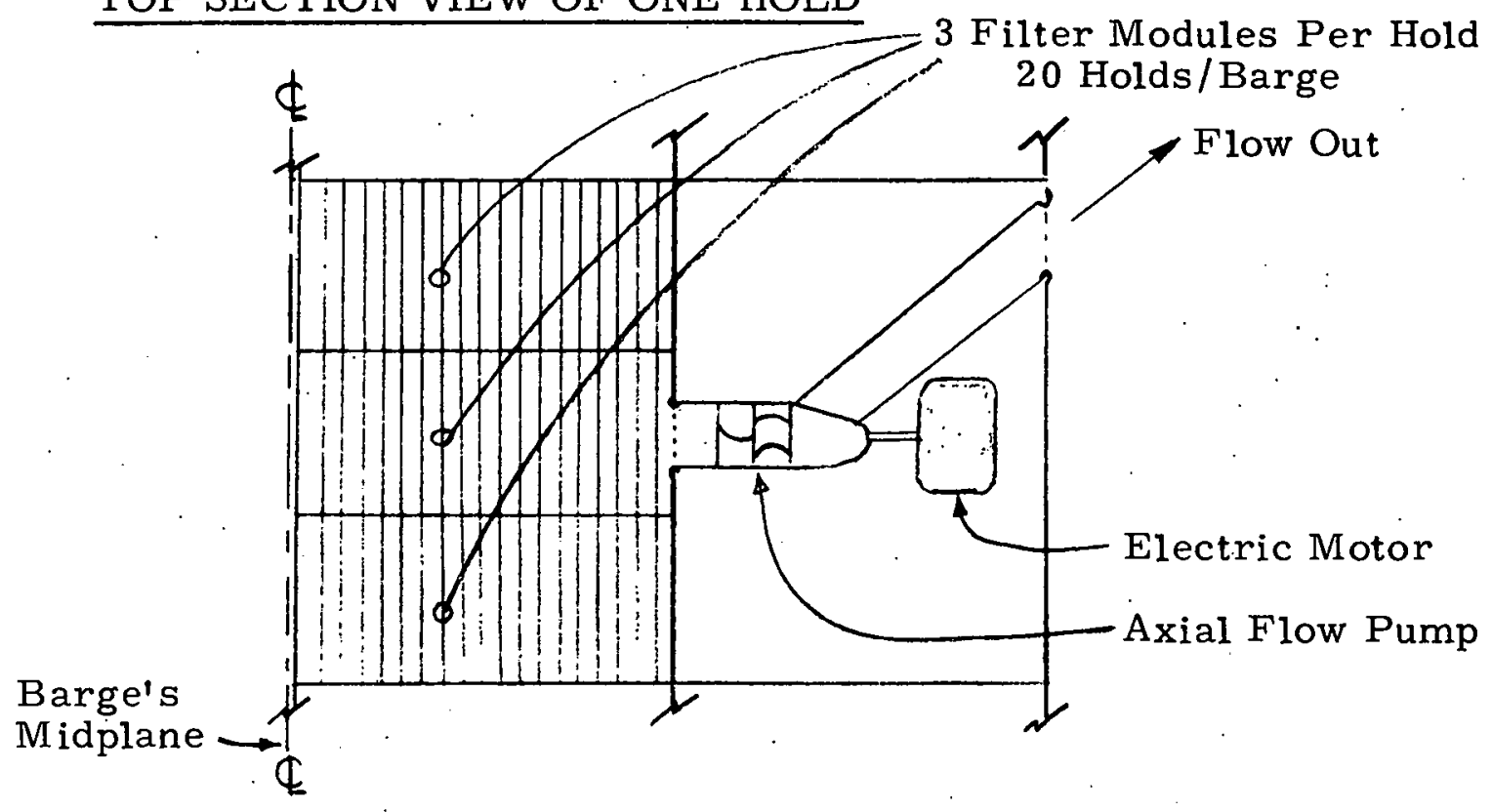

VERTICAL SECTION VIEW

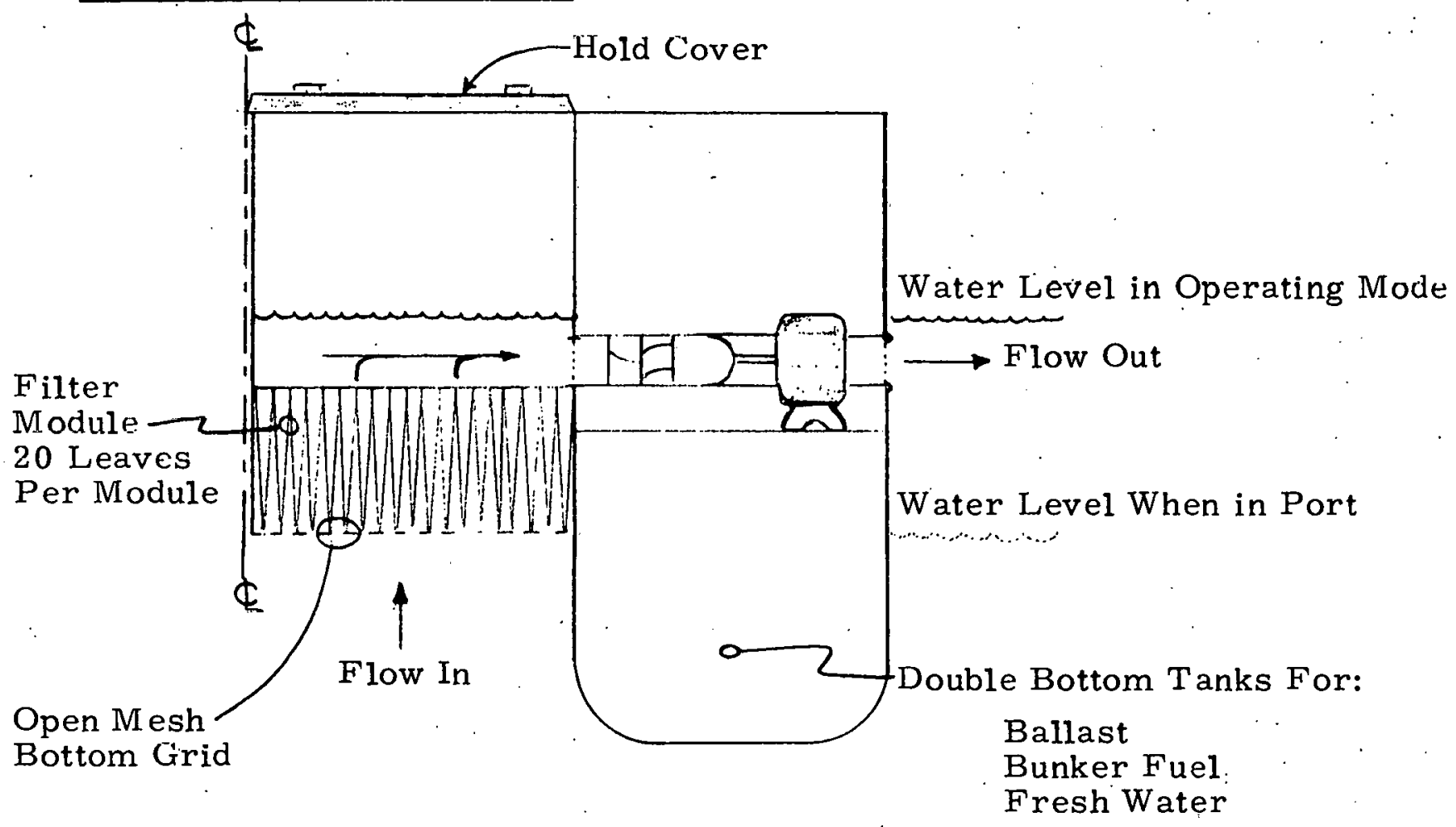

Fig. 9.1 Schematic views of essential features of a barge-mounted pumped filter system. 
tug/barge modifications fall outside of this welldefined envelope.

(c) Configurations of the type suggested (tug plus notched-stern barge) have a proven record of satisfactory performance in coastal and even oceanic waters.

(d) Tug designs having the requisite power rating are available commercially. It must be noted, however, that most are of the geared-diesel type, whereas we require an electric drive similar to that employed on many icebreakers and some military vessels.

The design shown in Figure 9.1 differs from that in Figures 1 and 2 of Chapter 8 in having a $90^{\circ}$ turn in flow path, which may add additional pressure drop. It may also be more suitable if the flow direction is reversed (inlet on the outside of the barge, outlet at the top of the slot underneath the barge) since this will facilitate sealing the filter modules against the bottom grid plate. Whatever advantage the filters provide against ingestion of trash by the pumps would be lost in this rearrangement; hence it may be desirable to re-examine the entire question of flow direction in the future.

In this design the basic "catamaran" configuration has been retained, primarily because the twin hulls provide a barrier to recirculation of already-filtered water from the 
outlet back to an inlet. In addition, this arrangement permits one to take on ballast water to ride low in the water while on station, and then discharge the ballast to ride high when entering port, while activating a fresh water shower to perform the first step in filter elution in situ and in transit, thereby saving both time and process equipment. The shallow draft achieved in this manner will also greatly expand the number of feasible sites for an on-shore processing facility.

In conclusion, then, an overall system concept has evolved through several generations, and is now sufficiently characterized to permit its use as the basis for making overall cost-of-product estimates and for setting R\&D goals as to sorber capacity and physical configuration. For example, it appears that if a sorber having a capacity of several thousand ppm can be deployed in the form of a wool-like mat, $\mathrm{U}_{3} \mathrm{O}_{8}$ costs on the order of 150 \$/ib may be within reach. Much remains to be done: the primary focus of future efforts must, of course, be on development of improved sorber materials; however, refined cost estimates on both the sea-borne recovery unit and the shore-based elution facilities are still required. 
Graphic Orts.

Please enlarge this photograph

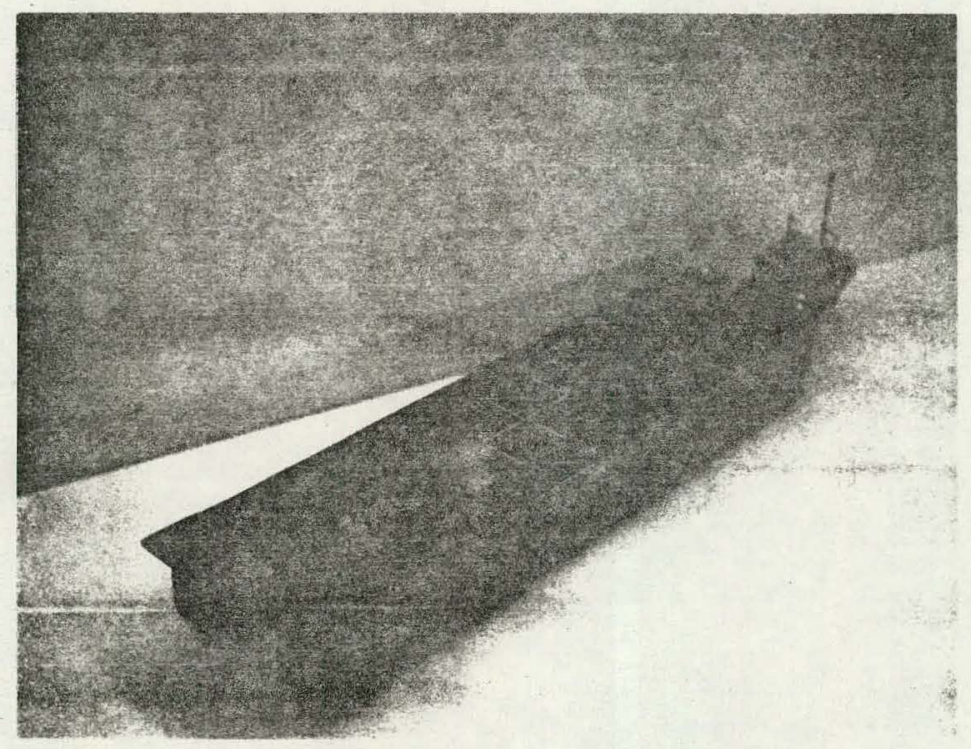
to fill space with margins, allowing for the caption as shown. Crop slighter if $\stackrel{\varpi}{\omega}$

Fig. 9.2 Model of Reference Design. 
Work reported in this document was sponsored by the Department of Energy under contract No. EX-76-A-01-2295. This report was prepared as an account of work sponsored by the United States Government.

Neither the United States nor the United States Department of Energy, nor any of their employees, makes any warranty, express or implied, or assumes any legal liability or responsibility for the accurary, completeness, or usefulness of any information, apparatus, product or process disclosed or represents that its use would not infringe provately owned rights. 